AUTARQUIA ASSOCIADA À UNIVERSIDADE DE SÃO PAULO

\title{
CARACTERIZAÇÃO DOSIMÉTRICA DO BeO EM FEIXES DE RADIODIAGNÓSTICO CONVENCIONAL, MAMOGRAFIA E TOMOGRAFIA COMPUTADORIZADA, PELAS TÉCNICAS DE TERMOLUMINESCÊNCIA E LUMINESCÊNCIA OPTICAMENTE ESTIMULADA
}

Fábio Junqueira Algarve

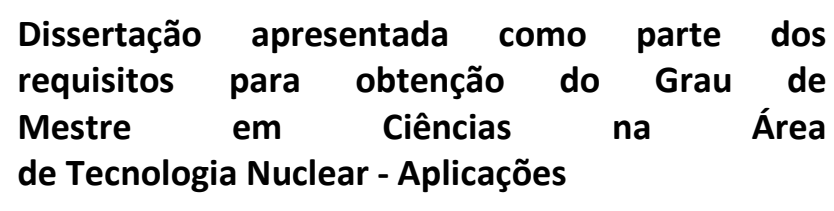

Orientadora:

Profa. Dra. Linda V. E. Caldas 
INSTITUTO DE PESQUISAS ENERGÉTICAS E NUCLEARES

Autarquia associada à Universidade de São Paulo

\section{CARACTERIZAÇÃO DOSIMÉTRICA DO BeO EM FEIXES DE RADIODIAGNÓSTICO CONVENCIONAL, MAMOGRAFIA E TOMOGRAFIA COMPUTADORIZADA, PELAS TÉCNICAS DE TERMOLUMINESCÊNCIA E LUMINESCÊNCIA OPTICAMENTE ESTIMULADA}

Fábio Junqueira Algarve

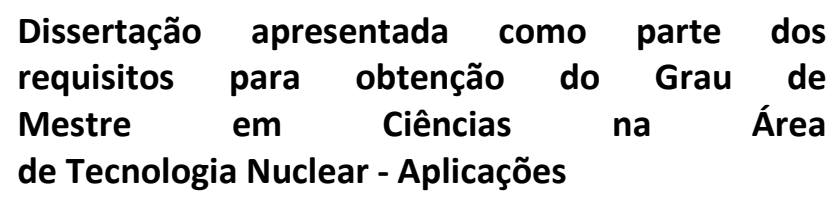

Orientadora:

Profa. Dra. Linda V. E. Caldas

Versão Corrigida

Versão Original disponível no IPEN

São Paulo 
Aos meus pais, Alcides e Maria

Helena, e à minha irmã, Juliana, com amor e carinho. 


\section{AGRADECIMENTOS}

Aos meus pais Alcides Algarve Filho e Maria Helena Baptista Junqueira Algarve e a minha irmã Juliana Junqueira Algarve, pelo amor e apoio incondicional que sempre me deram em todos os momentos da minha vida.

À minha orientadora, Dra. Linda V. E. Caldas, pela oportunidade proporcionada de crescimento durante todo o mestrado, por todo incentivo, por vibrar com cada conquista alcançada, por toda a paciência e pela amizade que construímos.

À Dra. Maria da Penha Albuquerque Potiens e à Dr. Letícia L. C. Rodrigues, por todo o auxílio prestado durante a realização deste trabalho.

Ao Dr. Vitor Vivolo, pela ajuda, paciência e todo o conhecimento compartilhado comigo durante todo o desenvolvimento do mestrado.

À Sra. Deise Aparecida Aras dos Santos por todo o auxílio administrativo e pelas risadas e a amizade.

Ao Instituto de Pesquisas Energéticas e Nucleares (IPEN), por possibilitar o desenvolvimento deste trabalho.

A CAPES, pelo suporte financeiro.

À Dra. Patrícia de Lara Antônio e à Msc. Daniela Piai Groppo, pela ajuda e incentivo durante todo o trabalho.

Aos amigos do IPEN Msc. Ivón Oramas Polo, Msc. Daniel Villani, Msc. Shirlane Barbosa, Msc. Lilian Kuahara, Renata Bressane, Msc. Tallyson Sarmento Alvarenga, Msc. Maysa Costa de Castro, Msc. Natália Fiorini da Silva, Dra. Hestia Lima, Dr. Danilo Junot, Dra. Maíra Góes Nunes, pela amizade, risadas, discussões, debates e todos os inúmeros momentos de alegria.

A todos meus amigos que me acompanham e que contribuíram pelo que sou e pelo desenvolvimento deste trabalho, direta ou indiretamente.

A todos os professores que conheci ao cursar as disciplinas, que tiveram paciência e vontade de transmitir um pouco do conhecimento que possuem para mim; sem eles a jornada seria mais difícil.

Aos funcionários da biblioteca Terezine Arantes Ferraz, pela ajuda na busca, reserva e empréstimo dos livros disponíveis, pela paciência e por permitir permanecer um tempo a mais na biblioteca além do horário de funcionamento. 


\title{
Caracterização dosimétrica do $\mathrm{BeO}$ em feixes padrões de radiodiagnóstico convencional, mamografia e tomografia computadorizada, pelas técnicas de termoluminescência e luminescência opticamente estimulada
}

\section{Fábio Junqueira Algarve}

\begin{abstract}
RESUMO
A radiação ionizante é amplamente utilizada em diversas áreas na indústria e na medicina. No campo da medicina, a radiação ionizante é utilizada tanto para fins terapêuticos como para fins diagnósticos, abrangendo assim um grande intervalo de doses de diferentes tipos de radiações. Para certificar que a finalidade da prática esteja sendo alcançada, são necessários estudos detalhados de detectores e dispositivos que atendam aos diferentes tipos de radiações. Neste trabalho foi realizado um estudo das características dosimétricas de amostras de $\mathrm{BeO}$ em feixes padronizados de radiodiagnóstico convencional, mamografia e tomografia computadorizada, utilizando as técnicas de termoluminescência ( $T L$ ) e luminescência opticamente estimulada (OSL) e propondo um sistema adequado para sua utilização em dosimetria de feixes. Os principais resultados obtidos foram: alta sensibilidade à luz branca durante a irradiação, boa reprodutibilidade das respostas TL e OSL (coeficientes de variação inferiores a 5\%), parâmetros cinéticos correspondentes aos valores obtidos em todos os métodos testados, sem fading dentro do período estudado para ambas as técnicas. As características dosimétricas obtidas neste trabalho mostram a possibilidade de aplicação das amostras de $\mathrm{BeO}$ em dosimetria da radiação $\mathrm{X}$, considerando os intervalos de dose empregados, pelas técnicas de TL e OSL. Assim, as amostras de BeO apresentaram sua utilização potencial para dosimetria de feixes de radiodiagnóstico convencional, mamografia e tomografia computadorizada.
\end{abstract}

Palavras-chave: Dosimetria, termoluminescência, BeO, luminescência opticamente estimulada, Monte Carlo 


\title{
Dosimetric characterization of $\mathrm{BeO}$ in standard beams of conventional diagnostic radiology, mammography and computed tomography, by the thermoluminescence and optically stimulated luminescence techniques
}

\author{
Fábio Junqueira Algarve
}

\begin{abstract}
The ionizing radiation is widely used in several areas in industry and medicine. In the field of medicine, the ionizing radiation is used both for therapeutic purposes and for diagnostic purposes, thus covering a wide range of doses of different types of radiation. To certify that the goal of practice is being achieved detailed studies of detectors and devices that respond to different types of radiation are required. In this work, a study of dosimetric characteristics of $\mathrm{BeO}$ samples was performed in standard beams of conventional diagnostic radiology, mammography and computed tomography, using the techniques of thermoluminescence (TL) and optically stimulated luminescence (OSL), and proposing a suitable system for its use in beam dosimetry. The main results obtained were: high sensitivity to white light during the irradiation, good reproducibility of responses TL and OSL (coefficients of variation of less than 5\%), and kinetics parameters corresponding to the values obtained in all of the tested methods, without fading within the observed period for both techniques. The dosimetric characteristics obtained in this work show the possibility of application of $\mathrm{BeO}$ samples for dosimetry of $\mathrm{X}$ radiation, considering the tested dose interval, by the TL and OSL techniques. Thus, the $\mathrm{BeO}$ samples presented potential use for dosimetry of conventional diagnostic radiology, mammography and computed tomography beams.
\end{abstract}

Key words: Dosimetry, thermoluminescence, $\mathrm{BeO}$, optically stimulated luminescence, Monte Carlo 
SUMÁRIO

Página

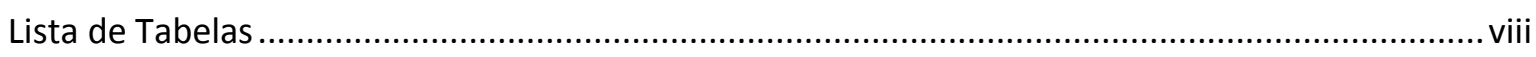

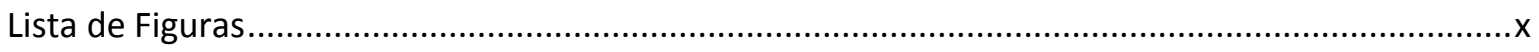

1. INTRODUÇÃO

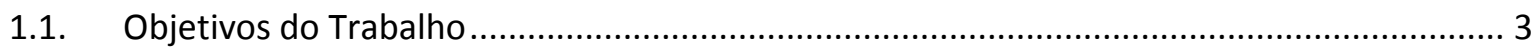

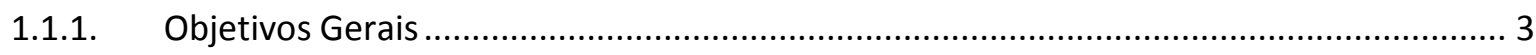

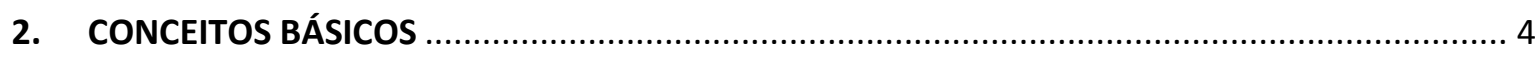

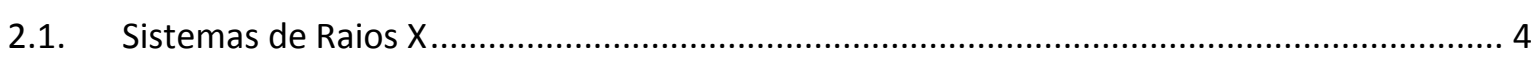

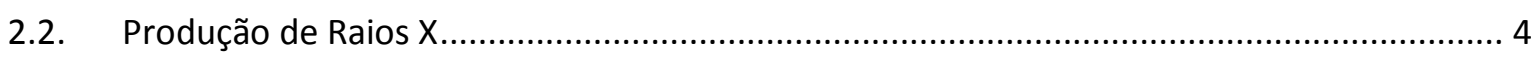

2.3. Interação da Radiação com a Matéria ........................................................................... 5

2.3.1. Interação da Radiação Eletromagnética com a Matéria .................................................. 6

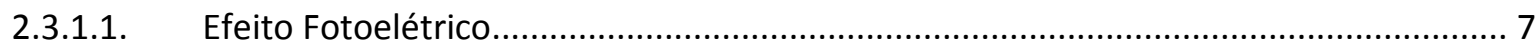

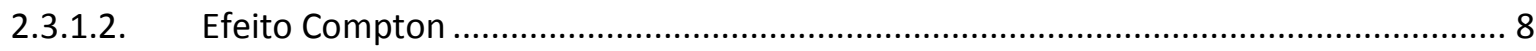

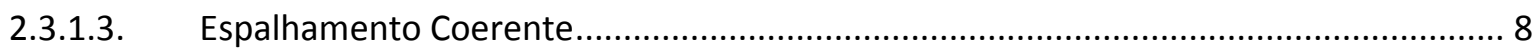

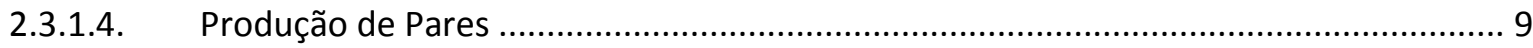

2.3.1.5. Predominância dos Efeitos Provocados pela Radiação Eletromagnética ..................... 10

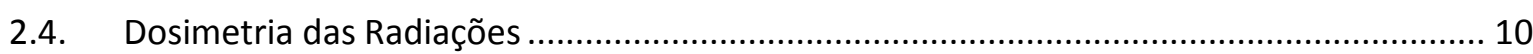

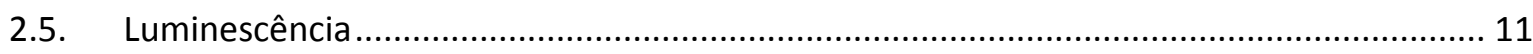

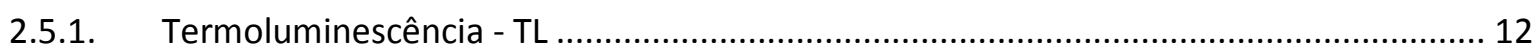

2.5.1.1. Energia de Ativação e Fator de Frequência ...................................................................... 16

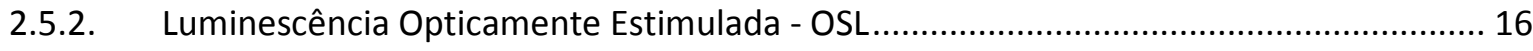

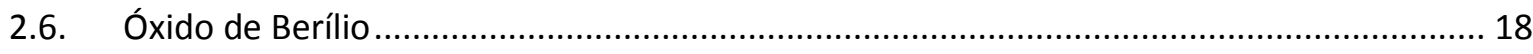

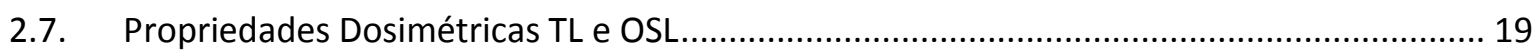

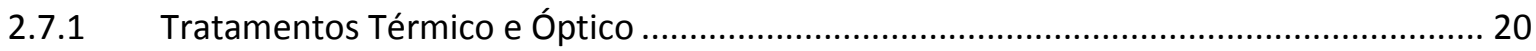

2.7.2 Teste de Homogeneidade e Reprodutibilidade ........................................................... 20

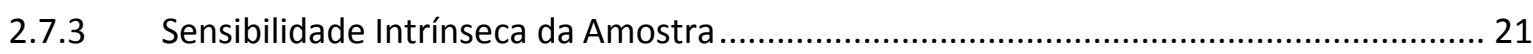

2.7.4 Curva de Emissão TL e Curva de Decaimento OSL .......................................................... 21

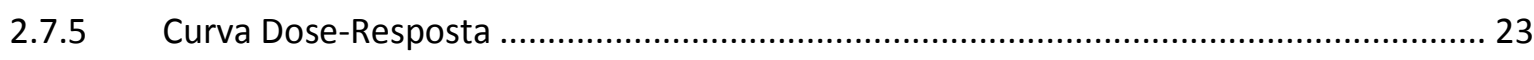

2.7.6 Dependência Energética das Respostas TL e OSL ......................................................... 23

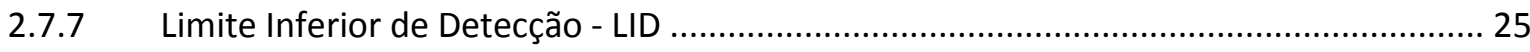

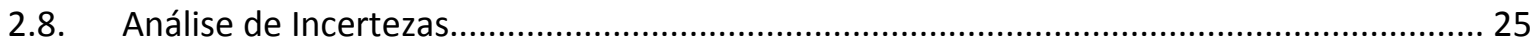

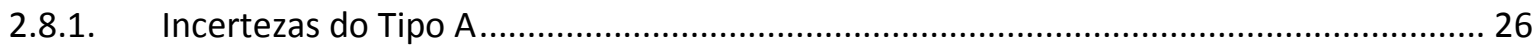




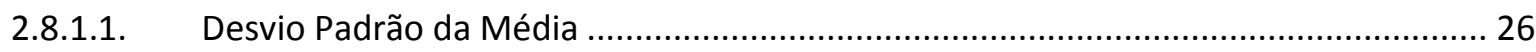

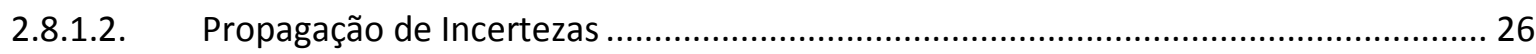

2.8.1.3. Média e Incerteza Ponderada pelas Incertezas. ......................................................... 27

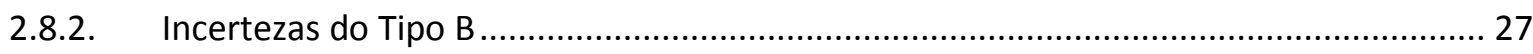

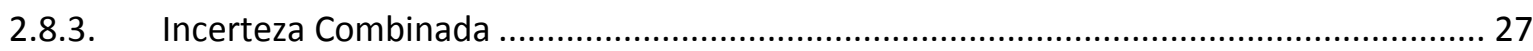

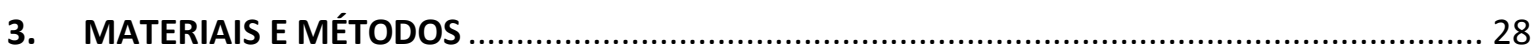

3.1. Amostras de $\mathrm{BeO}$ e Suportes para as Amostras................................................................... 28

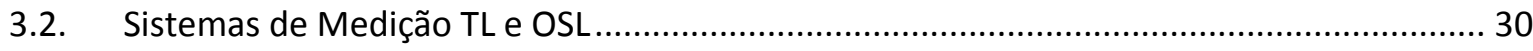

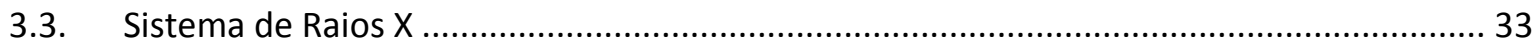

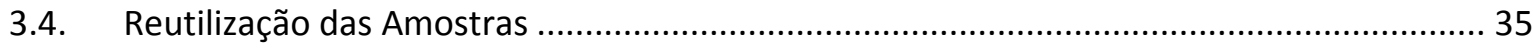

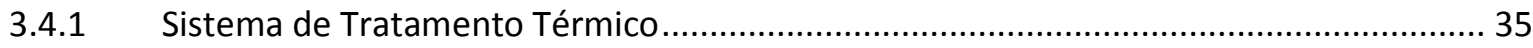

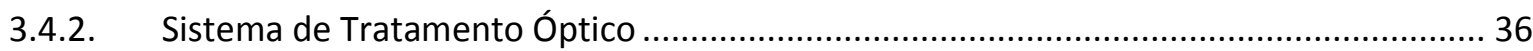

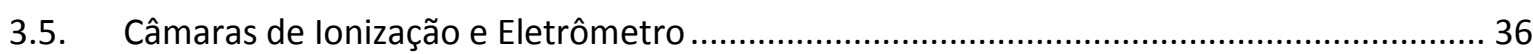

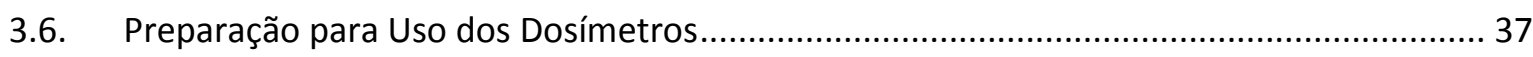

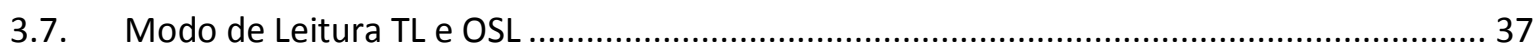

3.8. Métodos para Determinação da Energia de Ativação e do Fator de Frequência................. 38

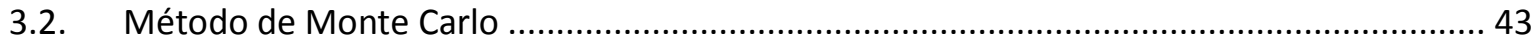

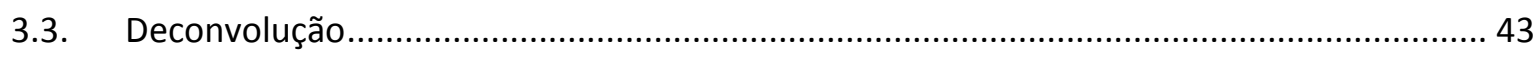

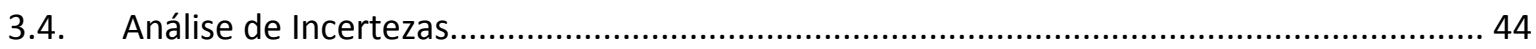

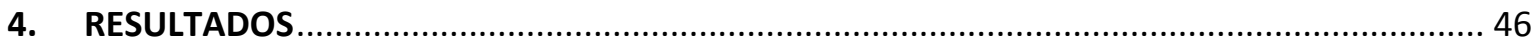

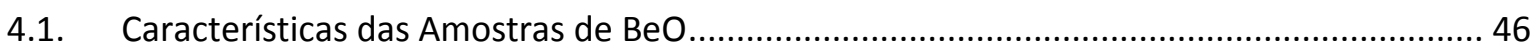

4.2. Definição da Situação da Lâmpada do Laboratório de Raios X (Acesa ou Apagada) ............ 46

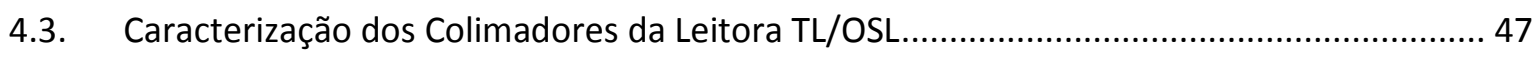

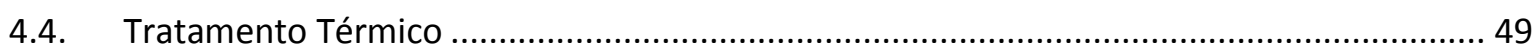

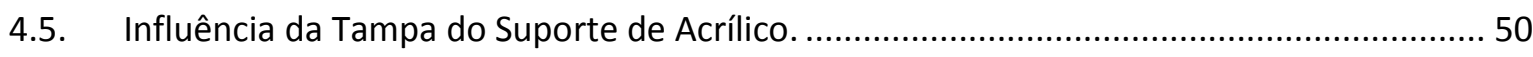

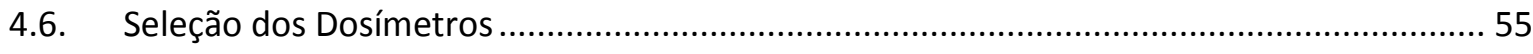

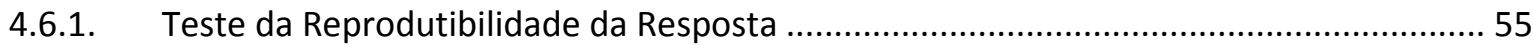

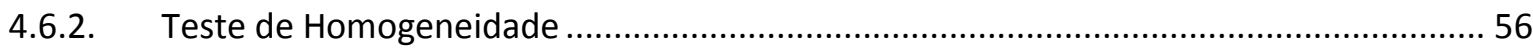

4.7. Curva de emissão TL e Curva de decaimento OSL ................................................................ 57

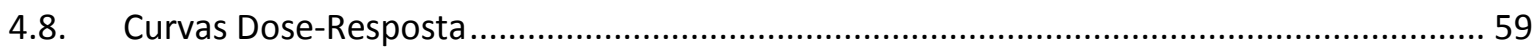

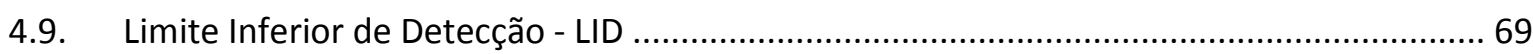

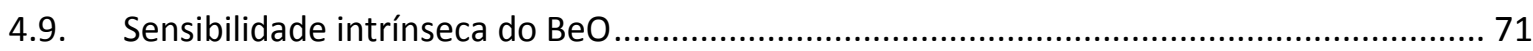

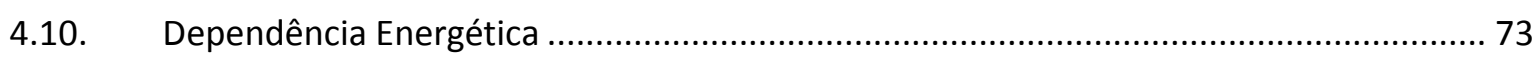

4.11. Determinação da Energia de Ativação e do Fator de Frequência..................................... 78 


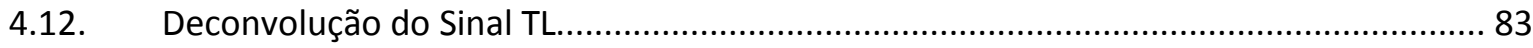

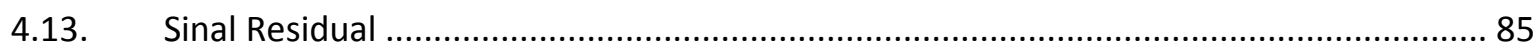

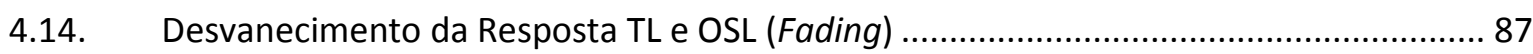

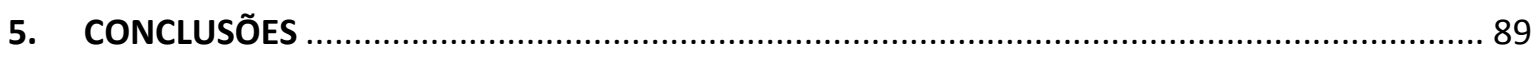

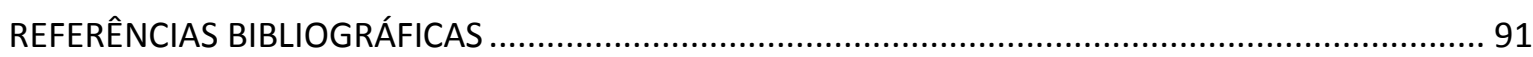

ANEXO 1 - Código do MCNP5 para Simulação do Suporte de Acrílico.............................................. 95 
Lista de Tabelas

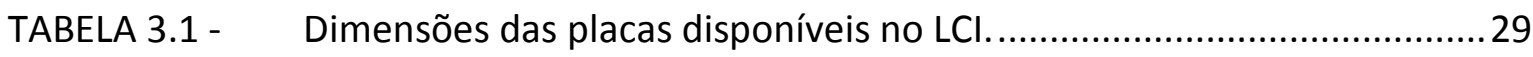

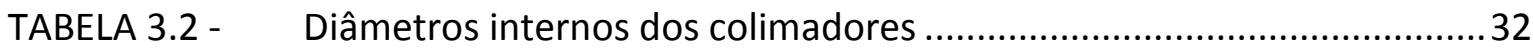

TABELA 3.3 - L Limites operacionais - Pantak/Seifert modelo ISOVOLT HS 160 ............33

TABELA 3.4 - Características dos feixes padrões de raios $X$ de radiodiagnóstico

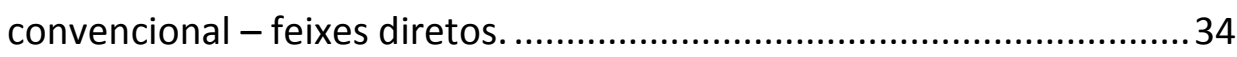

TABELA 3.5 - Características dos feixes padrões de raios $X$ de radiodiagnóstico convencional - feixes atenuados. ......................................................... 34

TABELA 3.6 - Características dos feixes padrões de raios $X$ de mamografia...................35

TABELA 3.7 - Características dos feixes padrões de raios $X$ de tomografia

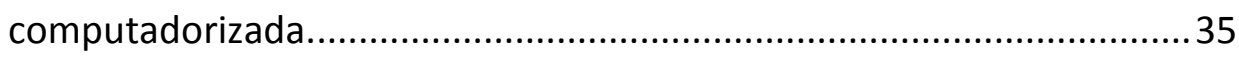

TABELA 4.1 - Respostas TL e OSL nas situações da Lâmpada (Acesa e Apagada). ........ 46

TABELA 4.2 - Fatores de correção obtidos para cada um dos colimadores de

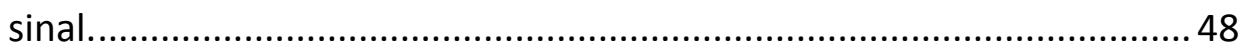

TABELA 4.3 - Qualidades de radiação testadas com a indicação de uso de colimadores.

TABELA 4.4 - Doses determinadas com e sem a tampa de acrílico e as variações percentuais para as qualidades de Radiodiagnóstico Convencional - Feixes Diretos e Feixes Atenuados.

TABELA 4.5 - Doses determinadas com e sem a tampa de acrílico e as variações percentuais para as qualidades de Tomografia Computadorizada e Mamografia. 53

TABELA 4.6 - Valores atribuídos às variáveis da simulação...........................................55

TABELA 4.7 - Teste de reprodutibilidade do BeO............................................................56

TABELA 4.8 - Teste de homogeneidade e definição de Lote. ........................................57

TABELA 4.9 - Coeficientes de calibração (OSL) do BeO para todas as qualidades

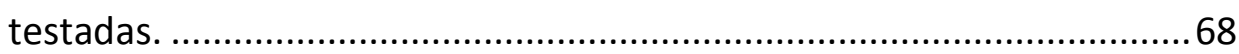

TABELA 4.10 - Coeficientes de calibração (TL) do BeO para todas as qualidades testadas.

TABELA 4.11 - Valores dos Limites Inferiores de Detecção (LID), pelas técnicas de TL e OSL. .70

TABELA 4.12- Sensibilidade intrínsica das amostras de $\mathrm{BeO}$ em relação às qualidades de radiação testadas pela técnica de TL. .72

TABELA 4.13 - Sensibilidade intrínsica das amostras de BeO em relação às qualidades de radiação testadas pela técnica de OSL. .73

TABELA 4.14 - Coeficientes mássicos de absorção de energia para o Ar, O, Be e BeO determinados a partir de NIST (2016). 
TABELA 4.15 - Dependência energética do $\mathrm{BeO}$ em relação ao ar, $\mathrm{S}(\mathrm{E})$, e dependência energética relativa, RER, a energia de 83,10 keV em relação ao ar. 75

TABELA 4.16 - Dependência energética relativa (RER) do BeO. 77

TABELA 4.17 - Temperaturas da intensidade máxima $\left(T_{M}\right)$ e da metade da intensidade máxima $\left(\mathrm{T}_{1}\right.$ e $\left.\mathrm{T}_{2}\right)$ dos picos $\mathrm{TL}$ do $\mathrm{BeO}$. .78

TABELA 4.18 - Parâmetros utilizados nos métodos de formato de pico. 79

TABELA 4.19 - Energia de ativação e fator de frequência para o primeiro pico do BeO.

TABELA 4.20 - Energia de ativação e fator de frequência para o segundo pico TL do BeO.

TABELA 4.21 - Energia de ativação e fator de frequência para o primeiro pico TL do BeO, informação extraída de Bacci et al (1989)

TABELA 4.22 - Energia de ativação e fator de frequência para o segundo pico do BeO, informação extraída de Bacci et al (1989). 82

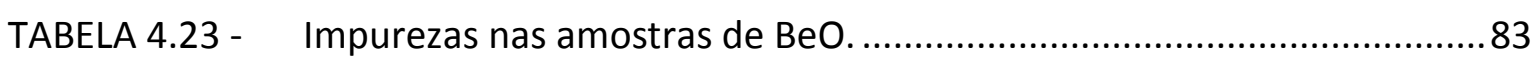

TABELA 4.24 - Sinal Residual após leituras TL e OSL........................................................86 


\section{Lista de Figuras}

FIGURA 2.1 - Espectro de raios $X$ do Molibdênio com a indicação de Brehmsstrahlung e dos raios $\mathrm{X}$ característicos (adaptado de OKUNO, YOSHIMURA, 2010)........................................................... 5

FIGURA 2.2 - Esquema do efeito fotoelétrico. (Adaptado de EVANS, 1955)..................7

FIGURA 2.3 - Esquema do efeito Compton. (Adaptado de EVANS, 1955).....................8

FIGURA 2.4 - Esquema da produção de pares. (Adaptado de EVANS, 1955).................9

FIGURA 2.5 - Gráfico da predominância das interações principais. (Adaptado de EVANS, 1955)

FIGURA 2.6 - Diagrama esquemático dos níveis de energia de um material que desencadeia o fenômeno termoluminescente. BV - Banda de valência; BP - Banda proibida; BC - Banda de condução (Adaptado de BOS, 2007).

FIGURA 2.7 - Curva de emissão TL típica do LiF (TLD-100) (Adaptado de FURETTA, 2003).

FIGURA 2.8 - Representação dos principais modos de estimulação OSL (Adaptado de AKSELROD et al, 2007)

FIGURA 2.9 - Curva de emissão TL do BeO exposto a uma dose de 1Gy com radiação beta (GROPPO, 2013).

FIGURA 2.10 - Curva de decaimento OSL do BeO exposto a uma dose de 1 Gy com radiação beta (GROPPO, 2013).

FIGURA 3.1 - Pastilha dentro e fora do clipe. 28

FIGURA 3.2 - Balança Mettler Toledo, modelo AB204-S. ...........................................28

FIGURA 3.3 - Pastilhas de BeO no suporte de cobre ...................................................29

FIGURA 3.4 - S Suporte de acrílico para pastilhas de BeO, à esquerda está tampa e à está direita a base 30

FIGURA 3.5 - ～Leitora RISÖ TL/OSL-DA20 (DTU NUTECH, 2016)...... 30

FIGURA 3.6 - Carrossel da leitora RISÖ TL/OSL-DA20 com capacidade para 48 amostras. 
FIGURA 3.7 - Eficiência quântica da fotomultiplicadora bialkali EMI9235QB como função do comprimento de onda do fóton incidente (adaptado de DTU NUTECH, 2016).

FIGURA 3.8 - Características de transmissão dos filtros utilizados na Leitora RISÖ TL/OSL-DA20 (adaptado de DTU NUTECH, 2016).

FIGURA 3.9 - Equipamento de raios X Pantak/Seifert modelo ISOVOLT HS 160..........33

FIGURA 3.10 - Forno tipo Mufla modelo MFLO1000 da Provecto Analítica. ...................36

FIGURA 3.11 - Lâmpada de diodo emissor de luz (LED) azul da marca Ourolux ${ }^{\circledR}$........... 36

FIGURA 3.12 - Parâmetros utilizados nos métodos de formato de pico

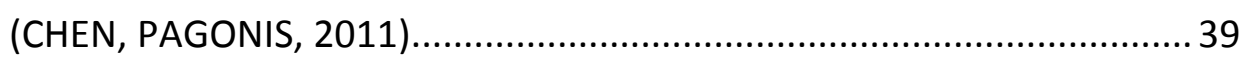

FIGURA 3.13 - Gráfico do fator geométrico versus ordem cinética. (Adaptado de CHEN, 1969).

FIGURA 4.1 - (a) Curvas de decaimento OSL sem colimador e com os colimadores 3 e 4 e (b) curvas de emissão TL sem colimador e com os colimadores 3 e 4 . .48

FIGURA 4.2 - Média das respostas TL das amostras de BeO após tratamento térmico. Erro! Indicador não definido.

FIGURA 4.3 - Atenuação dos feixes de radiodiagnóstico convencional, de mamografia e de tomografia computadorizada ao atravessarem uma (a) placa de acrílico e (b) um filme de PVC.Erro! Indicador não definido.

FIGURA 4.4 - Representação da experiência simulada no MCNP no plano XY. À esquerda está a representação do suporte com a pastilha e à direita a do laboratório com o suporte com a pastilha e o sistema de raios $X$. 54

FIGURA 4.5 - C Curvas de emissão TL (a) e de decaimento OSL (b) de amostras de $\mathrm{BeO}$ para doses diferentes de radiação X (RQR 8). 58

FIGURA 4.6 - Curvas dose-resposta OSL do BeO para as qualidades de mamografia, feixes diretos (a) RQR - 2M e (b) RQR - 4M.

FIGURA 4.7 - Curvas dose-resposta OSL do BeO para as qualidades de mamografia, feixes atenuados, (a) RQA - 2M e (b) RQA - 4M. 60 
FIGURA 4.8 - Curvas dose-resposta OSL do BeO para as qualidades de radiodiagnóstico convencional, feixes diretos (a) RQR 3 e (b) RQR 5 .

FIGURA 4.9 - Curvas dose-resposta OSL do BeO para as qualidades radiodiagnóstico convencional, feixes diretos (a) RQR 8 e (b) RQR 10 . 61

FIGURA 4.10 - Curvas dose-resposta OSL do BeO para as qualidades de radiodiagnóstico convencional, feixes atenuados (a) RQA 3 e (b) RQA 5

FIGURA 4.11 - Curvas dose-resposta OSL do BeO para as qualidades de radiodiagnóstico convencional, feixes atenuados (a) RQA 8 e (b) RQA 10

FIGURA 4.12 - Curvas dose-resposta OSL do BeO para as qualidades de tomografia computadorizada (a) RQT 8, (b) RQT 9 e (c) RQT 10

FIGURA 4.13 - Curvas dose-resposta TL do BeO para as qualidades de mamografia, feixes diretos (a) RQR - 2M e (b) RQR - 4M.

FIGURA 4.14 - Curvas dose-resposta TL do BeO para as qualidades de mamografia, feixes atenuados (a) RQR - $2 \mathrm{M}$ e (b) RQR - 4M. .64

FIGURA 4.15 - Curvas dose-resposta TL do BeO para as qualidades radiodiagnóstico convencional, feixes diretos (a) RQR 3 e (b) RQR 5 65

FIGURA 4.16 - Curvas dose-resposta TL do BeO para as qualidades radiodiagnóstico convencional, feixes diretos (a) RQR 8 e (b) RQR 10 65

FIGURA 4.17 - Curvas dose-resposta TL do BeO para as qualidades de radiodiagnóstico convencional, feixes atenuados (a) RQA 3 e (b) RQA 5 66

FIGURA 4.18 - Curvas dose-resposta TL do BeO para as qualidades radiodiagnóstico convencional, feixes atenuados (a) RQA 8 e (b) RQA 10 66

FIGURA 4.19 - Curvas dose-resposta TL do BeO para as qualidades de tomografia computadorizada (a) RQT 8, (b) RQT 9 e (c) RQT 10. 
FIGURA 4.20 - Flutuação da contagem de fundo da Leitora TL/OSL da marca RIS $\emptyset^{\text {TM }}$, modelo TL/OSL-DA-20.

FIGURA 4.21 - Dependência energética relativa das respostas TL e OSL do BeO.

A incerteza máxima dos pontos experimentais é de $3 \%$, não visível na figura.

FIGURA 4.22 - Determinação das ordens cinéticas do (a) primeiro pico TL e do (b) segundo pico TL do BeO com o método da área sob a curva TL.

FIGURA 4.23 - Fator de correlação versus ordem cinética dos picos TL 1 e 2 do $\mathrm{BeO}$. 80

FIGURA 4.24 - Deconvolução da curva de emissão TL do BeO utilizando os valores de fator de frequência e energia de ativação obtido pelo método de Chen com o parâmetro $\delta$.

FIGURA 4.25 - Deconvolução do primeiro pico da curva de emissão TL do BeO utilizando os valores de fator de frequência e energia de ativação da Tabela 4.18.

FIGURA 4.26 - Deconvolução do segundo pico da curva de emissão TL do BeO utilizando os valores de fator de frequência e energia de ativação da Tabela 4.19.

FIGURA 4.27 - Emissão TL após uma leitura OSL para diversas doses absorvidas. 86

FIGURA 4.28 - Desvanecimento da resposta (Fading) TL. ..........................................87

FIGURA 4.29 - Desvanecimento da resposta (Fading) OSL............................................ 88 


\section{INTRODUÇÃO}

Em 1895, com a publicação no artigo "On a new kind of rays" da célebre radiografia, que apresentava a mão da esposa do físico Roentgen, apresentou-se a descoberta dos raios X. Um ano mais tarde, em 1896, Becquerel publicou seu estudo sobre a fosforescência do urânio que, posteriormente, com os trabalhos de Marie Curie, foi denominada de radioatividade.

Com a descoberta da radioatividade e também dos estudos de Roentgen, a radiação ionizante tornou-se parte da vida do homem, o qual se empenha em utilizar as suas propriedades a seu favor.

A radiação ionizante foi utilizada primeiramente na área médica com a radioterapia, mas logo passou a ser empregada em outras áreas. Atualmente é utilizada na medicina, por exemplo, no combate contra o câncer, na imagiologia nuclear, na produção de radiofármacos, no radiodiagnóstico, na esterilização de produtos médicos e cosméticos, etc. Na indústria é aplicada para examinar soldas e junções de estruturas metálicas, no controle das espessuras de chapas metálicas, na detecção de rachaduras em peças e de vazamentos em tubulações e no tratamento de alimentos por radiação. Assim, reduz as perdas naturais causadas por processos fisiológicos, além de eliminar ou reduzir micro-organismos, parasitas e pragas, sem causar qualquer prejuízo ao alimento (PERUZZO, 2012).

O Radiodiagnóstico utiliza radiações ionizantes para identificar disfunções internas e/ou corpos estranhos no ser humano e também nos animais. Apesar de ampla utilização, os efeitos da radiação não podem ser considerados inofensivos. A sua interação com os seres vivos e o meio ambiente pode acarretar sérios danos, inclusive a morte. Outro problema é a irradiação não uniforme que causa valores de doses diferentes na matéria. Os riscos e os benefícios devem ser ponderados, por isso é de extrema importância a mensuração da dose provinda destes processos.

A dosimetria das radiações, isto é, a metrologia das doses de radiações, é fundamental em todos os processos de irradiação, de modo que qualquer irradiação esteja dentro dos níveis aceitáveis ao indivíduo e ao ambiente, e seja realizado de maneira correta e segura. 
Para realizar a metrologia das doses de radiação é necessário o uso de um sistema dosimétrico que é constituído de protocolos e equipamentos para determinar a dose que o objeto de estudo recebeu. Dentre os equipamentos empregados estão os materiais utilizados como dosímetros (câmaras de ionização, filmes, géis, cristais, entre outros), os de irradiação e de avaliação dos dosímetros (estes variam de acordo com a técnica utilizada e do dosímetro empregado).

Para que se estabeleça um tipo de sistema dosimétrico, mais coerente e adequado para uma determinada aplicação, é necessário um estudo detalhado das características dosimétricas de cada método e material.

Na dosimetria do estado sólido os materiais luminescentes são os mais utilizados, devido ao baixo custo, à alta confiabilidade e ao rendimento elevado, além de já existirem equipamentos e técnicas consolidadas (SOUZA et al, 2014).

São vários os compostos cristalinos que vêm sendo empregados como materiais luminescentes; dentre eles estão: $\mathrm{LiF}, \mathrm{Al}_{2} \mathrm{O}_{3}: \mathrm{C}, \mathrm{CaSO}_{4}$ e mais atualmente o $\mathrm{BeO}$. Esse último vem obtendo destaque internacional e suas diversas aplicações vêm sendo estudadas, tais como na dosimetria clínica, dosimetria in vivo, datações arqueológicas, dosimetria retrospectiva e monitorações para fins de proteção radiológica (AKSELROD et al, 2007; McKEEVER, 2011; YUKIHARA, 2011; SANTOS et al, 2013; GROPPO, CALDAS, 2014; SANTOS et al, 2015; SAHIN et al, 2015).

O BeO (óxido de berílio) é conhecido há mais de 60 anos e é utilizado em diversos campos, por exemplo, na indústria eletrônica por causa de sua condutividade térmica e alta resistividade elétrica. Na dosimetria, seu interesse surge na linearidade de sua resposta, que é de seis ordens de magnitude ( $5 \mu G y$ até $5 G y)$, e o seu número atômico efetivo (Zeff $\sim 7,22$ ) é similar ao número atômico efetivo do tecido biológico (Zeff $\sim 7,6$ ). Porém, é uma substância tóxica e a sua manipulação deve ser cuidadosa quando em pó (FURETTA, 2003; WATANABE et al, 2010; YUKIHARA, 2011; GROPPO, 2013; SAHIN et al, 2015).

Duas técnicas amplamente utilizadas na dosimetria com materiais luminescentes são a Luminescência Opticamente Estimulada (do inglês Optically Stimulate Luminescence, OSL) e a Luminescência Termicamente Estimulada (do inglês Thermoluminescence, $\mathrm{TL}$ ). Ambas empregam similarmente a mesma teoria, porém na OSL 
o estimulo é realizado por luz, e na TL por meio do calor (CHEN, McKEVEER, 1997; FURETTA, 2008; GROPPO, 2013; SANTOS et al, 2013; GROPPO, CALDAS, 2014).

Existem vantagens e desvantagens entre as técnicas OSL e TL. A técnica OSL necessita o uso de filtros e colimadores, para distinguir a luz luminescente da luz de iluminação. A técnica TL é destrutiva, isto é, após a leitura TL não há mais sinal no material, enquanto a OSL não é destrutiva (McKEEVER, MOSCOVITCH, 2003).

\subsection{Objetivos do Trabalho}

\subsubsection{Objetivos Gerais}

Nesse trabalho propõe-se o estabelecimento de um sistema dosimétrico para feixes de raios $X$ nas qualidades de radiodiagnóstico convencional, de mamografia e de tomografia computadorizada, pelas técnicas de Termoluminescência e Luminescência Opticamente Estimulada.

\subsubsection{Objetivos Específicos}

Neste trabalho também serão analisados, com as técnicas de Termoluminecência e Luminescência Opticamente Estimulada, os parâmetros a seguir:

- Reprodutibilidade da resposta;

- Linearidade da resposta;

- Limites mínimos de detecção;

- Dependência energética da resposta;

- Calibração dos detectores para as diversas qualidades de radiação.

- Desvanecimento térmico (fading);

- Sensibilidade intrínseca do material.

Os parâmetros a serem analisados somente com a técnica de Termoluminescência são:

- Homogeneidade;

- Energia de ativação;

- Fator de frequência. 


\section{CONCEITOS BÁSICOS}

Neste capítulo serão apresentados os tópicos necessários para a compreensão desse trabalho. Serão abordados principalmente os temas relacionados ao funcionamento e à utilização de dosímetros do estado sólido em laboratórios de calibração, hospitais e clínicas.

\subsection{Sistemas de Raios $X$}

Os sistemas de raios $\mathrm{X}$ são equipamentos capazes de produzir raios $\mathrm{X}$. Estes equipamentos podem emitir um ou mais espectros de radiação $X$, isto é, emitir um ou mais feixes com energias efetivas diferentes de acordo com a aplicação desejada. Exemplos desses equipamentos são os mamógrafos, tomógrafos computadorizados e os aparelhos de radiodiagnóstico convencional.

\subsection{Produção de Raios $X$}

A produção de raios $X$ nos equipamentos de radiodiagnóstico convencional, mamografia e tomografia computadorizada realizam-se da seguinte maneira:

Ao se aquecer um material (catodo), elétrons são emitidos (emissão termoiônica). Estes elétrons podem e são direcionados e acelerados a outro material (anodo) devido a uma diferença de potencial. Ao colidirem com o anodo, os elétrons podem interagir e produzir os raios $\mathrm{X}$ de duas formas:

A primeira forma é a desaceleração que o elétron sofre ao penetrar o material constituinte do anodo, interagindo com o núcleo ou a eletrosfera dos átomos. Por conservação do momento e da energia, o elétron, ao ser desacelerado, emite um fóton. Este fóton, por sua vez, pode ter qualquer energia, desde valores próximos a zero até um valor máximo que corresponde à energia cinética do elétron incidente. Esse tipo de radiação $X$ é denominado de Bremsstrahlung (radiação de freamento) ou de espectro contínuo (EISBERG, RESNICK, 1994; OKUNO, YOSHIMURA, 2010).

A segunda forma é quando um elétron interage com outro elétron do átomo constituinte do anodo e este é ionizado ou excitado. Quando o elétron excitado retorna ao seu estado fundamental ou quando ocorre a ionização e outro elétron, de outro nível energético maior preenche a lacuna deixada pelo elétron ionizado, acontece a emissão do 
excesso de energia na forma de um fóton, cuja energia é igual à diferença de energia dos níveis energéticos envolvidos. Este tipo de radiação $X$ é denominado de raios $X$ característicos, pois depende dos níveis energéticos característicos do material que constitui o anodo e são apresentados em forma de picos no espectro de raios X (Figura 2.1) (EISBERG, RESNICK, 1994; OKUNO, YOSHIMURA, 2010).

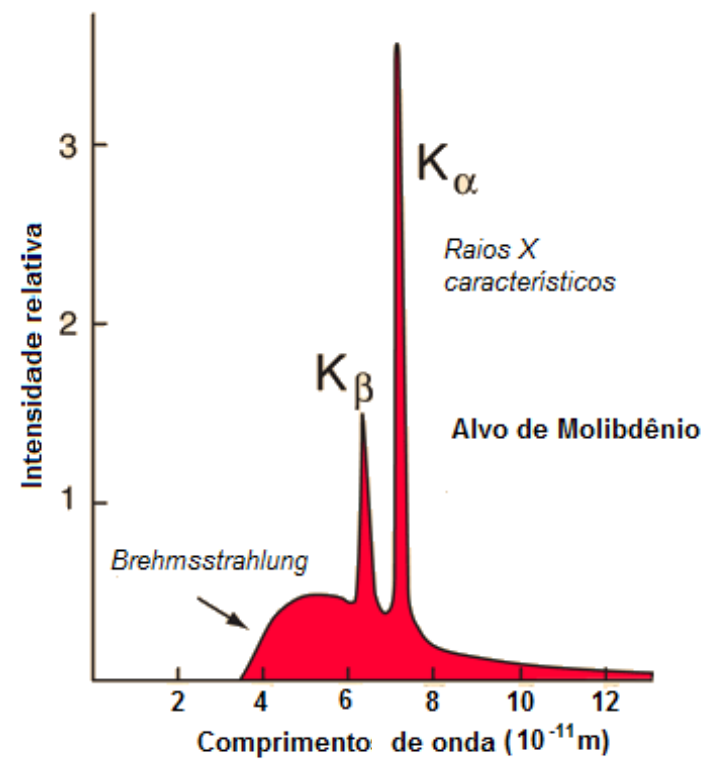

FIGURA 2.1 - Espectro de raios X do Molibdênio com a indicação de Brehmsstrahlung e dos raios X característicos (adaptado de OKUNO, YOSHIMURA, 2010).

Dependendo da aplicação pode-se utilizar os raios X de Bremsstrahlung ou os característicos. Em geral, no radiodiagnóstico convencional são utilizados raios $\mathrm{X}$ de Bremsstrahlung, porém na mamografia usam-se os raios $X$ característicos (OKUNO, YOSHIMURA, 2010).

\subsection{Interação da Radiação com a Matéria}

A interação da radiação com a matéria consiste na transferência de energia da radiação ao meio que atravessa. Esta transferência pode acontecer com os elétrons dos átomos ou mesmo com o núcleo atômico, dependendo do tipo de radiação incidente.

A radiação eletromagnética (fótons) interage pela ação de campos eletromagnéticos, atuando sobre as partículas carregadas do meio. As partículas carregadas (elétrons, partículas alfa, fragmentos de fissão, prótons, etc.) têm sua ação em 
elétrons do meio aproximada por interações coulombianas consecutivas. Os nêutrons atuam sobre prótons e nêutrons de núcleos atômicos pela força nuclear forte.

Em decorrência destas interações, podem ocorrer a excitação atômica ou nuclear, a ionização ou a ativação do núcleo.

A excitação é o fenômeno no qual um elétron salta do seu nível fundamental para outro mais energético. Ao retornar ao nível fundamental o átomo emite um fóton de luz ou de raios $X$ característicos com energia igual à diferença de energia entre os estados energéticos. A ionização é o fenômeno no qual um elétron é ejetado do átomo após receber uma quantidade de energia; como efeito, gera elétrons de energias altas, íons positivos ou radicais livres. A ativação do núcleo é o fenômeno no qual ocorrem reações nucleares; como efeito, pode ejetar um próton ou um nêutron do núcleo (EISBERG, RESNICK, 1994; OKUNO, YOSHIMURA, 2010; HEWITT,2011).

\subsubsection{Interação da Radiação Eletromagnética com a Matéria}

Na região de energias que incluem os raios $X$ e gama, há várias interações possíveis com o átomo inteiro ou com elétrons orbitais, ou ainda com o núcleo. A radiação eletromagnética, que ao atravessar a matéria pode depositar energia nesta em um processo que consiste de duas etapas: transferência de energia para uma partícula carregada (elétron ou pósitron) e posterior deposição da energia transferida à partícula carregada no meio. Mas há também a chance de não-interação, ou seja, a radiação eletromagnética pode atravessar distâncias consideráveis em um meio material sem modificá-lo e sem sofrer atenuação. As probabilidades de interação (e de não-interação) dependem do número atômico e densidade do meio e da energia da radiação. Esta probabilidade é, normalmente, expressa como uma grandeza chamada secção de choque. No caso da interação da radiação com a matéria, é utilizado o conceito de secção de choque total por átomo (EVANS, 1955, TSOULFANIDIS, 1995; OKUNO, YOSHIMURA, 2010).

A radiação eletromagnética é tratada, em boa parte dos casos, como um conjunto de partículas - os fótons. A cada energia de fóton corresponde um momento associado, e, dessa forma, podem ocorrer 'colisões' em que o fóton transfere energia e momento para outras partículas, mas a radiação também pode ser tratada como uma onda. As interações principais que ocorrem na matéria com fótons de energias na faixa de 
poucos keV até dezenas de MeV são: o efeito fotoelétrico, o efeito Compton, o espalhamento coerente e a produção de pares (EVANS, 1955; EISBERG, RESNICK, 1994; TSOULFANIDIS, 1995).

\subsubsection{Efeito Fotoelétrico}

O efeito fotoelétrico é o processo de interação entre um fóton e um elétron fortemente ligado a um átomo (elétron orbital). Nesta interação, o fóton é completamente absorvido e o elétron é ejetado com energia cinética K. Como a massa nuclear é grande, a energia de recuo do átomo é desprezível, assim, a energia cinética do elétron ejetado é definida pela Equação 2.1:

$$
K=h v-w
$$

onde

- $K$ é a energia cinética do elétron ejetado

- $h v$ é a energia do fóton incidente

- $h$ é a constante de Planck

- $v$ é a frequência do fóton incidente

- $\quad w$ é a função trabalho, energia mínima necessária para ejetar o elétron do átomo.

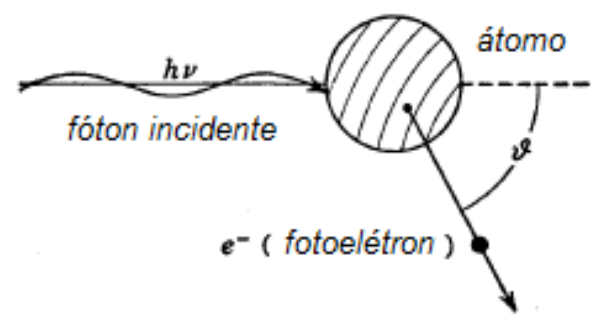

FIGURA 2.2 - Esquema do efeito fotoelétrico. (Adaptado de EVANS, 1955).

A ejeção do elétron deixa o átomo excitado e, para retornar ao estado fundamental, um elétron de outra camada preenche a lacuna deixada pelo elétron ejetado (EVANS, 1955; EISBERG, RESNICK, 1994). Nesta transição, um fóton é emitido com energia igual à diferença de energia dos níveis de energia envolvidos na transição. 
O fóton emitido é um fóton de raios $X$ característico, pois sua origem é de uma transição atômica de um elétron ligado (EISBERG, RESNICK, 1994; OKUNO, YOSHIMURA, 2010).

\subsubsection{Efeito Compton}

O efeito Compton é o processo de interação de um fóton com um elétron orbital fracamente ligado ao átomo. Como resultado desse processo, o fóton tem sua direção alterada e sua energia diminuída, pois cede ao elétron, que por sua vez é ejetado (EVANS, 1955; EISBERG, RESNICK, 1994).

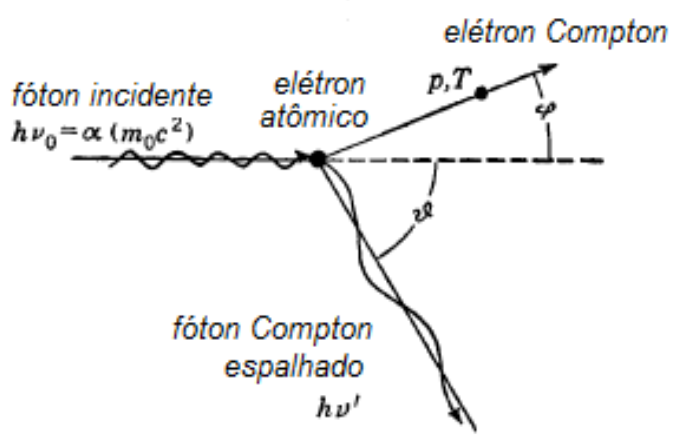

FIGURA 2.3 - Esquema do efeito Compton. (Adaptado de EVANS, 1955).

A energia do fóton espalhado é a diferença entre a energia do fóton incidente e a energia cinética do elétron, como apresentado na Equação 2.2:

$$
E=h v^{\prime}-(w+K)
$$

onde

- $h v^{\prime}$ é a energia do fóton incidente

- $\quad w$ é a função trabalho, energia mínima necessária para ejetar o elétron do átomo

- $K$ é a energia cinética do elétron ejetado.

\subsubsection{Espalhamento Coerente}

Quando o fóton interage com um elétron fracamente ligado (podendo ser considerado como um elétron livre) ocorre o espalhamento Thomson, pois o elétron oscila e após um curto intervalo de tempo reemite um fóton com a mesma energia do 
fóton incidente. Quando o fóton interage com elétrons atômicos ligados (não podendo considerá-los livres), ocorre o espalhamento Rayleigh, pois o átomo como um todo recebe o momento transferido, mas sua energia de recuo é muito pequena e um fóton é espalhado com a mesma energia do fóton incidente. Neste processo os ângulos de espalhamento são geralmente pequenos (EVANS, 1955; EISBERG, RESNICK, 1994).

\subsubsection{Produção de Pares}

A produção de pares é um processo de interação de um fóton com o campo elétrico do núcleo, porém para que ocorra, este fóton deve possuir energia igual ou superior a 1,022 Mev. Como resultado desta interação, toda a energia do fóton é transformada em duas partículas: um elétron e um pósitron, com energia cinética K. Esta energia cinética é dada pela Equação 2.3 (EVANS, 1955; EISBERG, RESNICK, 1994):

$$
h v=\left(K_{p}+m_{0}^{p} c^{2}\right)+\left(K_{e}+m_{0}^{e} c^{2}\right)
$$

onde

- $h v$ é a energia do fóton incidente

- $K_{p}$ é a energia cinética do pósitron

- $m_{0}^{p} c^{2}$ é a energia de repouso do pósitron

- $K_{e}$ é a energia cinética do elétron

- $m_{0}^{e} c^{2}$ é a energia de repouso do elétron.

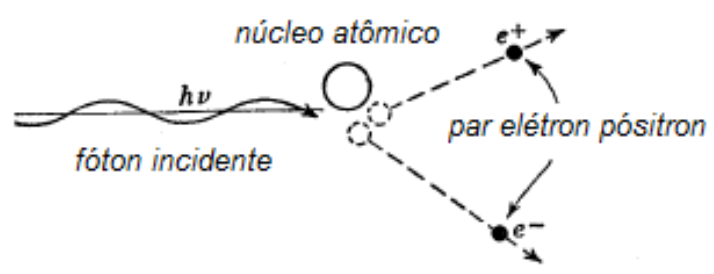

FIGURA 2.4 - Esquema da produção de pares. (Adaptado de EVANS, 1955).

O pósitron, por ser uma antipartícula do elétron, tem um tempo de vida pequeno. Ao interagir com um elétron do meio, dois fótons com a mesma energia são gerados, tendo suas direções diametralmente opostas. 


\subsubsection{Predominância dos Efeitos provocados pela Radiação Eletromagnética}

Sob o ponto de vista da probabilidade de ocorrência, o efeito coerente é proporcional a $Z^{2}$, o efeito fotoelétrico é proporcional a $Z^{4}$, o efeito Compton é proporcional a Z e a produção de pares é proporcional a $Z^{2}$ do material alvo, sabendo-se que o efeito coerente e o efeito fotoelétrico ocorrem com maior probabilidade para energias baixas, enquanto o efeito Compton ocorre para energias intermediárias. A produção de pares só acontece acima de um limiar de energia, ou seja, é necessário que o fóton incidente tenha no mínimo 1,022 MeV de energia (equivalente a duas massas de repouso do elétron) para que toda sua energia se converta em massa de repouso e energia cinética do par elétron-pósitron (EVANS, 1955; KNOLL, 2010).

A Figura 2.5 mostra com mais clareza que o efeito Compton predomina para todos os elementos da tabela periódica se as energias de fótons estão entre algumas centenas de keV e alguns $\mathrm{MeV}$, e predomina para todas as energias se os números atômicos são baixos. Para números atômicos elevados, o efeito fotoelétrico é o mais provável para energias baixas, e a produção de pares para energias elevadas.

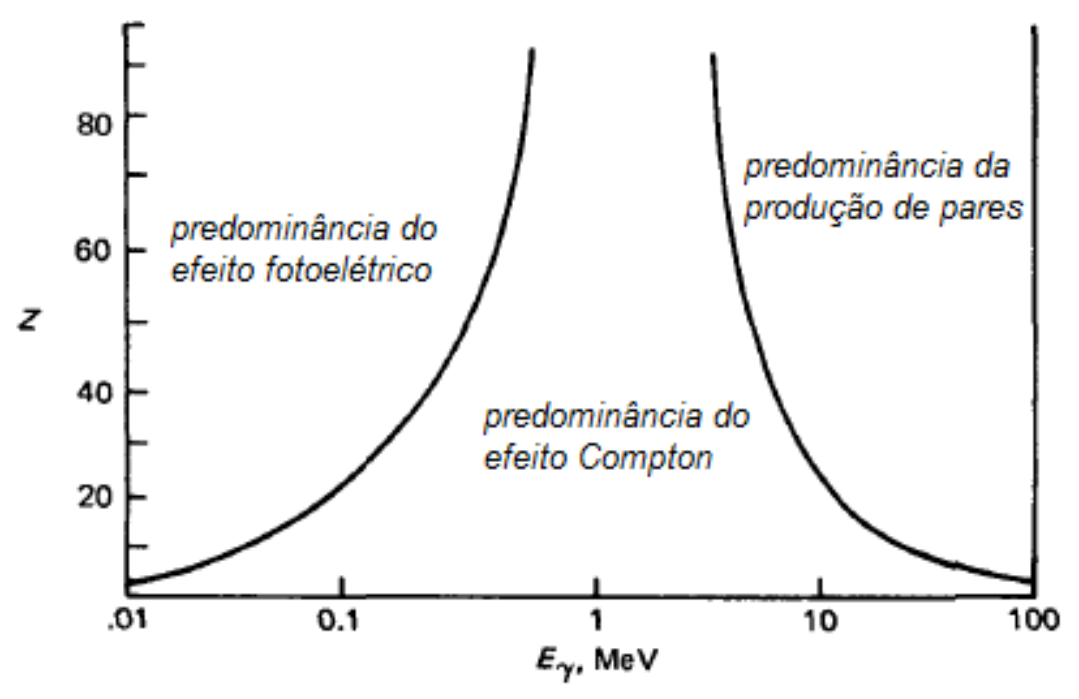

FIGURA 2.5 - Gráfico da predominância das interações principais. (Adaptado de EVANS, 1955).

\subsection{Dosimetria das Radiações}

A dosimetria das radiações, isto é, a metrologia das doses de radiações, é essencial em todos os processos de irradiação, de maneira que seja qual for a irradiação, 
esta permaneça dentro dos níveis aceitáveis ao indivíduo e ao ambiente, e seja efetuada de maneira correta e segura.

Para realizar a metrologia das doses de radiação é indispensável a aplicação de um sistema dosimétrico que é formado de protocolos e equipamentos para se estabelecer a dose que o objeto de estudo recebeu. Dentre os equipamentos empregados estão os materiais usados como dosímetros (câmaras de ionização, filmes, géis, cristais, entre outros), os de irradiação e de avaliação dos dosímetros (estes variam segundo a técnica adotada e do dosímetro utilizado).

A grandeza utilizada na dosimetria para se saber o quanto de radiação foi absorvido por um material é a dose absorvida e é definida como a razão entre a energia depositada $\mathrm{dE}$ em um volume e a massa dm deste volume.

$$
D=\frac{d \bar{E}}{d m}
$$

onde $\mathrm{dm}$ está em quilograma e $\mathrm{dE}$ em Joule. Esta razão também tem como unidade o Gray (Gy), que equivale a 1 J.kg (OKUNO, YOSHIMURA, 2010).

\subsection{Luminescência}

Alguns materiais isolantes ou semicondutores, quando são irradiados, podem emitir luz, e a este fenômeno dá-se o nome de luminescência, sendo o comprimento de onda da luz emitida maior que o da radiação incidente e esta luz emitida depende da composição do material (FURETTA, 2003).

A emissão luminescente, em geral, pode ser explicada pela transferência de energia da radiação incidente ao elétron do sólido, assim excitando o elétron do estado fundamental para o estado excitado, fenômeno este que pode ser descrito pela teoria de bandas de energia de sólidos. No entanto, dependendo do tempo entre a excitação e a emissão de luz, o fenômeno luminescente é classificado como fluorescência ou fosforescência. Quando a emissão é quase simultânea à excitação $\left(t<10^{-8} \mathrm{~s}\right)$, denominase fluorescência; contudo, quando a emissão ocorre após a excitação desaparecer e persiste por um longo tempo ( $\mathrm{t}>10^{-8} \mathrm{~s}$ ), denomina-se fosforescência (HEWITT, 2011). Entretanto, a fosforescência é explicada pela presença de estados metaestáveis entre o 
estado fundamental e o estado excitado, que atuam como armadilhas para elétrons e buracos e o atraso na transição do estado metaestável com outro estado mais energético é dependente da temperatura (FURETTA, 2003; McKEEVER, 1988).

\subsubsection{Termoluminescência - TL}

Quando ocorre o aquecimento de um material previamente irradiado e há liberação de fótons, tem-se o fenômeno conhecido como Termoluminescência (TL); em outras palavras, a Termoluminescência é a emissão luminescente estimulada de um material, previamente irradiado, quando este é aquecido.

Para se compreender basicamente a termoluminescência é necessário entender a teoria de bandas de energia de sólidos (FURETTA, 2003; McKEVEER, 1988). Os materiais termoluminescentes em geral são cristais que contêm defeitos e impurezas criando armadilhas, que correspondem aos estados metaestáveis localizados na banda proibida (BOS, 2007).

Em um cristal têm-se três bandas, a banda de valência, repleta de elétrons, a banca de condução vazia, e entre elas está a banda proibida, a qual apresenta uma larga faixa de estados energéticos não permitidos aos elétrons. Quando há impurezas ou defeitos no cristal surgem dentro da banda proibida os estados metaestáveis de energia, comumente denominados de centros de recombinação e armadilhas, dependendo de sua energia.

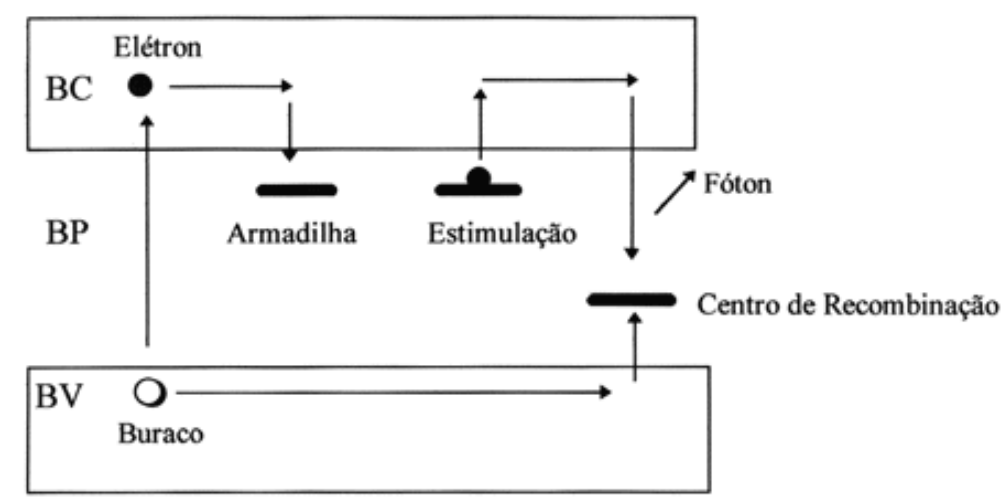

FIGURA 2.6 - Diagrama esquemático dos níveis de energia de um material que desencadeia o fenômeno termoluminescente. BV - Banda de valência; BP - Banda proibida; BC - Banda de condução (Adaptado de BOS, 2007). 
Quando o material é irradiado tem-se a formação dos pares elétron-buraco. Os elétrons passam para a banda de condução e os buracos para a banda de valência, podendo ser capturados por armadilhas, isto é, podem ficar localizados no estado metaestável dentro da banda proibida. Quando capturados, os elétrons podem ser liberados para a banda de condução ou outras armadilhas, e os buracos para a banda de valência ou outras armadilhas, caso recebam energia externa, que na termoluminescência ocorre pelo aquecimento controlado do material.

Com o retorno dos elétrons para a banda de condução, e dos buracos para a banda de valência, eles podem se recombinar nos centros de recombinação e, assim, ocorre a emissão de luz.

A intensidade de luz emitida é mensurável e, no processo de aquecimento, é igual à taxa de recombinação dos elétrons e dos buracos nos centros de recombinação e é dado por:

$$
I(t)=-\frac{d n}{d t}
$$

onde $I(t)$ é a intensidade da luz emitida em um determinado tempo, $d n$ é concentração de elétrons e buracos nos centros de recombinação e $d$ té o tempo.

Supondo que nenhum elétron liberado da armadilha seja recapturado e que os elétrons quando armadilhados têm uma distribuição Maxwelliana de energia, a probabilidade de escape dos elétrons de uma armadilha, devido à excitação térmica, é dada pela equação de Arrhenius:

$$
p(T)=s \times \exp \left(-\frac{E}{k T}\right)
$$

onde

- $s$ é o fator de frequência em $s^{-1}$, relacionado com a oscilação do elétron na armadilha

- E é a energia necessária para liberar o elétron da armadilha em keV

- $\mathrm{k}$ é a constante de Bolztman em eVK ${ }^{-1}$

- T é a temperatura em $\mathrm{K}$. 
Assim, com o aumento da temperatura, cresce a probabilidade de se liberar elétrons das armadilhas (McKEEVER, 1988, FURETTA, 2003).

A partir destas suposições e de que a taxa de aquecimento é constante e que todos os elétrons e buracos são recombinados nos centros de recombinação, Randall e Wilkins desenvolveram a Equação 2.7, que descreve o processo da termoluminescência.

$$
I(T)=n_{0} s \exp \left(\frac{-E}{k T}\right) \exp \left[-\frac{s}{\beta} \int_{T_{0}}^{T} \exp \left(\frac{-E}{k T}\right) d T\right]
$$

onde

- $E$ é a energia de ativação ou profundidade da armadilha (eV)

- $k$ é a constante de Boltzmann $\left(\mathrm{eVK}^{-1}\right)$

- $T$ é a temperatura (K)

- $s$ é o fator de frequência ou frequência de tentativa de escape $\left(s^{-1}\right)$

- $n_{0}$ é o número de elétrons armadilhados para $t=0\left(\mathrm{~m}^{-3}\right)$

- $T_{0}$ é a temperatura no tempo $t=0$ (K)

- $\quad \beta$ é a taxa de aquecimento.

Esta equação também é conhecida como cinética de primeira ordem devido à suposição de que somente uma armadilha e um centro de recombinação participam do processo (FURETTA, 2003; PAGONIS et al, 2006; FURETTA, 2008).

Além da cinética de primeira ordem, existem as cinéticas de segunda ordem e de ordem geral.

A cinética de segunda ordem foi desenvolvida por Garlick e Gibson. Eles consideraram que os elétrons e os buracos têm probabilidade de serem rearmadilhados ou de se recombinarem nos centros de recombinação. $O$ termo segunda ordem é usado para descrever a situação na qual o rearmadilhamento é predominante. A Equação 2.8 para cinética de segunda ordem é:

$$
I(T)=n_{0}^{2} \frac{s}{N} \exp \left(\frac{-E}{k T}\right)\left[1+\frac{n_{0} s}{\beta N} \int_{T_{0}}^{T} \exp \left(\frac{-E}{k T}\right) d T\right]^{-2}
$$


onde $E, k, T, s, n_{0}, T_{0}$ e $\beta$ têm a mesma definição que no caso da cinética de primeira ordem e $N$ é a concentração total de armadilhas $\left(m^{-3}\right)$ (FURETTA, 2003; PAGONIS et al, 2006; FURETTA, 2008).

Quando as suposições para cinética de primeira ou de segunda ordem não são satisfeitas, pode-se obter casos intermediários chamados de cinética de ordem geral. Neste caso, não existem suposições sobre algum modelo. A Equação 2.9 da ordem geral foi desenvolvida empiricamente (PAGONIS et al, 2006):

$$
I(T)=s^{\prime} n_{0}^{(b-1)} \exp \left(\frac{-E}{k T}\right)\left[1+\frac{s^{\prime} n_{0}^{(b-1)}(b-1)}{\beta} \int_{T_{0}}^{T} \exp \left(\frac{-E}{k T}\right) d T\right]^{\frac{-b}{b-1}}
$$

onde $E, k, T, s, n_{0}, T_{0}, N$ e $\beta$ têm a mesma definição que no caso da cinética de primeira e de segunda ordem e $b$ é a ordem cinética, um parâmetro adimencional que varia entre 1 (primeira ordem) e 2 (segunda ordem) (FURETTA, 2003; PAGONIS et al, 2006; FURETTA, 2008).

Independentemente da ordem cinética, monitorando a intensidade de luz emitida pelo material e a variação da temperatura ou o tempo de aquecimento, é possível construir a curva de emissão TL, ou seja, a curva da intensidade da luminescência emitida em função da temperatura ou do tempo de aquecimento (Figura 2.7).

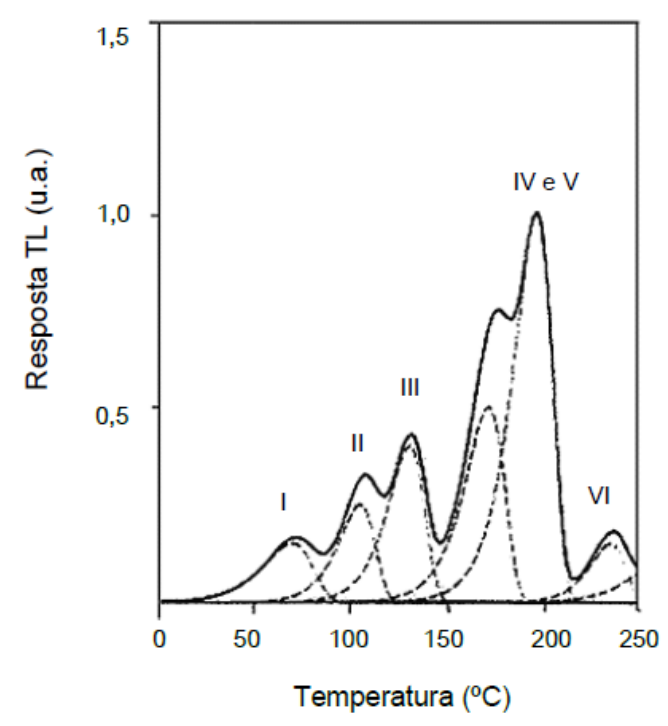

FIGURA 2.7 - Curva de emissão TL típica do LiF (TLD-100) (Adaptado de FURETTA, 2003). 
Desta forma, tem-se a possibilidade de aplicação deste processo em dosimetria das radiações, pois a intensidade da emissão da luz de um material depende da quantidade de radiação recebida, ou seja, da dose de radiação.

A forma de aplicação da resposta TL independe do seu modelo e ela pode ser de duas maneiras: utilizar a altura do pico, que é diretamente proporcional a luz emitida, que por sua vez é proporcional à população de elétrons capturados pelas armadilhas, no caso da produção de fótons mostar eficiência constante; e utilizar a área sob a curva, por ser proporcional à população eletrônica da armadilha.

\subsubsection{Energia de Ativação e Fator de Frequência}

A energia de ativação corresponde à profundidade da armadilha (nível energético), isto é, à quantidade de energia necessária para retirar um elétron de um estado metaestável para a banda de condução.

O fator de frequência é o número de vezes por segundo que um elétron interage com a estrutura considerando que está preso em um poço de potencial ou, de uma forma geral, como a frequência de tentativa de escape do elétron da armadilha.

Ambos são considerados parâmetros cinéticos os quais são importantes na descrição geral das características físicas de um material termoluminescente (CHEN, MCKEEVER, 1997; CHEN, PAGONIS, 2011).

\subsubsection{Luminescência Opticamente Estimulada - OSL}

Diversos materiais, utilizados na Termoluminescência, sofrem um resfriamento brusco. Este resfriamento causa uma perda de eficiência luminescente conforme ocorre o aumento da temperatura, já que, quanto maior a taxa de aquecimento, menor será a sensibilidade do dosímetro. Desta forma, quando se estimula o material com a luz, ao invés do calor, verifica-se um aumento de aproximadamente uma ordem de magnitude na sensibilidade da emissão luminescente. Portanto, o estímulo com a luz evita problemas decorrentes do aquecimento dos dosímetros (SCHEMBRI, HEIJMEN, 2007).

A Luminescência Opticamente Estimulada (do inglês Optically Stimulated Luminescence - OSL) é a emissão luminescente estimulada de um material, previamente 
irradiado, quando este é exposto à luz. O fenômeno OSL pode ser explicado do mesmo modo que o processo termoluminescente, mas ao invés de se aquecer o material, ele é exposto à luz.

Como na termoluminescência, quando o material é irradiado, tem-se a formação dos pares elétrons-buracos. Os elétrons passam para a banda de condução e os buracos para a banda de valência, podendo ser capturados por armadilhas. Quando capturados, os elétrons podem ser liberados para a banda de condução, e os buracos para a banda de valência, caso recebam energia externa, que na OSL é pela exposição à luz (YUKIHARA, McKEEVER, 2011).

Com o retorno dos elétrons para a banda de condução, e dos buracos para a banda de valência, eles podem se recombinar com os armadilhados e, assim, ocorrer a emissão de luz.

A OSL pode ser obtida empregando-se três modos de estimulação: por ondas contínuas (CW-OSL), por variação da intensidade luminosa (LM-OSL) ou por ondas pulsantes (POSL). O modo CW-OSL consiste na iluminação constante do material enquanto ocorre a monitoração da intensidade OSL. O modo LM-OSL consiste na variação da intensidade de iluminação do material enquanto ocorre a monitoração da intensidade OSL. O modo POSL consiste na estimulação do material com pulsos de luz; assim, a monitoração do sinal OSL é realizada no intervalo de tempo entre cada pulso de luz (AKSELROD et al, 2007; YUKIHARA, McKEEVER, 2008; YUKIHARA, 2011). 


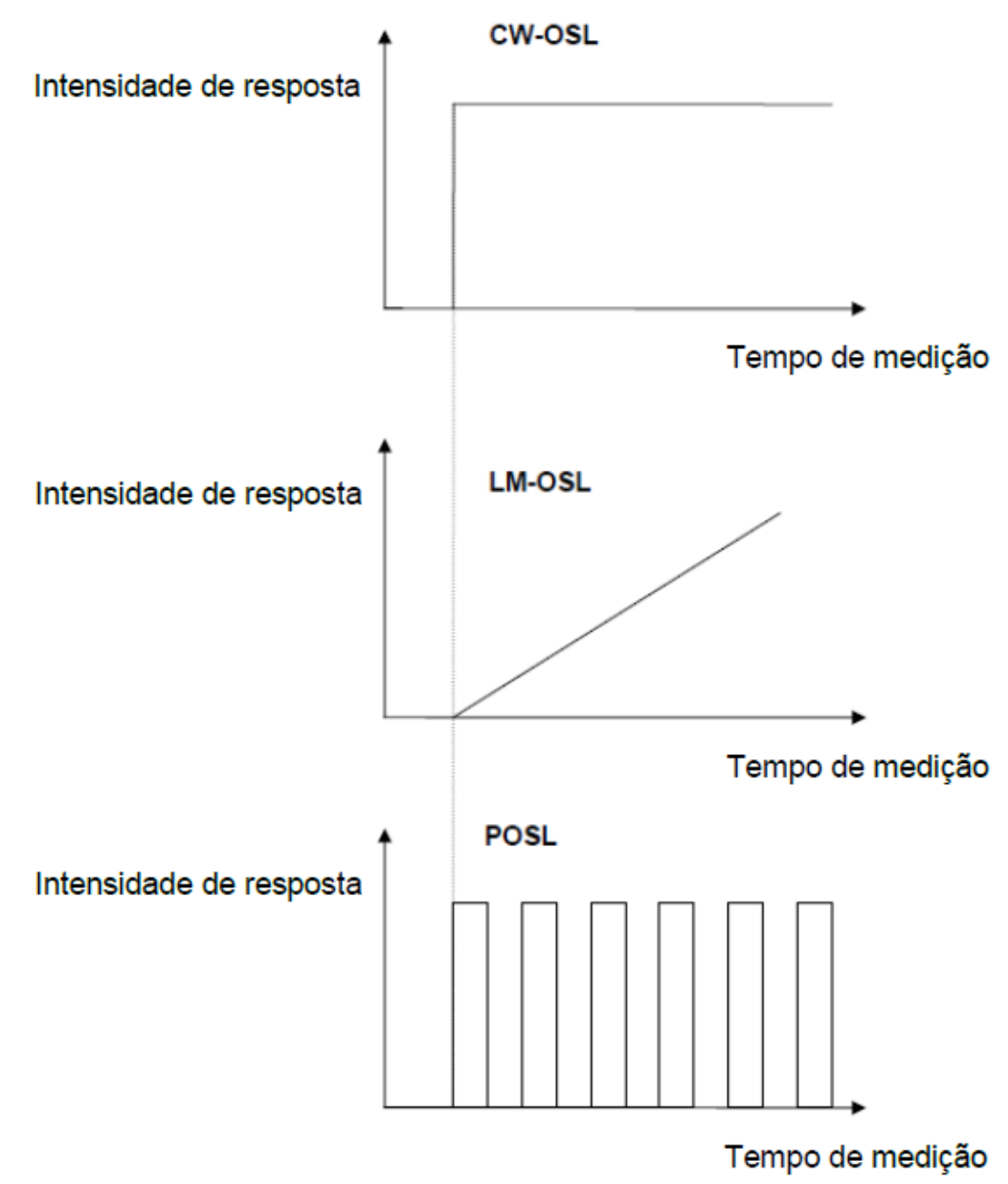

FIGURA 2.8 - Representação dos principais modos de estimulação OSL (Adaptado de AKSELROD et al, 2007)

A intensidade da luminescência opticamente estimulada emitida é uma função da dose de radiação absorvida pelo material (YUKIAHARA, McKEEVER, 2011) e a dependência da resposta em função da taxa de dose, da qualidade do feixe, de tamanho de campo e da profundidade do material é pequena ou praticamente desprezível (SCHEMBRI, HEIJMEN, 2007). Desta forma, a luminescência opticamente estimulada pode ser utilizada como um método dosimétrico (AKSELROD et al, 2007; YUKIHARA, McKEVEER, 2011).

\section{6. Óxido de Berílio}

O Óxido de Berílio (BeO) foi inicialmente investigado para a utilização na dosimetria no início dos anos 1950 com o intuito de substituir o fluoreto de lítio (LiF) como dosímetro termoluminescente por ser mais equivalente à água que o LiF. O seu 
número atômico efetivo $\left(Z_{\text {ef }} \sim 7,22\right)$ é similar ao número atômico efetivo do tecido biológico $\left(Z_{\text {ef }} \sim 7,6\right)$.

No entanto, os estudos envolvendo o $\mathrm{BeO}$ foram diminuindo ao longo da década de 1970 e somente na década de 1990 os estudos foram retomados como dosímetro TL e também como dosímetro OSL, pois tem alta sensibilida à luz (SOMMER et al, 2008; SOUZA et al, 2014).

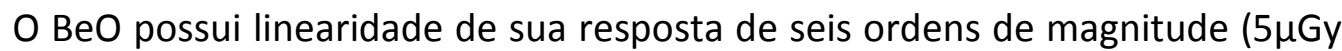
até $5 G y)$, elevada sensibilidade, alta resistência ao estresse mecânico, insensível a umidade (quando em formato de pastilhas), ausência de reação química e baixo custo de produção devido à ampla utilização na indústria eletrônica e aeroespacial. No entanto, o $\mathrm{BeO}$ tem alto desvanecimento estimulado pela luz branca e deve, preferencialmente, ser manuseado sob luz vermelha ou amarela (VIJ, SINGH, 1997; SOMMER et al, 2008; SOUZA et al, 2014).

É um elemento tóxico quando em pó. Sua produção em pastilhas é realizada em laboratórios comerciais. A pastilha de $\mathrm{BeO}$ mais utilizada é o Thermalox, que existe em quatro opções: 995, CR, BW3250 e BW1000, da empresa norte americana Materion (MATERION, 2017).

As amostras de $\mathrm{BeO}$, de modo geral, apresentam dois picos $\mathrm{TL}$ a $220^{\circ} \mathrm{C}$ e a $340^{\circ} \mathrm{C}$ para curvas de emissão até $450^{\circ} \mathrm{C}$ de aquecimento, sendo o pico de $220^{\circ} \mathrm{C}$ o pico dosimétrico principal (VIJ, SINGH, 1997).

\subsection{Propriedades Dosimétricas TL e OSL}

As pastilhas de $\mathrm{BeO}$ foram submetidos a diversos testes. Os parâmetros analisados foram:

- Tamanho, forma, espessura e composição;

- Tratamento térmico e óptico;

- Linearidade da resposta;

- Homogeneidade;

- Reprodutibilidade da resposta;

- Limites mínimos de deteç̧ão;

- Dependência energética da resposta; 
- Calibração dos detectores para as diversas qualidades de radiação.

- Desvanecimento térmico (fading);

- Energia de ativação;

- Fator de frequência;

- Sensibilidade intrínseca do material.

\subsubsection{Tratamentos Térmico e Óptico}

O tratamento térmico ou óptico tem por finalidade eliminar toda a informação devida a qualquer irradiação prévia, isto é, restaurar as condições iniciais do cristal antes de ser reutilizado. Este tratamento também tem como propósito estabilizar as armadilhas da estrutura do cristal.

No tratamento térmico utiliza-se o calor como fonte de energia para a restauração das condições iniciais do cristal; no tratamento óptico utiliza-se um feixe de luz. No caso do tratamento térmico, o resfriamento do material também é importante no desempenho do sistema termoluminescente. Em geral, a sensibilidade TL aumenta durante um rápido resfriamento (FURETTA, WENG, 1998; FURETTA, 2003).

\subsubsection{Teste de Homogeneidade e Reprodutibilidade}

A reprodutibilidade é uma característica importante em dosimetria, pois os dosímetros necessitam ter um comportamento estável ao longo do tempo e com isso manterem a mesma resposta.

Para a sua determinação, o coeficiente de variação percentual (\%CV) não pode variar mais que $5 \%$ e seu cálculo é realizado pela Equação:

$$
\% C V_{i}=\frac{\delta_{i}}{M_{i}} \times 100
$$

onde $\delta_{i}$ é a incerteza do dosímetro i, $M_{i}$ a resposta do dosímetro $i$.

Todo dosímetro cujo coeficiente de variação estiver acima de 5\% será descartado (FURETTA, WENG, 1998; FURETTA, 2003).

A homogeneidade é uma característica de um lote composto por dois ou mais dosímetros que têm aproximadamente as mesmas respostas quando irradiados com uma 
mesma dose. Dependendo da prática em que esses dosímetros forem utilizados a variação da resposta pode ser de até $30 \%$. A verificação da homogeneidade também é uma forma de controle de qualidade na dosimetria, verificando-se se as pastilhas ainda podem ser utilizadas.

Para determinar se um lote é homogêneo utiliza-se a Equação 2.11:

$$
\Delta m a ́ x(\%)=\frac{M_{M a ́ x i m a}-M_{\text {mínima }}}{M_{\text {mínima }}} \times 100
$$

onde $\Delta$ máx é a máxima variação do lote em porcentagem, $M_{\text {Máxima }}$ é a maior resposta TL ou OSL do lote e $M_{\text {mínima }}$ é a menor resposta TL ou OSL do lote (FURETTA, WENG, 1998; FURETTA, 2003).

\subsubsection{Sensibilidade Intrínseca da Amostra}

A sensibilidade intrínseca da amostra é o quão suscetível o material está em relação à radiação ionizante, isto é, a capacidade de resposta do material; sua unidade é contagens/Gykg. Ela é expressa por:

$$
S=\frac{M}{D \times m}
$$

onde $M$ é a resposta TL ou OSL de um dosímetro, $D$ a dose absorvida e $m$ a massa da amostra (FURETTA, WENG, 1998; FURETTA, 2003).

\subsubsection{Curva de Emissão TL e Curva de Decaimento OSL}

A curva de emissão TL é o gráfico da variação da resposta termoluminescente em função da temperatura de aquecimento da amostra durante a leitura mantendo constante a taxa de aquecimento. Variando-se a taxa de aquecimento, ocorre o deslocamento da posição do pico dosimétrico para valores mais altos (FURETTA, WENG, 1998; FURETTA, 2003; FURETTA, 2008). O tamanho e as impurezas no dosímetro também influenciam a forma da curva de emissão TL (McKEEVER et al, 1995). A Figura 2.9 representa uma curva de emissão TL. 


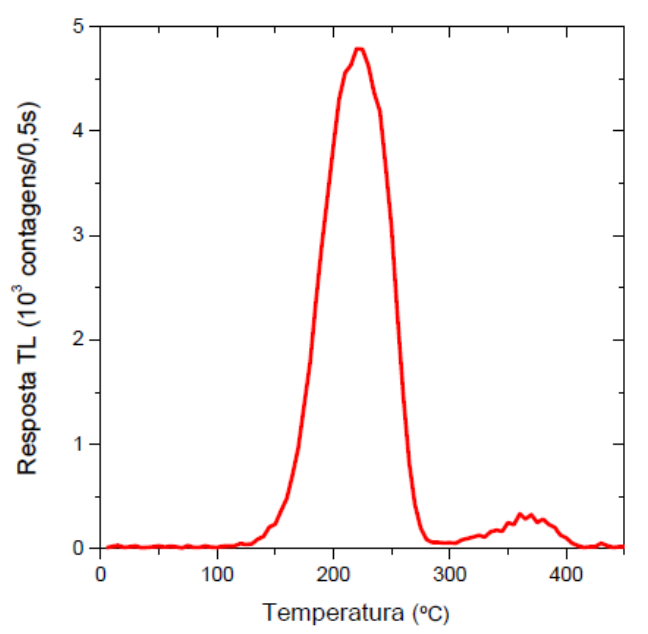

FIGURA 2.9 - Curva de emissão TL do BeO exposto a uma dose de 1Gy com radiação beta (GROPPO, 2013).

A curva de decaimento OSL é o gráfico da variação da resposta OSL em função do tempo de estimulação, tendo um comportamento exponencial. Este comportamento está vinculado ao desarmadilhamento dos elétrons e buracos (BOTTER-JENSEN et al, 2003). A Figura 2.10 apresenta uma curva de decaimento OSL.

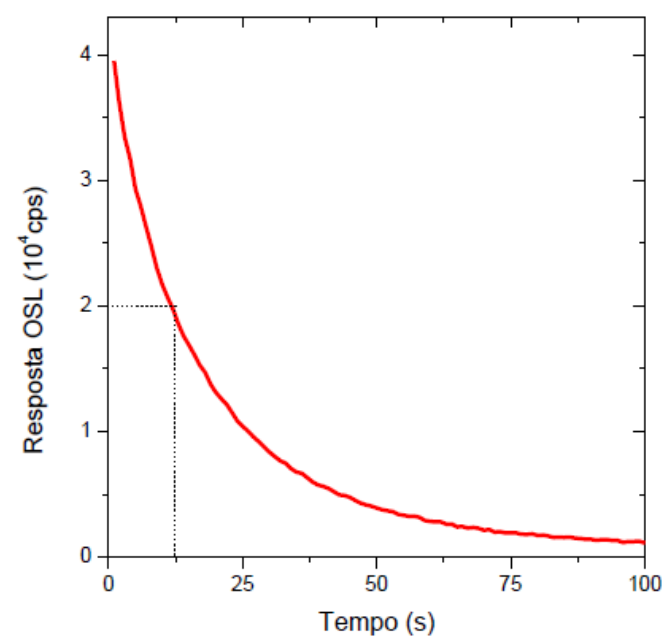

FIGURA 2.10 - Curva de decaimento OSL do BeO exposto a uma dose de $1 \mathrm{~Gy}$ com radiação beta (GROPPO, 2013). 


\subsubsection{Curva Dose-Resposta}

A curva dose-resposta é definida como a resposta TL ou OSL em função da dose absorvida do material irradiado. Um material ideal deveria apresentar uma relação linear da resposta TL ou OSL com a dose em um grande intervalo de dose; no entanto, a maioria dos materiais utilizados em dosimetria apresenta um comportamento não linear. Estes casos acontecem normalmente, à medida que se tem um aumento da dose, podendo ser supralinear e sublinear (McKEEVER et al, 1995; FURETTA, WENG, 1998; FURETTA, 2003).

Ao obter a curva dose-resposta e com o auxílio do método dos mínimos quadrados ou de um software, é possível obter o ajuste linear da curva. Com a equação da reta do ajuste linear é possível obter o Coeficiente de Calibração com a Equação:

$$
C_{c}=\frac{1}{\text { Coef.Angular }}
$$

Outro modo de obter o coeficiente de calibração é realizando o cálculo para cada ponto obtido na curva dose-resposta e posteriormente calculando a média ponderada pelas incertezas dos coeficientes de calibração obtidos (FURETTA, WENG, 1998; FURETTA, 2003; FURETTA, 2008). A Equação 2.14 para o cálculo do Coeficiente de Calibração é dado por:

$$
C_{C}=\frac{\text { Dose }}{M}
$$

onde $M$ é a resposta TL ou OSL.

\subsubsection{Dependência Energética das Respostas TL e OSL}

As respostas TL e OSL em função da dose absorvida podem variar com a energia da radiação incidente no material. Esta variação advém da dependência do coeficiente de absorção do material para diferentes energias e no caso dos fótons com energia definida, deve-se ao coeficiente mássico de absorção de energia $\left(\frac{\mu_{\text {en }}}{\rho}\right)$ (FURETTA, WENG, 1998; McKEEVER et al, 2003; FURETTA, 2003). 
Os materiais com número atômico efetivo alto são fortemente dependentes da energia do fóton incidente, por isso não são recomendados para dosimetria. Para a determinação de doses absorvidas em tecidos humanos, é desejável que o material seja equivalente ao tecido mole. Os dosímetros que apresentam $Z_{\text {eff }}$ diferente ao tecido biológico devem ter as doses corrigidas para a dependência energética da sua resposta (BOS, 2006).

$\mathrm{Na}$ área da dosimetria, o conhecimento sobre a resposta em função da energia da radiação, $\mathrm{S}(\mathrm{E})$, ou dependência energética do dosímetro, é uma das características que devem ser determinadas. É a medição da energia absorvida no material dosimétrico em comparação à energia absorvida em um material de referência como, por exemplo, o tecido mole ou o ar, quando irradiados com mesma dose (CHEN, McKEEVER, 1997; FURETTA, WENG, 1998; FURETTA, 2003; CHEN, PAGONIS, 2011).

A determinação teórica é dada pela Equação 2.15:

$$
\mathrm{S}(\mathrm{E})=\frac{\left(\frac{\mu_{\mathrm{en}}}{\rho}\right)_{\mathrm{TL}}}{\left(\frac{\mu_{\mathrm{en}}}{\rho}\right)_{\mathrm{ar}}}
$$

onde $\left(\frac{\mu_{\mathrm{en}}}{\rho}\right)_{\mathrm{TL}}$ e $\left(\frac{\mu_{\mathrm{en}}}{\rho}\right)_{\mathrm{ar}}$ são os coeficientes mássicos de absorção de energia para o material dosimétrico e o ar, respectivamente.

Contudo, é interessante normalizar a depedência energética em relação a alguma energia e, em alguns casos, ela é normalizada em relação ao ${ }^{60} \mathrm{Co}$. Quando normalizada recebe-se o nome de resposa relativa em energia (RER - do inglês Relative Energy Response). A RER é determinada pela Equação 2.16:

$$
R E R=\frac{S(E)}{S\left(E_{\text {referência })}\right.}
$$

onde $S\left(E_{\text {referência }}\right)$ é a dependência energética do material com a energia convencionada como referência. 
Como alguns materiais dosimétricos como, por exemplo, o BeO, são formados por uma mistura de elementos, o coeficiente mássico de absorção de energia tem que ser determinado utilizando-se a lei da mistura de elementos:

$$
\left(\frac{\mu_{\mathrm{en}}}{\rho}\right)_{\mathrm{TL}}=\sum_{\mathrm{i}}\left(\frac{\mu_{\mathrm{en}}}{\rho}\right)_{\mathrm{i}} \times \mathrm{W}_{\mathrm{i}}
$$

onde $\left(\frac{\mu_{\mathrm{en}}}{\rho}\right)_{\mathrm{i}}$ é o coeficiente mássico de absorção de energia do elemento i e $\mathrm{W}_{\mathrm{i}}$ é a fração de massa do elemento i no material (CHEN, McKEEVER, 1997; FURETTA, 2003; CHEN, PAGONIS, 2011).

\subsubsection{Limite Inferior de Deteç̧ão - LID}

Para que o dosímetro seja de fácil aplicação em dosimetria, a sua sensibilidade deve ser constante em um intervalo de dose absorvida. O limite inferior de detecção (LID), apresentado na Equação 2.18, depende de características do próprio sistema de medição TL e/ou OSL, de condições externas e das características intrínsecas do material. O LID é definido experimentalmente como:

$$
L I D=3 \times \sigma_{M_{0}} \times C_{c}
$$

onde $\sigma_{M_{0}}$ é o desvio padrão da leitura do dosímetro sem ser irradiado e $C_{c}$ é o coeficiente de calibração (CHEN, McKEEVER, 1997; FURETTA, WENG, 1998; FURETTA, 2003; FURETTA, 2008).

\subsection{Análise de Incertezas}

Todas as medições, embora cuidadosas, estão sujeitas a algumas incertezas. A capacidade de análise e avaliação dessas incertezas e de como mantê-las as menores possíveis é crucialmente importante.

As incertezas têm diversas origens; no entanto, elas podem ser agrupadas em dois tipos: as do Tipo $A$, grupo que compreende as incertezas relativas às medições 
propriamente ditas, e as do Tipo $\mathrm{B}$, que correspondem às incertezas dos instrumentos e métodos empregados (INMETRO, 20012; TAYLOR, 2012; VUOLO, 2015).

\subsubsection{Incertezas do Tipo A}

As incertezas do Tipo A, ou incertezas aleatórias, são todas aquelas relacionadas às medições, isto é, são todas as incertezas que podem ser obtidas a partir da repetição de medições, e são causadas pelas variações incontroláveis e aleatórias do processo de medição.

Para estimar esse tipo de incerteza foram utilizadas as equações referentes ao desvio padrão da média, a propagação de incertezas, a média ponderada pelas incertezas e a incerteza da média ponderada pelas incertezas (INMETRO, 2012; TAYLOR, 2012; VUOLO, 2015).

\subsubsection{Desvio Padrão da Média}

$$
\sigma_{m e ́ d i a}=\frac{\sigma}{\sqrt{n}}
$$

onde $\sigma$ é o desvio padrão amostral e n é o número de amostras (INMETRO, 2012; TAYLOR, 2012; VUOLO, 2015).

\subsubsection{Propagação de Incertezas}

Se $f=f(x, \ldots, z)$ é qualquer função de $x, \ldots, z$, então

$$
\sigma_{f}=\sqrt{\left(\frac{\partial f}{\partial x}\right)^{2} \sigma_{x}^{2}+\cdots+\left(\frac{\partial f}{\partial z}\right)^{2} \sigma_{z}^{2}}
$$

onde $\sigma_{f}$ é a incerteza de $f,\left(\frac{\partial f}{\partial x}\right)$ é a derivada parcial de $f$ em relação a $x, \sigma_{x}$ é a incerteza de $x,\left(\frac{\partial f}{\partial z}\right)$ é a derivada parcial de $f$ em relação a $z, \sigma_{z}$ é a incerteza de $z$ e assim sucessivamente para cada variável que compõe $f$ (INMETRO, 2012; TAYLOR, 2012; VUOLO, 2015). 


\subsubsection{Média e Incerteza Ponderada pelas Incertezas.}

Se $x_{1}, x_{2}, \ldots, x_{n}$ são medições de uma única grandeza $x$, com incertezas conhecidas, então o valor da média $(\bar{x})$ é dado por:

$$
\bar{x}=\frac{\sum_{i=1}^{n}\left(\frac{x_{i}}{\sigma_{x_{i}}^{2}}\right)}{\sum_{i=1}^{n}\left(\frac{1}{\sigma_{x_{i}}^{2}}\right)}
$$

A incerteza da média ponderada pelas incertezas é dada por:

$$
\sigma_{m e ́ d i a}=\frac{1}{\sqrt{\sum_{i=1}^{n}\left(\frac{1}{\sigma_{i}^{2}}\right)}}
$$

onde $x_{i}$ é o valor da medição e $\sigma_{x_{i}}$ é a incerteza da medição $x_{i}$ (INMETRO, 2012;TAYLOR, 2012; VUOLO, 2015).

\subsubsection{Incertezas do Tipo $B$}

As incertezas do Tipo B, ou incertezas sistemáticas, são todas aquelas relacionadas aos equipamentos utilizados em uma ou mais medições, a procedimentos incorretos ou mal estruturados e falhas da teoria. As incertezas dos equipamentos vêm nos manuais ou neles próprios (INMETRO, 2012; TAYLOR, 2012; VUOLO, 2015).

\subsubsection{Incerteza Combinada}

A incerteza combinada é a incerteza que considera as incertezas do Tipo A e do Tipo B (INMETRO, 2012; TAYLOR, 2012; VUOLO, 2015). Ela é dada por:

$$
\sigma=\sqrt{\sigma_{\text {Tipo A }}^{2}+\sigma_{\text {Tipo B }}^{2}}
$$




\section{MATERIAIS E MÉTODOS}

Nesta seção serão apresentados os materiais, os equipamentos e os métodos de realização da caracterização dosimétrica do material nos feixes de radiação empregados no desenvolvimento deste trabalho.

\subsection{Amostras de BeO e Suportes para as Amostras}

Foram utilizadas 48 amostras de $\mathrm{BeO}$ em formato de disco. As pastilhas estavam presas em clipes de metal com silicone para uso como dosímetro anelar. Com o auxílio de estilete, as pastilhas foram retiradas dos clipes sem sofrerem danos - Figura 3.1.

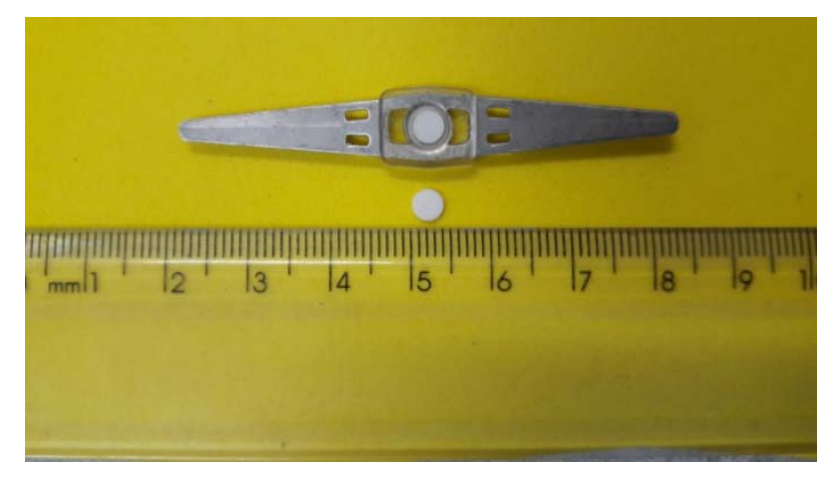

FIGURA 3.1 - Pastilha dentro e fora do clipe.

Para a determinação da massa das amostras foi utilizada a balança Mettler Toledo modelo AB204-S (Figura 3.2), que apresenta possibilidade de leitura no intervalo de $10 \mathrm{mg}$ a $220 \mathrm{~g}$ de massa.

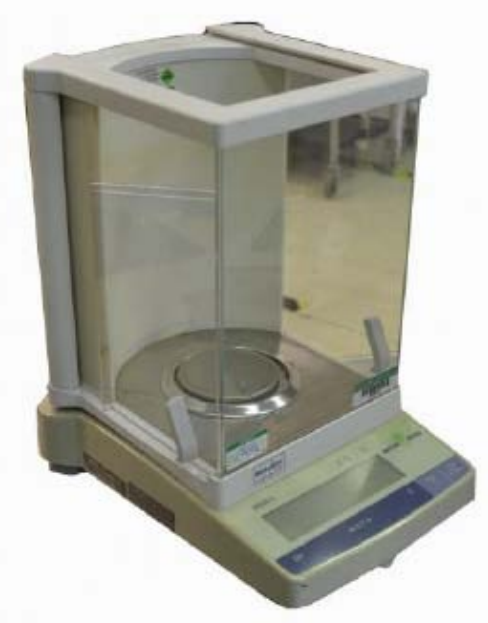

FIGURA 3.2 - Balança Mettler Toledo, modelo AB204-S. 
O suporte disponível para a irradiação e tratamento óptico é formado por duas partes: uma base e uma tampa, sendo ambas de acrílico. O suporte para o tratamento térmico é uma única placa de cobre. Tanto a base de acrílico quanto a placa de cobre possuem sulcos para deposição das pastilhas.

A placa de acrílico como base do suporte e a placa de cobre têm $(100,1 \pm 0,3) \mathrm{mm}$ de largura, $(60,2 \pm 0,3) \mathrm{mm}$ de comprimento, $(3,15 \pm 0,03) \mathrm{mm}$ de espessura, contendo 56 sulcos com $(5,33 \pm 0,07) \mathrm{mm}$ de diâmetro e $(1,5 \pm 0,4) \mathrm{mm}$ de profundidade para o depósito das pastilhas.

No LCl estão disponíveis placas de acrílico, que podem ser utilizadas como tampa, com espessuras a partir de $1 \mathrm{~mm}$, com as mesmas dimensões de largura e comprimento. Na Tabela 3.1 estão as dimensões das placas disponíveis no $\mathrm{LCl}$ e nas Figuras 3.3 e 3.4 estão os suportes de acrílico e de cobre.

TABELA 3.1 - Dimensões das placas disponíveis no LCl.

\begin{tabular}{cccc}
\hline & $\begin{array}{c}\text { Largura } \\
(\mathrm{mm})\end{array}$ & $\begin{array}{c}\text { Comprimento } \\
(\mathrm{mm})\end{array}$ & $\begin{array}{c}\text { Espessura } \\
(\mathrm{mm})\end{array}$ \\
\hline & & & $1,01 \pm 0,15$ \\
Placa de & & & $3,0 \pm 0,3$ \\
Acrílico & $100,0 \pm 0,6$ & $60,0 \pm 0,5$ & $5,03 \pm 0,21$ \\
& & & $10,0 \pm 0,4$ \\
\hline
\end{tabular}

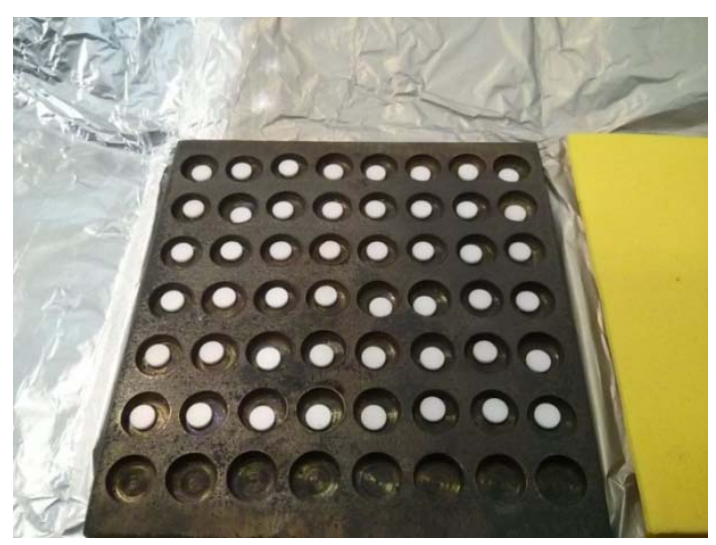

FIGURA 3.3 - Pastilhas de BeO no suporte de cobre. 


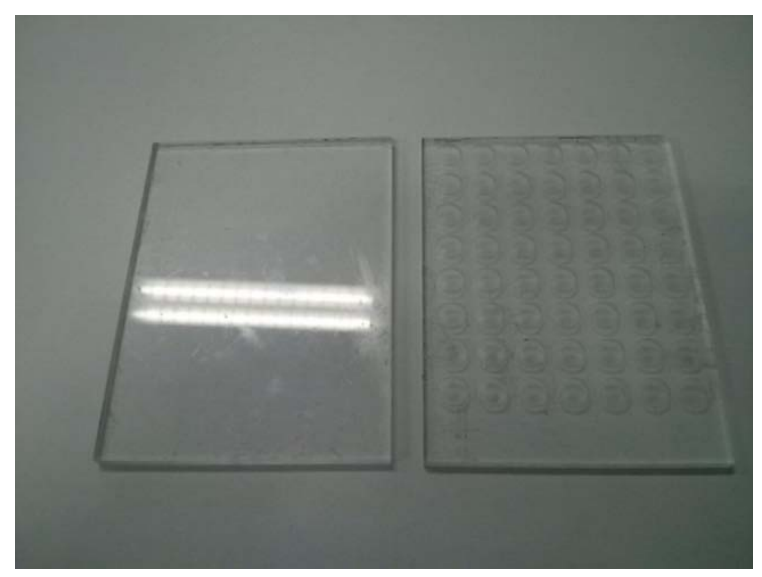

FIGURA 3.4 - Suporte de acrílico para pastilhas de BeO; à esquerda está a tampa e à direita, a base.

\subsection{Sistemas de Medição TL e OSL}

Para se avaliar o sinal termoluminescente e o sinal luminescente opticamente estimulado, foi utilizado o sistema RISÖ TL/OSL-DA20 - Figura 3.5.

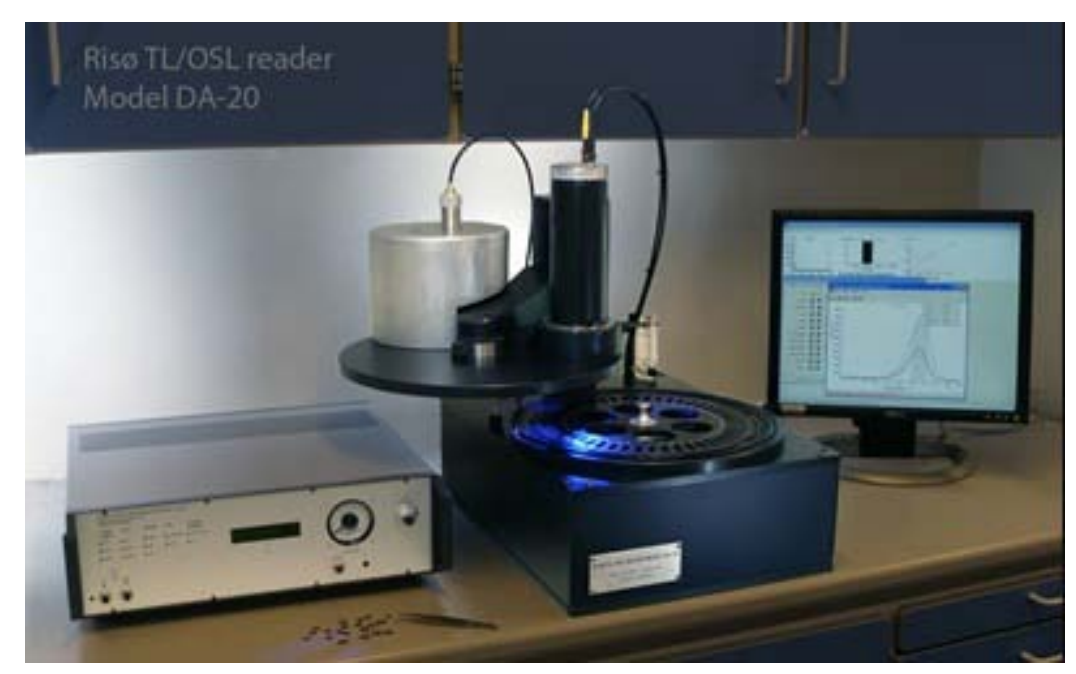

FIGURA 3.5 - Leitora RISÖ TL/OSL-DA20 (DTU NUTECH, 2016).

O suporte das amostras no sistema RISÖ TL/OSL-DA20 consiste em um carrossel com capacidade para 48 amostras, que podem ser avaliadas da maneira como o usuário necessitar - Figura 3.6. O equipamento apresenta também duas fontes radioativas, possibilitando expor as amostras à radiação alfa $\left({ }^{241} \mathrm{Am}\right)$, com taxa de dose de $45 \mathrm{mGy} / \mathrm{s}$ (Calibração em 2010), e à radiação beta $\left({ }^{90} \mathrm{Sr}+{ }^{90} \mathrm{Y}\right.$ ), com taxa de dose de $0,1 \mathrm{~Gy} / \mathrm{s}$ (Calibração em 2010) (DTU NUTECH,2016). 


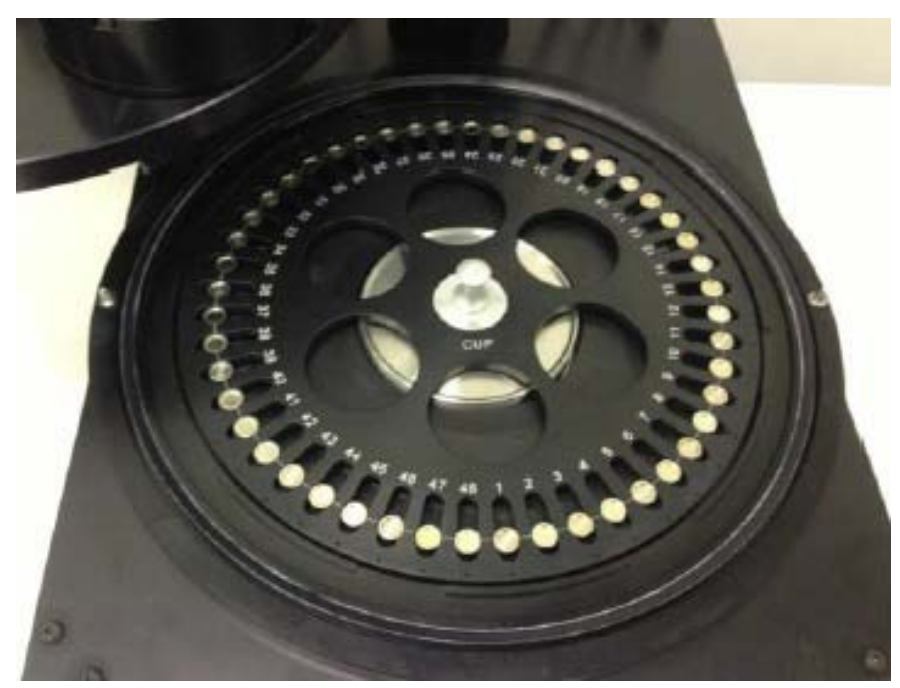

FIGURA 3.6 - Carrossel da leitora RISÖ TL/OSL-DA20 com capacidade para 48 amostras.

O sistema leitor permite realizar medições TL com taxas de aquecimento de $0,1^{\circ} \mathrm{C} / \mathrm{s}$ a $10^{\circ} \mathrm{C} / \mathrm{s}$, podendo alcançar temperatura de até $700^{\circ} \mathrm{C}$ com $0,25^{\circ} \mathrm{C}$ de incerteza (embora não seja recomendável passar de $500^{\circ} \mathrm{C}$ ).

É composto por uma fotomultiplicadora bialkali EMI9235QB com eficiência quântica de aproximadamente $30 \%$ no intervalo de detecção do comprimento de onda do fóton de 200 a $400 \mathrm{~nm}$ - Figura 3.7.

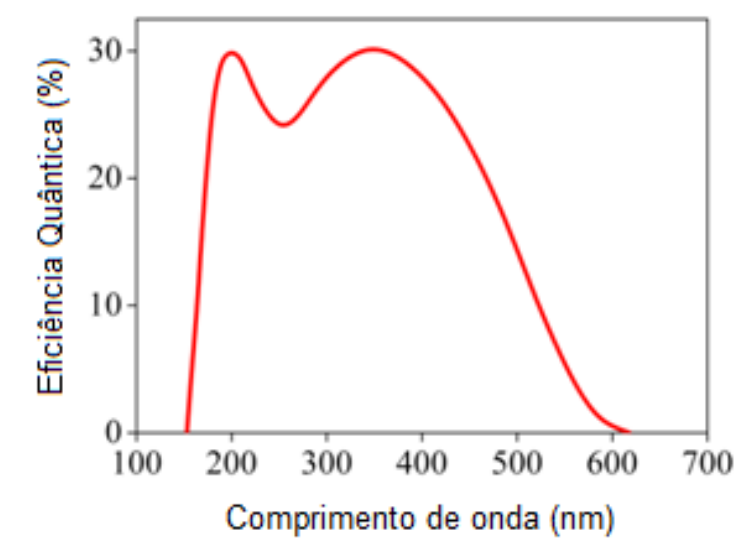

FIGURA 3.7- Eficiência quântica da fotomultiplicadora bialkali EMI9235QB como função do comprimento de onda do fóton incidente (adaptado de DTU NUTECH, 2016).

O sistema de iluminação da leitora RISÖ TL/OSL-DA20 consiste em 28 LEDs na faixa de luz azul (NICHIA tipo NSPB-500AS) com pico de emissão em (470 \pm 20 ) nm, 
gerando $80 \mathrm{~mW} / \mathrm{cm}^{2}$, e 21 LEDs na faixa do infravermelho com pico de emissão em $(870 \pm 20) \mathrm{nm}$, gerando $145 \mathrm{~mW} / \mathrm{cm}^{2}$. O sistema leitor possui um conjunto de filtros para evitar que a luz espalhada, a partir da estimulação, atinja a fotomultiplicadora evitando contagens espúrias ou a saturação da fotomultiplicadora.

Os filtros que a compõem são o Hoya U340 (2,5 mm de espessura), Schott BG39 (1 mm de espessura), Schott BG3 (1 mm de espessura) e o Corning 7-59 (4 mm de espessura). Cada filtro tem a finalidade de permitir a transmissão de um pequeno intervalo de comprimento de onda - Figura 3.8.

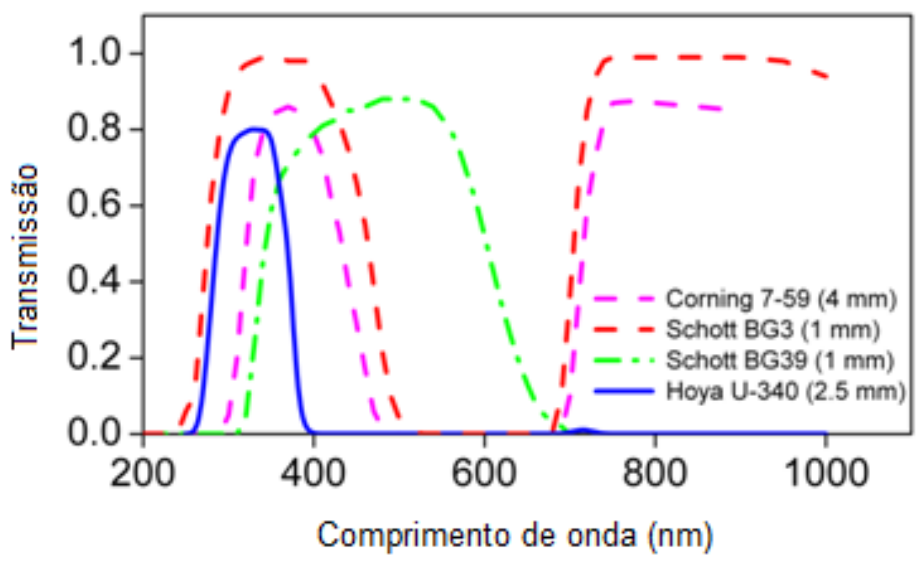

FIGURA 3.8 - Características de transmissão dos filtros utilizados na Leitora RISÖ TL/OSLDA20 (adaptado deDTU NUTECH, 2016).

Além dos filtros, o sistema RISÖ TL/OSL-DA20 contém colimadores de sinal para evitar o saturamento da fotomultiplicadora. As dimensões dos colimadores disponíveis no $\mathrm{LCl}$ estão indicadas na Tabela 3.2 .

TABELA 3.2 - Diâmetros internos dos colimadores

\begin{tabular}{cc}
$\begin{array}{c}\text { Número } \\
\text { do } \\
\text { Colimador }\end{array}$ & $\begin{array}{c}\text { Diâmetro } \\
\text { interno } \\
(\mathbf{m m})\end{array}$ \\
\hline 1 & $1,89 \pm 0,05$ \\
2 & $2,50 \pm 0,05$ \\
3 & $5,70 \pm 0,15$ \\
4 & $9,35 \pm 0,14$ \\
\hline
\end{tabular}




\subsection{Sistema de Raios $X$}

Para a caracterização do BeO foi utilizado o sistema de radiação X. Este sistema é composto por um equipamento Pantak/Seifert modelo ISOVOLT HS 160, com energias médias de $15 \mathrm{keV}$ a $150 \mathrm{keV}$, filtração inerente de 0,138 mmAl e janela de berílio de $0,8 \mathrm{~mm}$ de espessura, do Laboratório de Calibração de Instrumentos (LCI/IPEN) Figura 3.9. Este sistema contém uma roda de filtros PTW, modelo T90010/900011, com 24 posições disponíveis, com a filtração necessária para cada qualidade de diagnóstico convencional, mamografia, tomografia computadorizada, radioproteção e radioterapia.

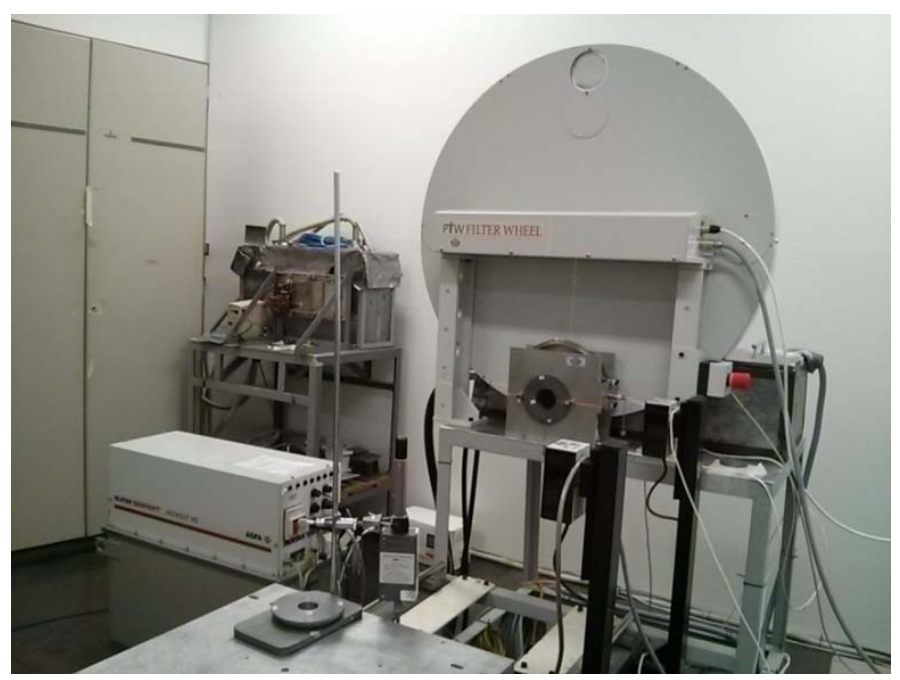

FIGURA 3.9 - Equipamento de raios X Pantak/Seifert modelo ISOVOLT HS 160.

Este equipamento contém limites operacionais (Tabela 3.3), que devem ser respeitados para garantir que a dose entregue seja a dose requerida e, também, para preservar o equipamento.

TABELA 3.3 - Limites operacionais - Pantak/Seifert modelo ISOVOLT HS 160.

\begin{tabular}{cccc}
\hline $\begin{array}{c}\text { Tensão } \\
(\mathbf{k V})\end{array}$ & $\begin{array}{c}\text { Corrente } \\
(\mathbf{m A})\end{array}$ & $\begin{array}{c}\text { Tempo máximo } \\
\text { de irradiação } \\
\text { (min) }\end{array}$ & $\begin{array}{c}\text { Tempo mínimo } \\
\text { de irradiação }\end{array}$ \\
\hline 15 a 120 & 0 a 20 & 20 & 12 \\
120 a 150 & 0 a 20 & 5 & 12 \\
\hline
\end{tabular}


Neste trabalho, as qualidades padronizadas de radiodiagnóstico convencional (feixes diretos e atenuados), mamografia e tomografia computadorizada foram utilizadas. Nas Tabelas 3.4, 3.5, 3.6 e 3.7 estão listadas as características destes feixes de radiação.

TABELA 3.4 - Características dos feixes padrões de raios $X$ de radiodiagnóstico convencional - feixes diretos.

\begin{tabular}{lcccccc}
\hline \multicolumn{7}{c}{ Radiodiagnóstico- Feixes diretos } \\
\hline Qualidade & $\begin{array}{c}\text { Energia } \\
(\mathbf{k e V})\end{array}$ & $\begin{array}{c}\text { Tensão } \\
(\mathbf{k V})\end{array}$ & $\begin{array}{c}\text { Corrente } \\
(\mathbf{m A})\end{array}$ & $\begin{array}{c}\text { CSR } \\
(\mathbf{m m A l})\end{array}$ & $\begin{array}{c}\text { Filtração } \\
(\mathbf{m m A l})\end{array}$ & $\begin{array}{c}\text { Taxa de } \\
\text { kerma no ar } \\
\text { (mGy/min) }\end{array}$ \\
\hline RQR 3 & 29,7 & 50 & 10 & 1,78 & 2,4 & 21,2 \\
RQR 5 & 34,0 & 70 & 10 & 2,58 & 2,8 & 36,6 \\
RQR 8 & 38,1 & 100 & 10 & 3,97 & 3,2 & 66,4 \\
RQR 10 & 46,5 & 150 & 10 & 6,57 & 4,2 & 115 \\
\hline
\end{tabular}

TABELA 3.5 - Características dos feixes padrões de raios $X$ de radiodiagnóstico convencional - feixes atenuados.

\section{Radiodiagnóstico - Feixes atenuados}

\begin{tabular}{lcccccc}
\hline Qualidade & $\begin{array}{c}\text { Energia } \\
(\mathbf{k e V})\end{array}$ & $\begin{array}{c}\text { Tensão } \\
(\mathbf{k V})\end{array}$ & $\begin{array}{c}\text { Corrente } \\
(\mathbf{m A})\end{array}$ & $\begin{array}{c}\text { CSR } \\
(\mathbf{m m A l})\end{array}$ & $\begin{array}{c}\text { Filtração } \\
(\mathbf{m m A l})\end{array}$ & $\begin{array}{c}\text { Taxa de kerma } \\
\text { no ar } \\
\text { (mGy/min) }\end{array}$ \\
\hline RQA 3 & 37,7 & 50 & 10 & 3,8 & 12,4 & 1,63 \\
RQA 5 & 47,6 & 70 & 10 & 6,8 & 23,8 & 1,56 \\
RQA 8 & 65,1 & 100 & 10 & 10,1 & 37,2 & 2,55 \\
RQA 10 & 83,1 & 150 & 10 & 13,3 & 49,2 & 5,65 \\
\hline
\end{tabular}


TABELA 3.6 - Características dos feixes padrões de raios $X$ de mamografia.

\begin{tabular}{lcccccc}
\hline \multicolumn{7}{c}{ Mamografia } \\
Qualidade & $\begin{array}{c}\text { Energia } \\
(\mathbf{k e V})\end{array}$ & $\begin{array}{c}\text { Tensão } \\
(\mathbf{k V})\end{array}$ & $\begin{array}{c}\text { Corrente } \\
(\mathbf{m A})\end{array}$ & $\begin{array}{c}\text { CSR } \\
(\mathbf{m m A l})\end{array}$ & $\begin{array}{c}\text { Filtração } \\
(\mathbf{m m})\end{array}$ & $\begin{array}{c}\text { Taxa de } \\
\text { kerma no ar } \\
(\mathbf{m G y} / \mathbf{m i n})\end{array}$ \\
\hline RQR-2M & 15,7 & 28 & 10 & 0,37 & $0,07 \mathrm{Mo}$ & 11,2 \\
RQR-4M & 16,25 & 35 & 10 & 0,41 & $0,07 \mathrm{Mo}$ & 19,7 \\
RQA-2M & 18,6 & 28 & 10 & 0,61 & $0,07 \mathrm{Mo}+2,0 \mathrm{Al}$ & 0,69 \\
RQA-4M & 21,6 & 35 & 10 & 0,93 & $0,07 \mathrm{Mo}+2,0 \mathrm{Al}$ & 1,55 \\
\hline
\end{tabular}

TABELA 3.7 - Características dos feixes padrões de raios $X$ de tomografia computadorizada.

\section{Tomografia computadorizada}

\begin{tabular}{lcccccc}
\hline Qualidade & $\begin{array}{c}\text { Energia } \\
(\mathbf{k e V})\end{array}$ & $\begin{array}{c}\text { Tensão } \\
\mathbf{( k V )}\end{array}$ & $\begin{array}{c}\text { Corrente } \\
(\mathbf{m A})\end{array}$ & $\begin{array}{c}\text { CSR } \\
(\mathbf{m m A l})\end{array}$ & $\begin{array}{c}\text { Filtração } \\
(\mathbf{m m})\end{array}$ & $\begin{array}{c}\text { Taxa de kerma } \\
\text { no ar } \\
(\mathbf{m G y} / \mathbf{m i n})\end{array}$ \\
\hline RQT 8 & 48,0 & 100 & 10 & 6,9 & $3,2 \mathrm{Al}+0,3 \mathrm{Cu}$ & 22 \\
RQT 9 & 55,6 & 120 & 10 & 8,4 & $3,5 \mathrm{Al}+0,35 \mathrm{Cu}$ & 34 \\
RQT 10 & 65,1 & 150 & 10 & 10,1 & $4,2 \mathrm{Al}+0,35 \mathrm{Cu}$ & 57 \\
\hline
\end{tabular}

\subsection{Reutilização das Amostras}

Nesta parte estão apresentados os dois sistemas empregados neste trabalho na reutilização das amostras de $\mathrm{BeO}$.

\subsubsection{Sistema de Tratamento Térmico}

Para a reutilização do material dosimétrico, ele foi submetido a um tratamento térmico, no forno tipo mufla, com aquecimento por micro-ondas, da Provecto Analítica modelo MFLO1000, com taxa de aquecimento de $0,95^{\circ} \mathrm{C} / \mathrm{s}$, que permite temperatura máxima de $1.000^{\circ} \mathrm{C}$ e precisão de $\pm 3^{\circ} \mathrm{C}$ - Figura 3.10 (PROVECTO ANALITICA, 2016). Este sistema de tratamento foi utilizado sempre que se realizou uma leitura TL. 


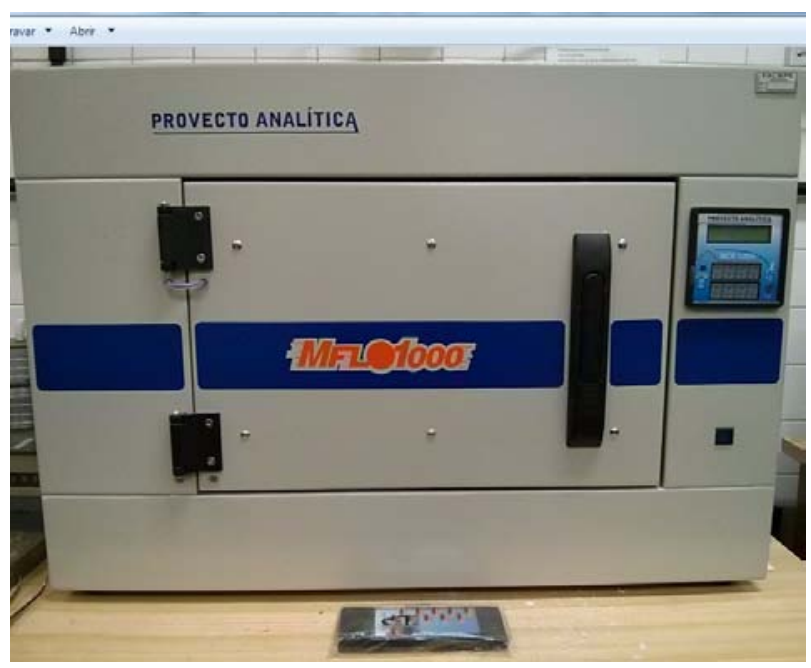

FIGURA 3.10 - Forno tipo Mufla modelo MFLO1000 da Provecto Analítica.

\subsubsection{Sistema de Tratamento Óptico}

Para a reutilização do material dosimétrico, ele foi submetido a um tratamento óptico e foi empregada uma lâmpada de diodo emissor de luz (LED) azul da marca Ourolux ${ }^{\circledast}$, de 1,3 watts de potência (composta por 30 LEDs) e $30^{\circ}$ de abertura do feixe. Este sistema foi elaborado para este trabalho - Figura 3.11. Este sistema de tratamento foi utilizado sempre que se realizou uma leitura OSL.

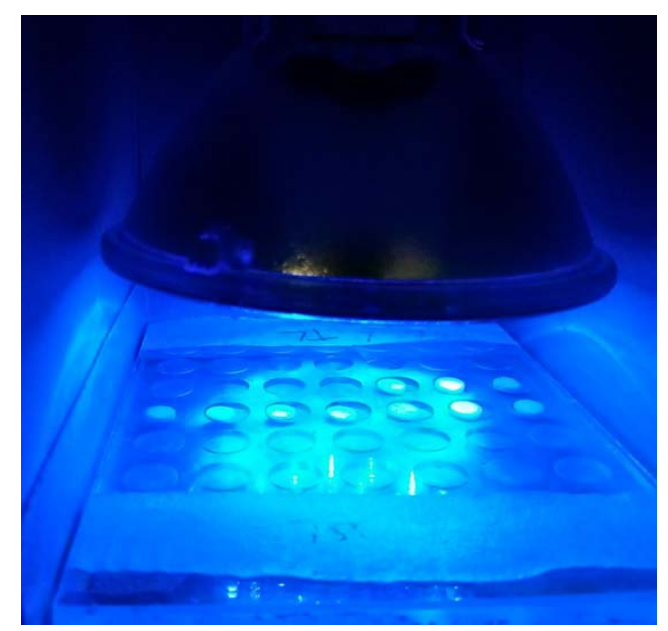

FIGURA 3.11 - Lâmpada de diodo emissor de luz (LED) azul da marca Ourolux ${ }^{\circledR}$.

\subsection{Câmaras de Ionização e Eletrômetro}

Para o estudo da viabilidade do suporte das pastilhas, foram utilizadas câmaras de ionização padrão e um eletrômetro do Laboratório de Calibração e Instrumentação do IPEN (LCI/IPEN). 
Câmara de ionização padrão nas qualidades de radiodiagnóstico convencional: Radcal RC6 - Série: 16675 - Calibrada no PTB, Incerteza de 0,77\%;

Câmara de ionização padrão nas qualidades de mamografia: Radcal RC6M Série: 9231 - Calibrada no PTB, Incerteza de 0,96\%;

Câmara de ionização padrão nas qualidades de tomografia computadorizada: Radcal RC3T - Série: 8769 - Calibrada no PTB, Incerteza de 1,5\%;

Eletrômetro Keithley 6517a - Nº de série: 0989665.

\subsection{Preparação para Uso dos Dosímetros}

Antecedendo a utilização dos dosímetros no estudo, eles foram irradiados com $1 \mathrm{~Gy}$ da fonte de ${ }^{90} \mathrm{Sr}+{ }^{90} \mathrm{Y}$ da leitora RISÖ TL/OSL-DA20 e tratados termicamente por 15 minutos à temperatura de $750^{\circ} \mathrm{C}$, para estabilizar as armadilhas (FURETTA, WENG, 1998).

\subsection{Modo de Leitura TL e OSL}

Em todas as medições $T L$, a taxa de aquecimento utilizada foi de $5^{\circ} \mathrm{C} / \mathrm{s}$, variando a temperatura de $0^{\circ} \mathrm{C}$ até $450^{\circ} \mathrm{C}$. Para as medições $\mathrm{OSL}$, o modo de leitura foi o CW-OSL com tempo de contagem de 100 segundos (GROPPO, 2013).

Para todas as medições TL e OSL foi considerada como resposta a área sob as curvas de emissão TL e de decaimento OSL.

Para todos os cáculos realizados neste trabalho, a resposta, TL ou OSL, $M$, foi considerada como a resposta líquida de cada amostra, isto é, foi feita a subtração da resposta TL ou OSL a resposta da contagem de fundo de cada amostra (resposta TL ou OSL da amostra não irradiada), resultando em uma resposta líquida TL ou OSL: Equação 3.1.

$$
M_{\text {Líquido }}=M_{\text {Bruto }}-M_{\text {Contagem de fundo }}
$$

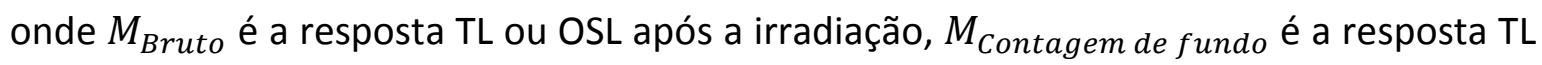
ou OSL após o tratamento térmico (caso de leitura TL) ou óptico (no caso de leitura OSL) (FURETTA, WENG, 1998; FURETTA, 2003). 
Em todos os estudos, tanto com TL quanto com OSL, foi utilizado o filtro Hoya U-340 para discriminar os fótons emitidos pelos LEDs e aqueles provenientes da amostra.

\subsection{Métodos para Determinação da Energia de Ativação e do Fator de Frequência.}

Existem alguns métodos de cálculo da energia de ativação, dentre eles encontram-seos métodos de formato de pico de Chen, Lushchik, Grosswiener, Halperin e Braner, o método da área sob a curva e o método de Urbach. Para o fator de frequência existe o método de Chen (BACCl et al, 1989; CHEN, McKEEVER, 1997; FURETTA, 2003).

Estes métodos foram aplicados considerando os modelos de cinética de primeira e segunda ordem e de ordem geral, tendo como base as Equações (2.7), (2.8) e (2.9).

\subsubsection{Método de Urbach}

Este método pode ser utilizado como primeira aproximação do valor da energia de ativação. Urbach determinou empiricamente sua equação ao estudar o $\mathrm{KCl}$ e para isto fixou o valor de frequência como $10^{9} \mathrm{~s}^{-1}$. A equação deste método é: (FURETTA, 2003; CHEN, PAGONIS, 2011).

$$
E=T_{M} / 500
$$

onde $T_{M}$ é a temperatura do pico.

\subsubsection{Métodos de Formato de Pico.}

Os métodos que se enquadram nesta terminologia utilizam poucos pontos da curva de emissão TL para determinar os parâmetros cinéticos. Estes pontos são a temperatura de máxima $\left(T_{M}\right)$ intensidade do pico $\left(I_{M}\right)$ e as temperaturas correspondentes à metade da intensidade do pico $\left(\frac{I_{M}}{2}\right), T_{1}$ para a temperatura menor que $T_{M}$ e $T_{2}$ para temperatura maior que $T_{M}$ (FURETTA, 2003; CHEN, PAGONIS, 2011). Um esquema está ilustrado na Figura 3.12. 


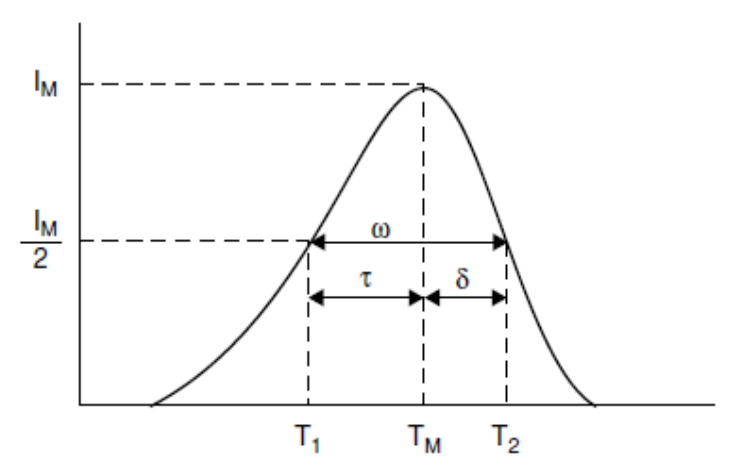

FIGURA 3.12 - Parâmetros utilizados nos métodos de formato de pico (CHEN, PAGONIS, 2011).

Com as temperaturas é possível obter outros parâmetros que facilitam os cálculos:

$$
\omega=T_{2}-T_{1} \quad \tau=T_{M}-T_{1} \quad \delta=T_{2}-T_{M} \quad \mu=\frac{\delta}{\omega}
$$

\subsubsection{Método de Chen}

Este método considera que a ordem cinética b do pico TL pode variar, isto é, as equações que descrevem o comportamento de emissão TL são de ordem geral, e que a ordem cinética está relacionada com o fator geométrico (fator de simetria) $\mu$ - Figura 3.13. 


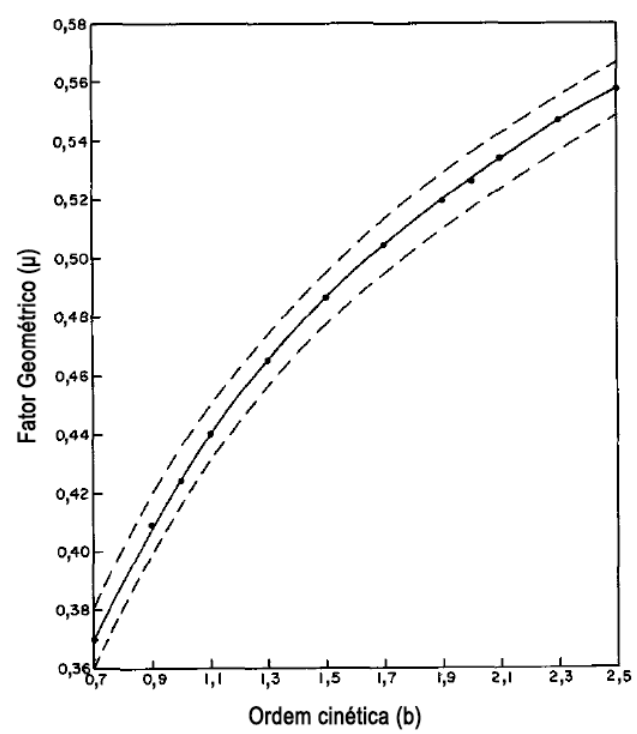

FIGURA 3.13 - Gráfico do fator geométrico versus ordem cinética. (Adaptado de

CHEN, 1969)

Com estas suposições e com os parâmetros de formato de pico as equações que determinam a energia de ativação e o fator de frequência são (FURETTA, 2003; CHEN, PAGONIS, 2011):

$$
\begin{gathered}
E_{\tau}=\left\{[1,51+3 \times(\mu-0,42)] \times \frac{k T_{M}^{2}}{\tau}\right\}-\left\{[1,58+4,2 \times(\mu-0,42)] \times 2 k T_{M}\right\} \\
E_{\delta}=[0,976+7,3 \times(\mu-0,42)] \times \frac{k T_{M}^{2}}{\delta} \\
E_{\omega}=\left\{[2,55+10,2 \times(\mu-0,42)] \times \frac{k T_{M}^{2}}{\omega}\right\}-2 k T_{M} \\
S=\frac{\beta E}{k T_{M}^{2}} \times\left[e^{\left(-\frac{E}{k T_{M}}\right)} \times\left(1+(b-1) \times \frac{2 k T_{M}}{E}\right)\right]^{-1}
\end{gathered}
$$

onde $E_{\tau}, E_{\delta}$ e $E_{\omega}$ são as energias de ativação em keV utilizando os parâmetros do formato de pico e $s$ é o fator de frequência em $\mathrm{s}^{-1}$. Os demais parâmetros foram definidos anteriormente. 


\subsubsection{Método de Grosswiner}

Este método foi deduzido a partir de uma série assintótica, para ordem cinética de primeira e segunda ordem, e considerou somente os parâmetros $T_{M}, T_{1}$ e $\tau$ (FURETTA, 2003; CHEN, PAGONIS, 2011).

$$
E_{\tau}=\frac{\alpha k T_{1} T_{M}}{\tau}
$$

onde $\alpha$ tem valores de 1,41 e 1,68 para ordem cinética de primeira e segunda ordem, respectivamente.

\subsubsection{Método de Lushchik}

Este método considera que a área do pico em declive é igual à área de um triângulo que tem a mesma altura e largura à meia altura, que a ordem cinética é de somente de primeira ou de segunda ordem e utilizou o parâmetro $\delta$. As equações para determinar a energia de ativação para ordem cinética de primeira e segunda ordem, respectivamente, são (FURETTA, 2003; CHEN, PAGONIS, 2011):

$$
\begin{gathered}
E_{\delta}=0,976 \times \frac{k T_{M}^{2}}{\delta} \\
E_{\delta}=1,706 \times \frac{k T_{M}^{2}}{\delta}
\end{gathered}
$$

\subsubsection{Método de Halperin e Braner}

Este método utiliza os valores de $T_{M}$ e $T_{1}$ para obter as equações para primeira e segunda ordem cinéticas, respectivamente (FURETTA, 2003; CHEN, PAGONIS, 2011).

$$
\begin{aligned}
& E_{\tau}=1,52 \frac{k T_{M}^{2}}{\tau}-3,16 k T_{M} \\
& E_{\tau}=1,813 \frac{k T_{M}^{2}}{\tau}-4 k T_{M}
\end{aligned}
$$




\subsubsection{Método Adicional de Chen}

Este método Chen utiliza a meia altura total do pico e somente para as ordens cinéticas de primeira e segunda ordem. Para diferenciar do método anterior de Chen que também utiliza o parâmetro $\omega$ será denotado como $\omega^{\prime}$, mas ambos têm o mesmo valor (FURETTA, 2003; CHEN, PAGONIS, 2011).

$$
\begin{gathered}
E_{\omega \prime}=\frac{2,29 k T_{M}}{\omega} \\
E_{\omega \prime}=2 k T_{M} \times\left(1,756 \times \frac{T_{M}}{\omega}-1\right)
\end{gathered}
$$

\subsubsection{Método da Medida da Área}

Este método considera a área sob o pico de emissão TL. Ao definir os limites de integração como T e $T_{f}$, onde T é variável e $T_{f}$ é fixo e corresponde ao fim da cauda, o valor da área é obtido. As equações resultantes para os casos de primeira e segunda ordem cinéticas, respectivamente, são (FURETTA, 2003; CHEN, PAGONIS, 2011):

$$
\begin{aligned}
& \ln \left[\frac{I}{\int_{T}^{T} f(d T}\right]=\ln \left(\frac{s}{\beta}\right)-\frac{E}{k T} \\
& \ln \left[\frac{I}{\int_{T}^{T_{f} I d T}{ }^{b}}\right]=\ln \left(\frac{s^{\prime}}{\beta}\right)-\frac{E}{k T}
\end{aligned}
$$

onde $\ln \left[\frac{I}{\int_{T}^{T} f d T}\right]$ e $\ln \left[\frac{I}{\int_{T}^{T} I^{n} I d T}\right]$ são funções lineares de $\frac{1}{k T}$, com coeficiente angular igual a - $E$; o ponto de interceptação do eixo é igual a $\ln \left(\frac{s}{\beta}\right)$ para o caso de primeira ordem e a $\ln \left(\frac{s^{\prime}}{\beta}\right)$ para o caso de segunda ordem: $\beta$ é a taxa de aquecimento,

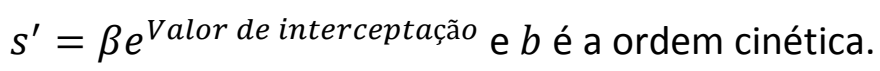




\subsection{Método de Monte Carlo}

O método de Monte Carlo é um método estatístico que emprega números aleatórios para encontrar soluções de problemas matemáticos ou físicos, cuja solução por métodos diretos é muito difícil ou impossível de se obter. Assim, qualquer cálculo de Monte Carlo é iniciado com a criação de um modelo que represente o problema de interesse, que neste caso, é o transporte de radiação.

A partir de então, simulam-se as interações da radiação com este modelo por meio de amostragens aleatórias das densidades de distribuições de probabilidade conhecidas e que caracterizam o transporte de radiação. Esse processo é repetido inúmeras vezes e o resultado é obtido mediante cálculos estatísticos (média, desvio padrão, etc.) sobre um determinado número de amostras que podem chegar a bilhões. Esses resultados são valores médios que estão relacionados com o fluxo de partículas, deposição de energia da radiação ou dose (X-5 MONTE CARLO TEAM, 2003; YORIYAZ, 2009).

Existem diversos softwares que realizam simulações com o método de Monte Carlo, dentre eles está o MCNP5 (adotado neste trabalho). Para utilizar este software é necessário definir a geometria do experimento, os materiais que compõem todos os integrantes da geometria, a fonte de radiação e a grandeza física que se quer determinar dentre as disponíveis pelo MCNP5 (X-5 MONTE CARLO TEAM, 2003; YORIYAZ, 2009).

\subsection{Deconvolução}

A deconvolução consiste em um método matemático (um algoritmo) que cria uma curva utilizando alguns parâmetros determinados teoricamente e/ou experimentalmente.

Na dosimetria, a deconvolução é utilizada para comprovar se os parâmetros cinéticos e a ordem cinética obtidos por diferentes métodos estão condizentes entre si ou com o observado experimentalmente e para distinguir picos TL quando estes estão sobrepostos, impossibilitando a distinção clara entre os picos TL.

O método utilizado neste trabalho foi desenvolvido por Kitis (PAGONIS et al, 2006) e é dividido em duas Equações conforme a ordem cinética.

Para o caso de primeira ordem: 


$$
I(T)=I_{m} \exp \left[1+\Delta-\frac{T^{2}}{T_{M}^{2}}\left(1-\frac{2 k T_{M}}{E}\right) \exp (\Delta)-\frac{2 k T_{M}}{E}\right]
$$

Para o caso de segunda ordem ou ordem geral:

$$
I(T)=I_{m} b^{\left(\frac{b}{b-1}\right)} \exp (\Delta)\left\{Z_{M}+(b-1)\left(1-\frac{2 k T}{E}\right)\left[\frac{T^{2}}{T_{M}^{2}} \exp (\Delta)\right]\right\}^{\left(-\frac{b}{b-1}\right)}
$$

Com:

$$
\begin{array}{r}
Z_{M}=1+\frac{(b-1) 2 k T_{M}}{E} \\
\Delta=\frac{E\left(T-T_{M}\right)}{k T T_{M}}
\end{array}
$$

onde $I_{m}$ é a intensidade máxima do pico TL obtido experimentalmente, $k$ é a constante de Boltzmann em $\frac{e V}{K}, T$ é a temperatua em $\mathrm{K}, T_{M}$ é a temperatura na intensidade máxima do pico em K, $E$ é a energia de ativação em eV e $b$ é a ordem cinética do pico para todas as equações acima (PAGONIS et al, 2006).

O método de Kitis deve ser realizado pico a pico, isto é, a deconvolução com este método cria somente uma curva.

\subsection{Análise de Incertezas}

Todas as incertezas expressas neste trabalho já são as incertezas combinadas obtidas com as Equações. (2.19), (2.20), (2.21), (2.22) e (2.23). Considerando as incertezas do Tipo $B$ indicadas abaixo:

- Incerteza da Balança: $\pm 0,1 \%$;

- Inceteza da Leitora RISÖ TL/OSL-DA20 para medições TL: \pm 0,05\%;

- Inceteza da Leitora RISÖ TL/OSL-DA20 para medições OSL: $\pm 0,014 \%$;

- Incerteza na temperatura do Tratamento Térmico: $\pm 0,04 \%$;

- Incerteza na intensidade luminosa do Tratamento Óptico: $\pm 0,04 \%$ 
- Incerteza da taxa de kerma no ar para as qualidades de Radiodiagnóstico Convencional - Feixes diretos e atenuados: $\pm 0,77 \%$;

- Incerteza da taxa de kerma no ar para as qualidades de Mamografia: $\pm 0,96 \%$;

- Incerteza da taxa de kerma no ar para as qualidades de Tomografia Computadorizada: $\pm 1,5 \%$;

- Incerteza do Paquímetro: $\pm 0,1 \%$;

- Incerteza do Cronômetro Digital: $\pm 1 \%$. 


\section{RESULTADOS}

\subsection{Características das Amostras de BeO}

A primeira avaliação das amostras de $\mathrm{BeO}$ foi em relação à medição da massa, da espessura e do diâmetro, porque a variação destas características entre as amostras não deve ser grande, já que uma amostra com mais massa ou maior espessura ou diâmetro tem uma resposta dosimétrica diferente de uma amostra com menor massa ou menor espessura ou diâmetro.

Todas as 48 amostras de $\mathrm{BeO}$ tiveram suas massas e as dimensões medidas com o auxílio de uma balança e de um paquímetro. As amostras têm $(4,004 \pm 0,003) \mathrm{mm}$ de diâmetro, $(0,771 \pm 0,003) \mathrm{mm}$ de espessura e $(27,184 \pm 0,015) \mathrm{mg}$ de massa.

\subsection{Definição da Situação da Lâmpada do Laboratório de Raios $X$ (Acesa ou Apagada)}

Em consequência à sua alta sensibilidade à luz ambiente, é preciso identificar qual deverá ser a situação da lâmpada do laboratório de raios $\mathrm{X}$, acesa ou apagada, para termenor influência nos sinais TL e OSL do BeO durante a irradiação. Determinar esta situação foi imprescindível para realizar qualquer outro estudo posterior.

As amostras de BeO foram irradiadas 3 vezes com 36,6 mGy na qualidade RQR 5 nas duas situações possíveis da lâmpada (acesa e apagada). Esta dose e esta qualidade foram escolhidas arbitrariamente.

Os resultados, para as respostas TL e OSL, estão indicados na Tabela 4.1.

TABELA 4.1 - Respostas TL e OSL nas situações da Lâmpada (Acesa e Apagada).

\begin{tabular}{lcc}
\hline \multicolumn{1}{c}{$\begin{array}{c}\text { Situação } \\
\text { da Lâmpada }\end{array}$} & TL & OSL \\
(Contagens) & (Contagens) \\
\hline Acesa & $(7,34 \pm 0,13) \times 10^{4}$ & $(5,1 \pm 0,3) \times 10^{5}$ \\
Apagada & $(19,5 \pm 0,8) \times 10^{4}$ & $(15,1 \pm 0,7) \times 10^{5}$ \\
\hline
\end{tabular}

Como se pode observar na Tabela 4.1, as respostas TL e OSL, quando a lâmpada do laboratório de raios $X$ está apagada, são maiores por um fator 10 em relação à situação onde a lâmpada está acesa durante a irradiação. Por este motivo, todas as irradiações ao longo do trabalho foram realizadas com a luz apagada. 


\subsection{Caracterização dos Colimadores da Leitora TL/OSL}

Devido à alta sensibilidade $\mathrm{TL}$ e, principalmente, à OSL já conhecida do $\mathrm{BeO}$, é necessária, para algumas qualidades de radiação, a utilização de colimadores de sinal, a fim de proteger o tubo fotomultiplicador da leitora TL/OSL de atingir a saturação, e possibilitar aindaum intervalo de dosimetria mais amplo.

Os fatores de correção para os colimadores (Tabela 3.1) foram determinadas de acordo com a Equação 4.1:

$$
f_{c o l}=\frac{\bar{M}_{0}}{\bar{M}_{c o l}}
$$

onde $\overline{\mathrm{M}}_{0}$ é a resposta média das amostras sem o uso de colimador, e $\overline{\mathrm{M}}_{\text {col }}$ é a resposta média das amostras com o uso de colimador.

A determinação da dose foi a partir da observação da formação da curva de emissão TL e de decaimento OSL sem a utilização de colimadores, tomando sempre o cuidado de não atingir a saturação da fotomultiplicadora. Foi estabelecida a dose de 73,2 mGy na qualidade RQR 5 para este estudo.

Ao longo do desenvolvimento deste estudo observou-se que os colimadores 3 e 4 geram uma grande diminuição na resposta TL e OSL (Figura 4.1). Como os colimadores 1 e 2 têm uma abertura menor que os colimadores 3 e 4, a redução da quantidade de fótons que chegam à fotomultiplicadora será maior e as respostas TL e OSL não serão perceptíveis e não podem ser distinguidos do sinal de fundo. Para que fosse possível determinar todos os fatores de correção para todos os colimadores, seria necessária uma irradiação com uma dose maior; no entanto, observando a Figura 4.1, uma dose maior saturaria a fotomultiplicadora ao se realizar uma leitura sem utilização de colimadores, impossibilitando qualquer medição. Portanto, não foram determinados os fatores de correção para os colimadores 1 e 2. 
(a)

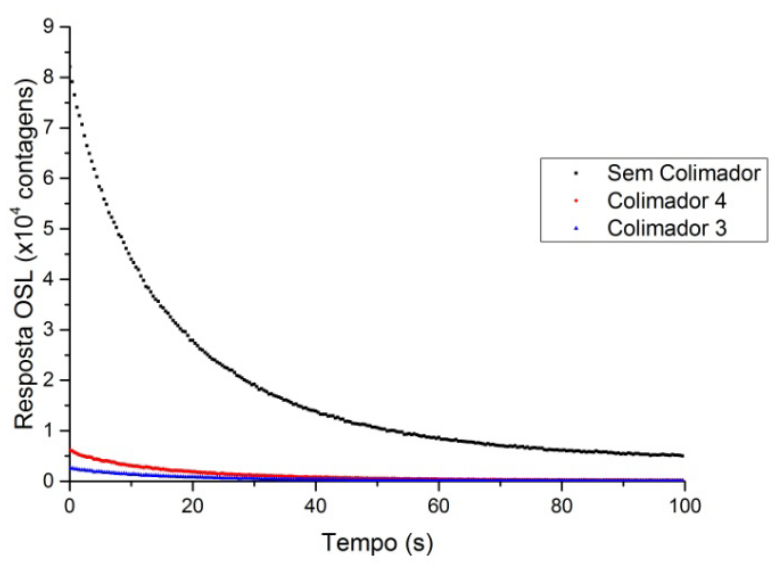

(b)

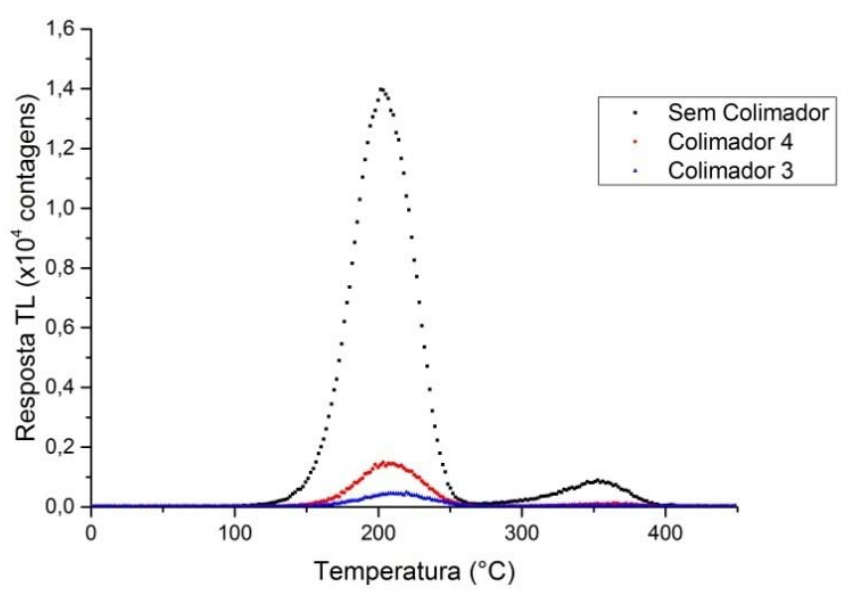

FIGURA 4.1 - (a) Curvas de decaimento OSL sem colimador e com os colimadores 3 e 4 e (b) curvas de emissão TL sem colimador e com os colimadores 3 e 4.

Na Tabela 4.2 estão apresentados os fatores de correção obtidos para os colimadores 3 e 4 .

TABELA 4.2 - Fatores de correção obtidos para cada um dos colimadores de sinal.

\begin{tabular}{ccc|cc}
\hline \multirow{2}{*}{ Colimador } & \multicolumn{2}{c|}{ TL } & \multicolumn{2}{c}{ OSL } \\
\cline { 2 - 5 } & Leitura (contagens) & $f_{\text {col }}$ & Leitura (contagens) & $f_{\text {col }}$ \\
\hline Sem & $(4,17 \pm 0,09) \times 10^{5}$ & 1 & $(3,13 \pm 0,21) \times 10^{6}$ & 1 \\
colimador & & & & \\
Colimador 3 & $(1,46 \pm 0,03) \times 10^{4}$ & $28,5 \pm 0,9$ & $(1,03 \pm 0,06) \times 10^{5}$ & $30,4 \pm 0,9$ \\
Colimador 4 & $(4,16 \pm 0,16) \times 10^{4}$ & $10,0 \pm 0,4$ & $(2,91 \pm 0,13) \times 10^{5}$ & $10,7 \pm 0,9$ \\
\hline
\end{tabular}


Portanto, para o desenvolvimento do restante deste trabalho, exceto o estudo do tratamento térmico, somente os colimadores 3 e 4 foram utilizados para algumas qualidades de radiação testadas. Na Tabela 4.3 são apresentadas as qualidades e seus respectivos colimadores.

TABELA 4.3 - Qualidades de radiação testadas com a indicação de uso de colimadores.

\begin{tabular}{lc|lc}
\hline Qualidade & Colimador & Qualidade & Colimador \\
\hline RQR 3 & 4 & RQA 3 & Não \\
RQR 5 & 4 & RQA 5 & Não \\
RQR 8 & 3 & RQA 8 & Não \\
RQR 10 & 3 & RQA 10 & Não \\
\hline RQR-2M & 4 & RQT 8 & 4 \\
RQR-4M & 4 & RQT 9 & 4 \\
RQA-2M & Não & RQT 10 & 4 \\
RQA-4M & Não & & \\
\hline
\end{tabular}

\subsection{Tratamento Térmico}

No estudo para determinar o tratamento térmico ideal para as pastilhas de $\mathrm{BeO}$, elas foram irradiadas com uma dose de $1 \mathrm{~Gy}$ com a fonte beta de ${ }^{90} \mathrm{Sr}+{ }^{90} \mathrm{Y}$ da própria leitora RISÖ e a temperatura e o tempo de aquecimento foram determinados de acordo com os trabalhos de Furetta e Groppo que apresentaram um mesmo tempo de aquecimento de $15 \mathrm{~min}$, mas com temperaturas diferentes. No trabalho de Groppo, as pastilhas foram aquecidas a $750^{\circ} \mathrm{C}$ e no trabalho de Furetta, foi apresentada uma temperatura de $400^{\circ}$ ou $600^{\circ}$ (FURETTA, WENG, 1998; GROPPO, 2013).

Neste trabalho iniciou-se o estudo com $400^{\circ} \mathrm{C}$, aumentando-se a temperatura para $500^{\circ} \mathrm{C}, 600^{\circ} \mathrm{C}$ e $750^{\circ} \mathrm{C}$ e mantendo-se o tempo em $15 \mathrm{~min}$. Também foi realizado o estudo mantendo-se a temperatura em $400^{\circ} \mathrm{C}$, porém com um tempo de 30 min de aquecimento. Foi realizada a leitura das pastilhas subtraindo-se a leitura de fundo e calculando-se a média. Determinou-se que o tratamento térmico ideal para estas pastilhas é o aquecimento a $500^{\circ} \mathrm{C}$ por $15 \mathrm{~min}$, porque não se obteve uma variação significativa nos valores das médias, conforme apresentado na Figura 4.2. 


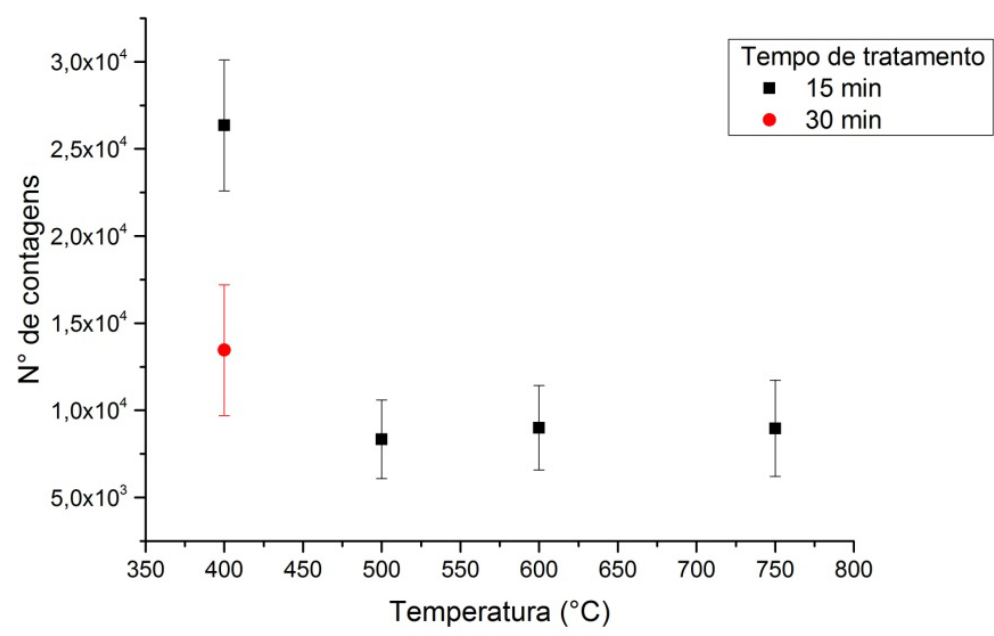

FIGURA 4.2 - Média das respostas TL das amostras de BeO após tratamento térmico.

\subsection{Influência da Tampa do Suporte de Acrílico.}

A radiação sofre atenuação com qualquer material, sendo que alguns atenuam mais que outros. No caso do acrílico, material do suporte das pastilhas, a sua atenuação pode influenciar as medições das emissões TL e OSL do BeO. Além do suporte em acrílico, foi considerado como opção o uso de um suporte de filme de PVC. Estes materiais foram escolhidos, pois são os disponíveis no $\mathrm{LCl}$ e estão disponíveis com espessuras a partir de $1 \mathrm{~mm}$ para a placa de acrílico e de 0,3 $\mathrm{mm}$ para o filme de PVC.

O cálculo desta atenuação foi realizado com a Equação 4.2:

$$
\mathrm{I}=\mathrm{I}_{0} \cdot \mathrm{e}^{(-\mu \mathrm{x})}
$$

onde I é a intensidade do feixe após atravessar um material com espessura $x, \mu$ é o coeficiente de atenuação linear do material para uma dada energia de radiação e $\mathrm{I}_{0}$ é a intensidade inicial do feixe.

Para o cálculo da atenuação, a energia considerada foi a energia efetiva de cada qualidade de radiação, indicada nas Tabelas 3.4, 3.5, 3.6 e 3.7 e os coeficientes de atenuação linear do $\mathrm{BeO}$ e as densidades da acrílico e do filme de PVC foram obtidos no site do NIST (2016). O resultado do cálculo tanto para o acrílico quanto para o filme de PVC, para todas as qualidades estudadas, está indicado na Figura 4.3. 
a)

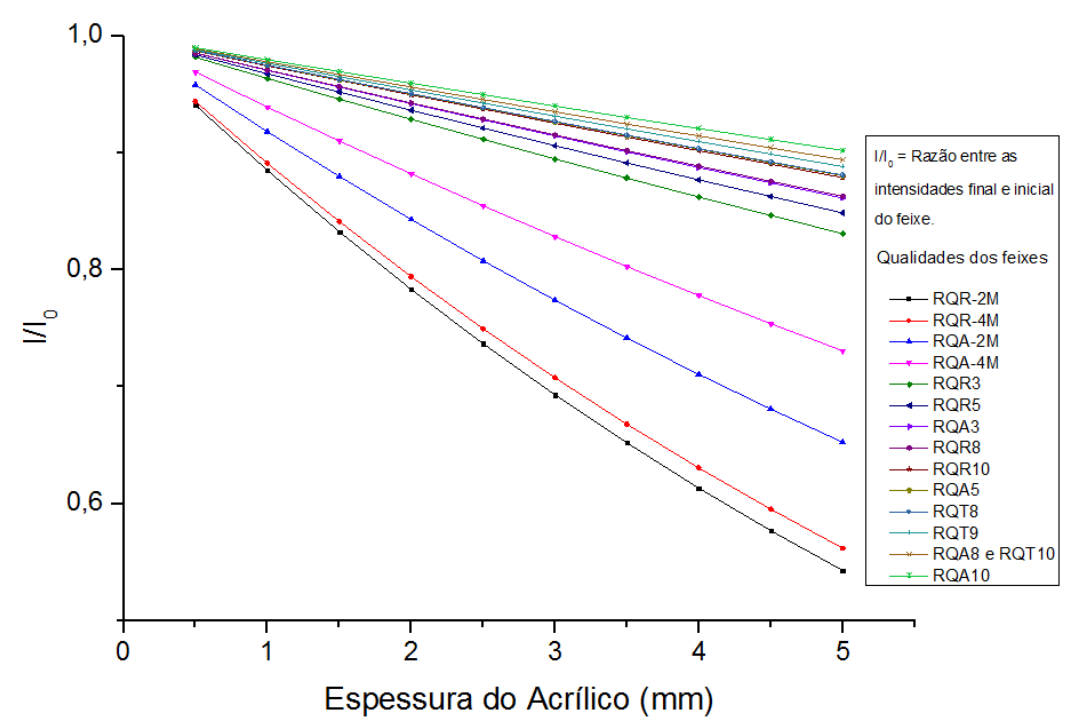

b)

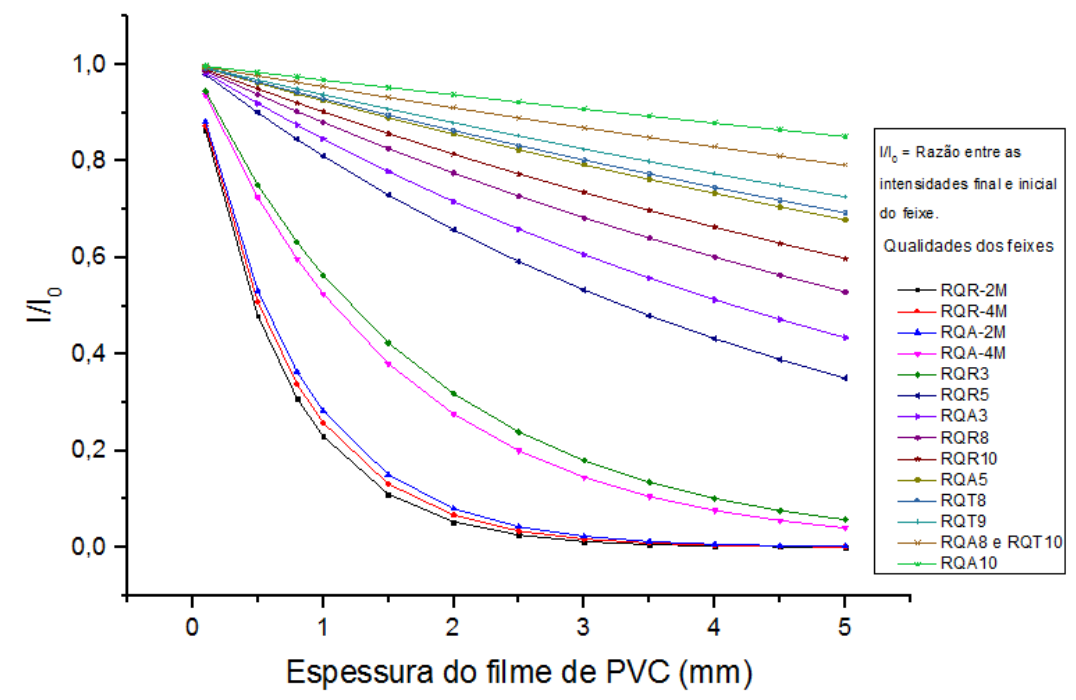

FIGURA 4.3 - Atenuação dos feixes de radiodiagnóstico convencional, de mamografia e de tomografia computadorizada ao atravessarem uma (a) placa de acrílico e (b) um filme de PVC.

Comparando-se os gráficos da Figura 4.3, a diferença de atenuação causada pela placa de acrílico com $1 \mathrm{~mm}$ de espessura e pelo filme de PVC com 0,3 $\mathrm{mm}$ de espessura é mínima; no entanto, o filme de PVC pode não suportar o peso das amostras e criar "barrigas", ocasionando uma variação no ângulo de irradiação ou até queda das amostras para outros sulcos. Assim, seria necessário aumentar a espessura do filme de PVC e ao realizar este aumento, de acordo com a Figura 4.3b, a atenuação dos feixes pelo filme de PVC seria maior que a atenuação pela placa de acrílico, portanto, a placa de acrílico com $1 \mathrm{~mm}$ de espessura foi escolhida. 
Para confirmar a predição teórica obtida na Figura 4.3a, que considerou a energia efetiva de cada feixe, foram realizadas medições com câmaras de ionização padrão do LCI/IPEN. Para cada qualidade, foram realizadas5 medições de carga coletada com e sem a tampa de acrílico entre a câmara de ionização e o equipamento de raios $X$. Os resultados da taxa de kerma no ar e da diferença máxima percentual obtida estão indicados nas Tabelas 4.4 e 4.5 .

TABELA 4.4 - Doses determinadas com e sem a tampa de acrílico e as variações percentuais para as qualidades de Radiodiagnóstico Convencional - Feixes Diretos e Feixes Atenuados.

\begin{tabular}{|c|c|c|c|}
\hline $\begin{array}{l}\text { Qualidade } \\
\text { da radiação }\end{array}$ & $\begin{array}{l}\text { Placa de } \\
\text { acrílico }\end{array}$ & $\begin{array}{c}\text { Taxa de kerma no ar } \\
(\mathrm{mG} / \mathrm{min})\end{array}$ & $\begin{array}{c}\text { Diferença percentual } \\
(\%)\end{array}$ \\
\hline \multirow[b]{2}{*}{ RQR3 } & Não & $21,4 \pm 0,3$ & \multirow[b]{2}{*}{2,65} \\
\hline & Sim & $20,9 \pm 0,3$ & \\
\hline \multirow{2}{*}{ RQR5 } & Não & $37,2 \pm 0,5$ & \multirow{2}{*}{2,26} \\
\hline & Sim & $36,3 \pm 0,5$ & \\
\hline \multirow{2}{*}{ RQR8 } & Não & $67,6 \pm 0,9$ & \multirow{2}{*}{1,32} \\
\hline & Sim & $66,7 \pm 0,9$ & \\
\hline \multirow{2}{*}{ RQR10 } & Não & $117,9 \pm 1,6$ & \multirow{2}{*}{0,97} \\
\hline & Sim & $116,8 \pm 1,6$ & \\
\hline \multirow{2}{*}{ RQA3 } & Não & $1,91 \pm 0,06$ & \multirow{2}{*}{0,49} \\
\hline & Sim & $1,90 \pm 0,06$ & \\
\hline \multirow{2}{*}{ RQA5 } & Não & $1,80 \pm 0,06$ & \multirow{2}{*}{0,38} \\
\hline & Sim & $1,79 \pm 0,05$ & \\
\hline \multirow{2}{*}{ RQA8 } & Não & $2,82 \pm 0,08$ & \multirow{2}{*}{1,83} \\
\hline & Sim & $2,77 \pm 0,08$ & \\
\hline \multirow{2}{*}{ RQA10 } & Não & $6,17 \pm 0,17$ & \multirow{2}{*}{0,36} \\
\hline & Sim & $6,14 \pm 0,17$ & \\
\hline
\end{tabular}


TABELA 4.5 - Doses determinadas com e sem a tampa de acrílico e as variações percentuais para as qualidades de Tomografia Computadorizada e Mamografia.

\begin{tabular}{|c|c|c|c|}
\hline $\begin{array}{l}\text { Qualidade } \\
\text { da radiação }\end{array}$ & $\begin{array}{l}\text { Placa de } \\
\text { acrílico }\end{array}$ & $\begin{array}{c}\text { Taxa de kerma no ar } \\
(\mathrm{mG} / \mathrm{min})\end{array}$ & $\begin{array}{c}\text { Diferença percentual } \\
(\%)\end{array}$ \\
\hline \multirow{2}{*}{ RQT8 } & Não & $20,68 \pm 0,17$ & \multirow{2}{*}{0,30} \\
\hline & Sim & $20,6 \pm 0,5$ & \\
\hline \multirow{2}{*}{ RQT9 } & Não & $32,0 \pm 0,3$ & \multirow{2}{*}{1,9} \\
\hline & Sim & $31,4 \pm 0,7$ & \\
\hline \multirow{2}{*}{ RQT10 } & Não & $53,6 \pm 0,4$ & \multirow{2}{*}{2,3} \\
\hline & Sim & $52,4 \pm 1,2$ & \\
\hline \multirow{2}{*}{ RQR-2M } & Não & $11,4 \pm 0,4$ & \multirow{2}{*}{11,6} \\
\hline & Sim & $10,2 \pm 0,3$ & \\
\hline \multirow{2}{*}{ RQR-4M } & Não & $16,8 \pm 0,5$ & \multirow{2}{*}{10,6} \\
\hline & Sim & $15,2 \pm 0,5$ & \\
\hline \multirow{2}{*}{ RQA-2M } & Não & $0,64 \pm 0,08$ & \multirow{2}{*}{1,5} \\
\hline & Sim & $0,63 \pm 0,08$ & \\
\hline \multirow{2}{*}{ RQA-4M } & Não & $1,40 \pm 0,16$ & \multirow{2}{*}{4,9} \\
\hline & Sim & $1,34 \pm 0,15$ & \\
\hline
\end{tabular}

Comparando-se a Figura 4.3a com os resultados das Tabelas 4.4 e 4.5, concluise que a predição teórica está correta, mesmo sem conhecer efetivamente o espectro de energia dos feixes e a composição do acrílico. Desta mesma comparação, verifica-se que a qualidade RQR-2M é a mais atenuada e por este motivo foi escolhida para se averiguar se as pastilhas de $\mathrm{BeO}$ sofrem influência em sua resposta TL com a atenuação.

Escolheu-se a dose absorvida de 11,2 mGy para examinar a influência na resposta $\mathrm{TL}$ do BeO. Esta dose foi determinada de forma arbitrária, considerando e respeitando os limites operacionais dos equipamentos do LCI/IPEN.

Desta forma, foram realizados 8 ciclos de irradiação, leitura da emissão TL, tratamento térmico e nova leitura da emissão $T L$, sendo que quatro irradiações foram realizadas com a tampa do suporte entre as pastilhas e o equipamento de raios $\mathrm{X}$ e as outras quatro sem a tampa. 
Os resultados obtidos foram de $(6.469 \pm 55)$ contagens com a tampa de acrílico e (6.119 \pm 38$)$ contagens para suporte sem a tampa de acrílico.

A diferença percentual entre as medições obtida foi entre 5,4\% e 5,7\%, isto é, a resposta TL com a tampa de acrílico foi $5,7 \%$ maior que a resposta TL sem a tampa de acrílico.

Partindo da hipótese inicial de que um material entre o feixe e as pastilhas atuaria como atenuador, era esperado ter uma diminuição da resposta TL; entretanto, não foi isto o observado. Um pequeno aumento na resposta TL foi encontrado quando se utiliza a tampa de acrílico. Esta variação pode ser explicada considerando que teve a absorção de elétrons secundários e fótons espalhados, gerados na interação dos raios $X$ com a tampa de acrílico, pelo BeO.

Para averiguar os resultados experimentais foi utilizado o Método de Monte Carlo em conjunto com o MCNP5 para simular o experimento. O arranjo experimental simulado está indicado na Figura 4.4, e na Tabela 4.6, os valores de partículas simuladas, distância fonte-pastilha, densidade da pastilha e energia efetiva, inseridos no código para simulação e no Anexo 1 está o código utilizado.

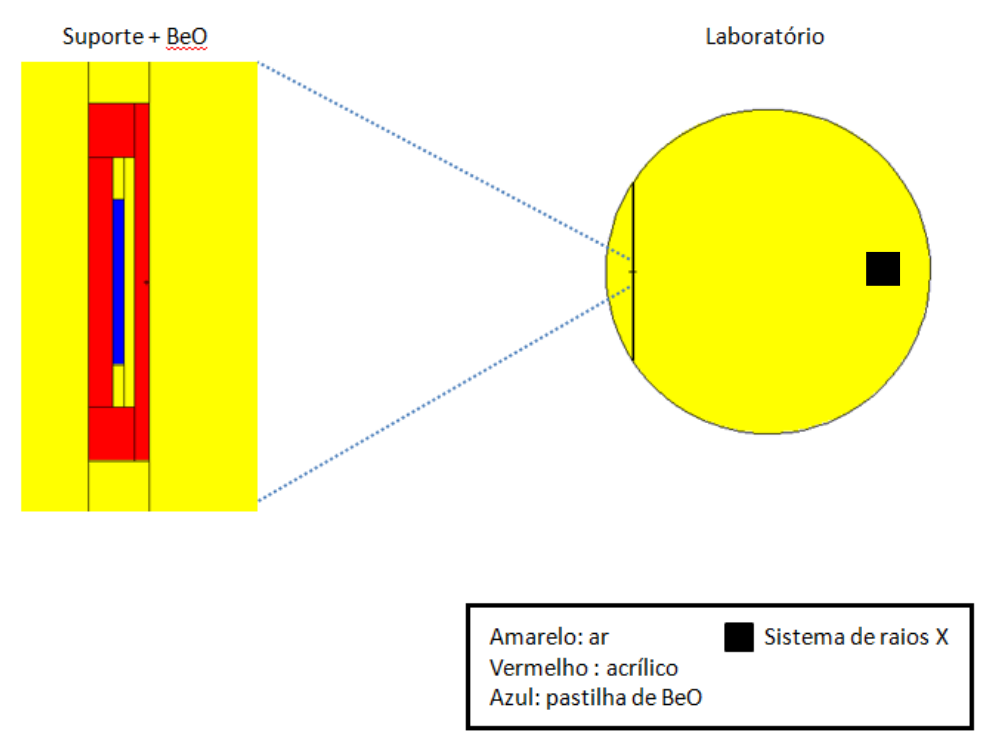

FIGURA 4.4 - Representação da experiência simulada no MCNP no plano XY. À esquerda está a representação do suporte com a pastilha e à direita a do laboratório com o suporte com a pastilha e o sistema de raios $\mathrm{X}$. 
TABELA 4.6 - Valores atribuídos às variáveis da simulação.

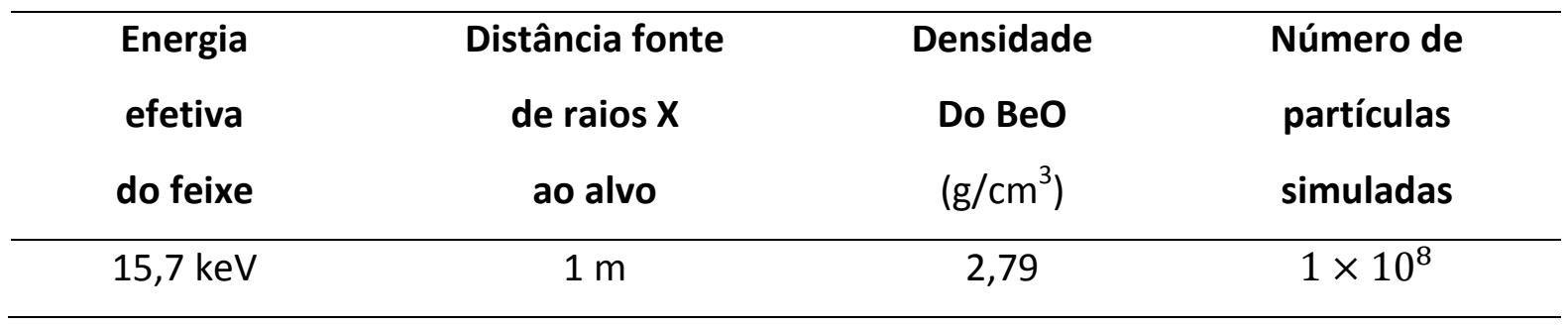

O tally pedido como resposta foi o tally *F8 que obtém a energia absorvida em MeV (X-5 MONTE CARLO TEAM, 2003). Este arranjo foi simulado considerando o suporte com e sem a tampa. O resultado para energia absorvida no caso com a tampa foi de $\left(2,43 \times 10^{-6}\right) \mathrm{MeV}$ e para o caso sem a tampa foi de $\left(2,29 \times 10^{-6}\right) \mathrm{MeV}$, que resultou em uma diferença percentual máxima de 5,7\% condizente com o obtido experimentalmente.

No entanto, como a diferença percentual entre as respostas TL, obtida experimentalmente e por meio de simulação, é pequena e está muito próxima da reprodutibilidade da resposta teórica máxima de 5\% (CHEN, McKEEVER, 1997; FURETTA, 2003), pode-se considerar que a resposta TL não é alterada com a inserção de uma tampa de acrílico com espessura de $1 \mathrm{~mm}$ no suporte e que a atenuação do feixe não é perceptível ao sistema dosimétrico utilizado. Assim, esse suporte pode ser usado para o estudo das características dosimétricas do $\mathrm{BeO}$ para as qualidades de radiação utilizadas.

\subsection{Seleção dos Dosímetros}

O trabalho começou com 48 pastilhas, entretanto para se trabalhar com as pastilhas é interessante separar aquelas que têm um comportamento dosimétrico semelhante entre si das demais. Para isso foram realizados dois testes, o de reprodutibilidade e o de homogeneidade.

\subsubsection{Teste da Reprodutibilidade da Resposta}

Para este estudo foram realizados 10 ciclos de irradiação (com uma dose de 10 mGy, na qualidade RQR 2M); leitura TL; tratamento térmico; e leitura da contagem de fundo para cada amostra.

Após os 10 ciclos, foram calculados o valor médio e o desvio padrão da média de cada amostra. 
Com o valor médio e o seu respectivo desvio padrão, foi calculado o coeficiente de variação percentual com a Equação (2.10). Os resultados estão na Tabela 4.7.

TABELA 4.7 - Teste de reprodutibilidade do BeO.

\begin{tabular}{ccc|ccc}
\hline No da pastilha & $\begin{array}{c}\text { Média } \\
\text { (u.a.) }\end{array}$ & $\begin{array}{c}\text { CV* } \\
\text { (\%) }\end{array}$ & No da pastilha & $\begin{array}{c}\text { Média } \\
\text { (u.a.) }\end{array}$ & $\begin{array}{c}\text { CV* } \\
\text { (\%) }\end{array}$ \\
\hline 1 & $6.678 \pm 295$ & 4,4 & 26 & $7.386 \pm 225$ & 3,1 \\
2 & $6.534 \pm 235$ & 3,6 & 28 & $7.209 \pm 189$ & 2,7 \\
3 & $6.331 \pm 293$ & 4,6 & 29 & $5.048 \pm 210$ & 4,2 \\
4 & $6.161 \pm 259$ & 4,2 & 31 & $6.720 \pm 248$ & 3,7 \\
7 & $4.664 \pm 213$ & 4,6 & 33 & $4.549 \pm 221$ & 4,9 \\
9 & $5.527 \pm 249$ & 4,5 & 34 & $5.892 \pm 187$ & 3,2 \\
13 & $4.360 \pm 202$ & 4,6 & 37 & $5.698 \pm 251$ & 4,4 \\
16 & $6.602 \pm 205$ & 3,1 & 38 & $5.259 \pm 228$ & 4,3 \\
17 & $6.836 \pm 222$ & 3,2 & 39 & $6.135 \pm 259$ & 4,2 \\
18 & $6.579 \pm 202$ & 3,1 & 41 & $5.641 \pm 230$ & 4,1 \\
21 & $6.334 \pm 295$ & 4,3 & 43 & $5.891 \pm 247$ & 4,2 \\
22 & $5.348 \pm 245$ & 4,6 & 44 & $5.541 \pm 249$ & 4,5 \\
23 & $7.038 \pm 288$ & 4,1 & 47 & $5.841 \pm 157$ & 2,7 \\
24 & $6.656 \pm 310$ & 4,7 & 48 & $5.831 \pm 143$ & 2,5 \\
\hline
\end{tabular}

*CV: Coeficiente de variação

Nesta tabela são apresentados os resultados das amostras com Coeficiente de Variação inferior a 5\%, que foram selecionadas para continuar o estudo. As demais foram descartadas.

\subsubsection{Teste de Homogeneidade}

Para o teste de homogeneidade, foram utilizadas as amostras aprovadas no teste de reprodutibilidade e foram selecionadas somente aquelas que em conjunto têm uma variação da resposta menor de 30\%, utilizando a Equação (2.11). As pastilhas que não satisfizeram a esse limite foram excluídas do trabalho. O resultado do teste de 
homogeneidade e consequentemente o lote definido para este trabalho está na Tabela 4.8 .

TABELA 4.8 - Teste de homogeneidade e definição de Lote.

Teste de homogeneidade: $29,62 \%$

Lote

$1,2,3,4,16,17,18,21,23,24,26$,

$28,31,34,37,39,43,47,48$

\section{Pastilhas excluídas}

$7,9,13,22,29,33,38,41,44$

Todos os estudos com as técnicas de TL e OSL a seguir foram realizados utilizando o lote selecionado.

\subsection{Curva de Emissão TL e Curva de Decaimento OSL}

Na Figura 4.5 estão apresentadas as curvas de emissão TL e as curvas de decaimento OSL para a qualidade de radiação $R Q R$, escolhida arbitrariamente. $\mathrm{Na}$ Figura 4.5a é possível verificar que o segundo pico necessita de doses mais altas para a sua identificação. 
a)

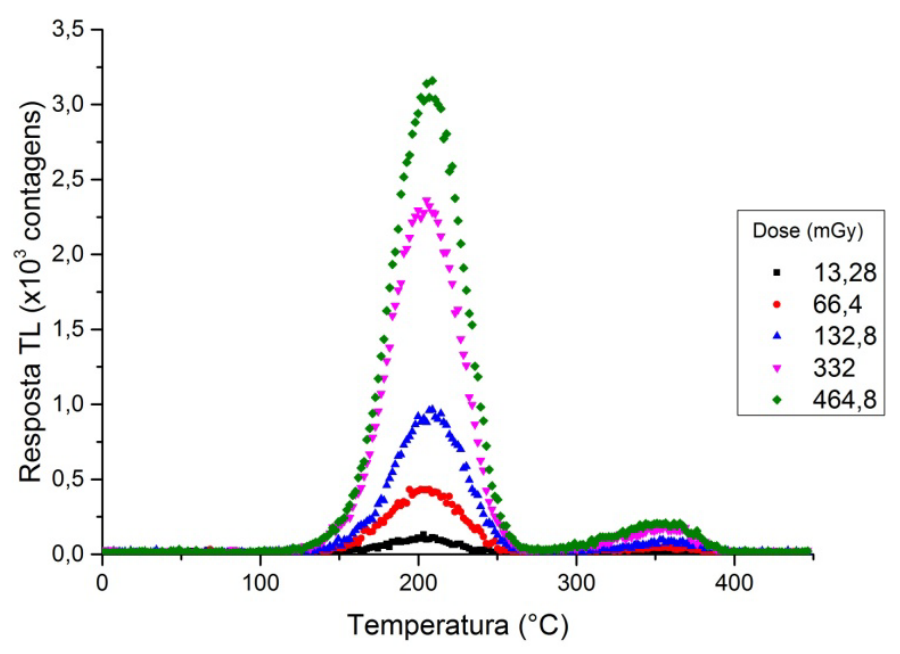

b)

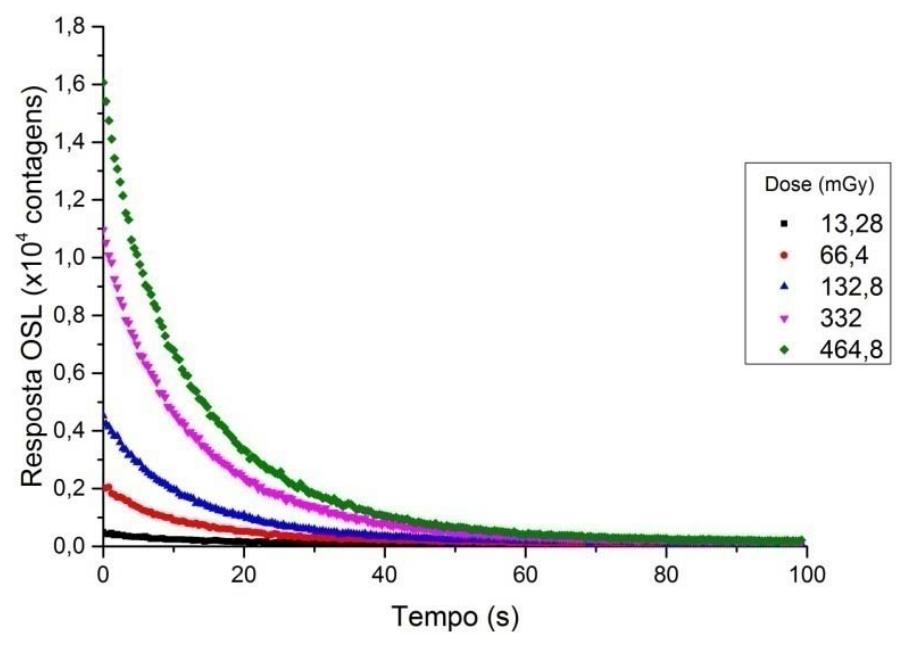

FIGURA 4.5 - Curvas de emissão TL (a) e de decaimento OSL (b) de amostras de BeO para doses diferentes de radiação X (RQR 8).

Pela observação do formato dos picos na curva de emissão TL e do decaimento na curva de decaimento OSL, é possível perceber algumas características relacionadas à ordem cinética. Na curva de emissão TL, o segundo pico tem a ordem cinética igual a 1, porque o pico é assimétrico, com o lado do pico de menor temperatura mais alongado que o lado de maior temperatura. Para o primeiro pico a ordem cinética é igual a 2, pois o pico é simétrico (BACCl et al, 1989; CHEN, McKEEVER, 1997; FURETTA, 2003; CHEN, PAGONIS, 2011).

Na curva de decaimento OSL o formato do decaimento para as diferentes doses não varia, isto significa que a taxa de decaimento OSL não se altera, pois a intensidade luminosa é fixa, que é uma característica da leitura CW-OSL no caso de cinética de primeira ordem (YUKIAHARA, McKEEVER, 2008). 


\subsection{Curvas Dose-Resposta}

As curvas das respostas TL e OSL em função da dose absorvida do BeO à radiação $\mathrm{X}$ foram estabelecidas para as qualidades padronizadas de radiodiagnóstico convencional, feixes diretos (RQR3, RQR5, RQR8 e RQR10), feixes atenuados (RQA3, RQA5, RQA8 e RQA10), feixes de tomografia computadorizada (RQT8, RQT9 e RQT10) e mamografia (RQR-2M, RQR-4M, RQA-2M e RQA-4M). Os intervalos de dose foram estabelecidos com a determinação do tempo de exposição, considerando os limites operacionais do equipamento Pantak/Seifert modelo ISOVOLT HS 160. Todos os materiais apresentam comportamento linear da resposta no intervalo de dose estudado. Nas Figuras 4.6 a 4.12 estão apresentadas as curvas de dose-resposta do $\mathrm{BeO}$ obtidas com a técnica da luminescência opticamente estimulada e nas Figuras de 4.13 a 4.19 com a técnica da termoluminescência. 

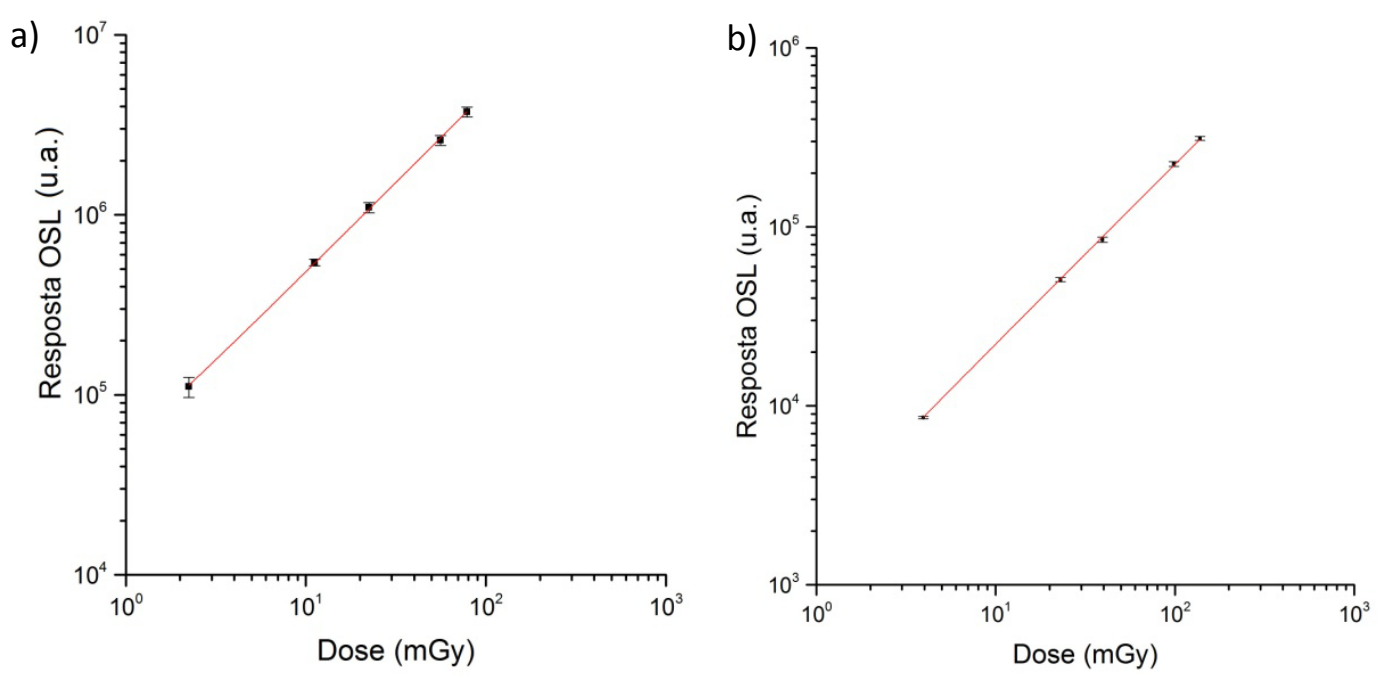

FIGURA 4.6 - Curvas dose-resposta OSL do BeO para as qualidades de mamografia, feixes diretos (a) RQR- 2M e(b) RQR - 4M.
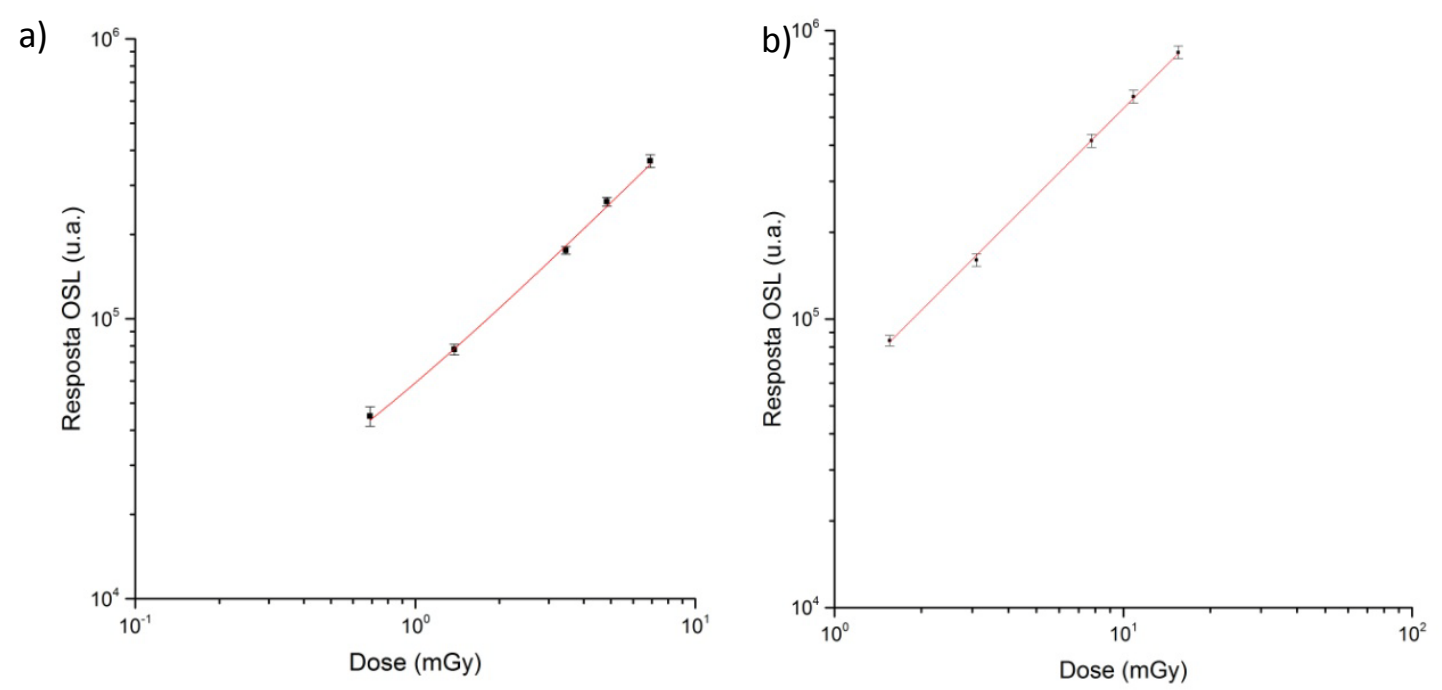

FIGURA 4.7 - Curvas dose-resposta OSL do BeO para as qualidades de mamografia, feixes atenuados (a) RQA- 2M e (b) RQA - 4M. 
a)

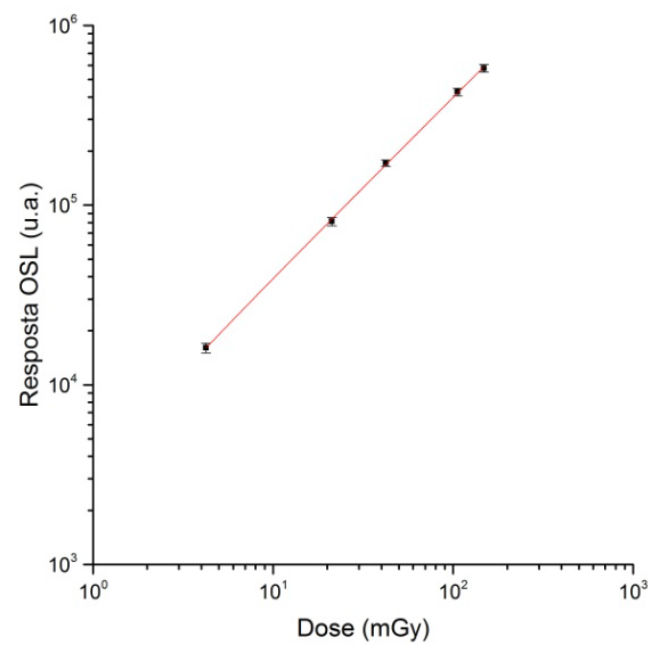

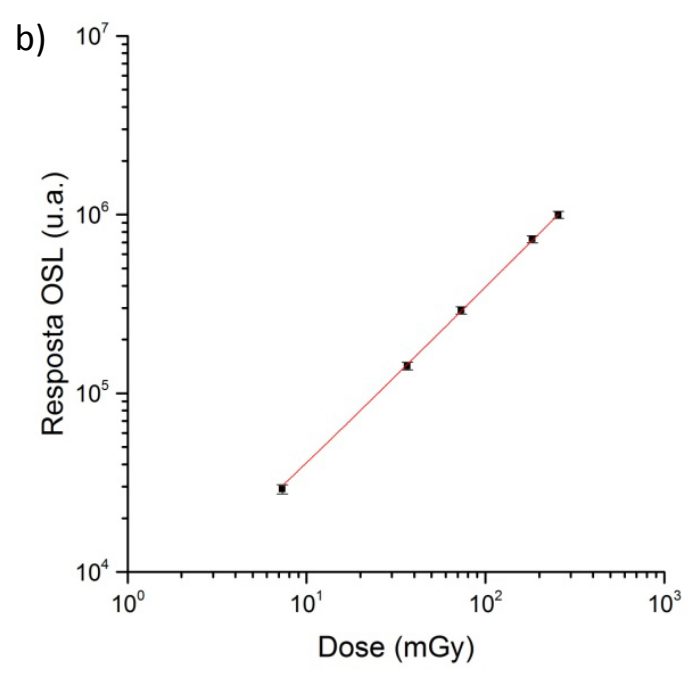

FIGURA 4.8 - Curvas dose-resposta OSL do BeO para as qualidades de radiodiagnóstico convencional, feixes diretos (a) RQR 3 e (b) RQR 5.

a)

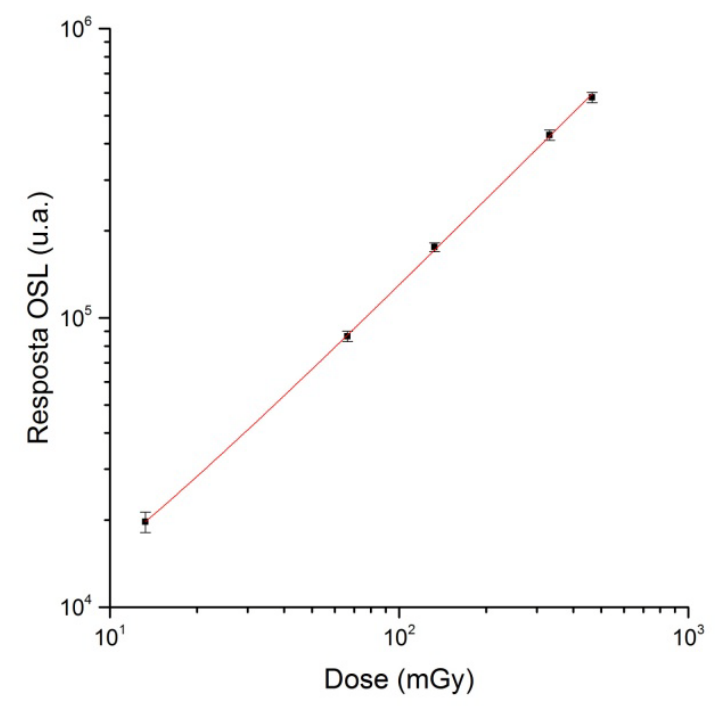

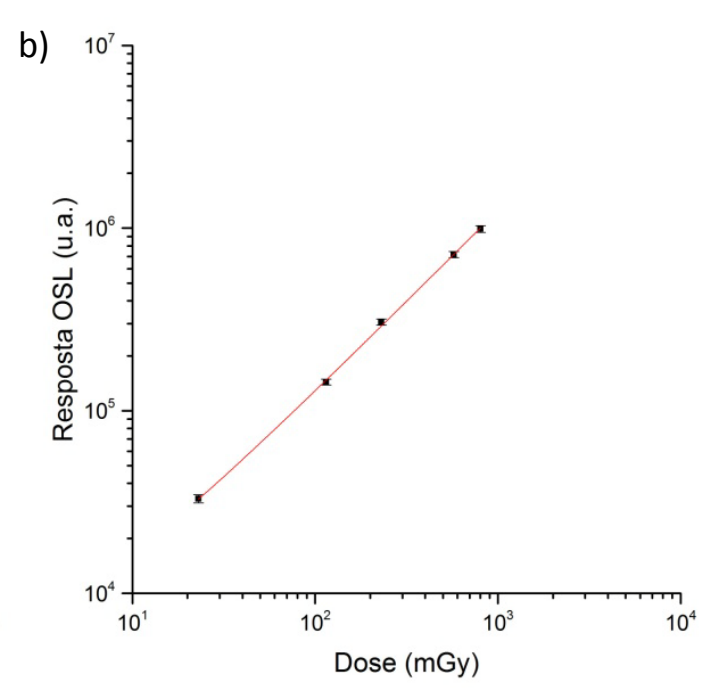

FIGURA 4.9 - Curvas dose-resposta OSL do BeO para as qualidades de radiodiagnóstico convencional, feixes diretos (a) RQR 8 e (b) RQR 10. 
a)

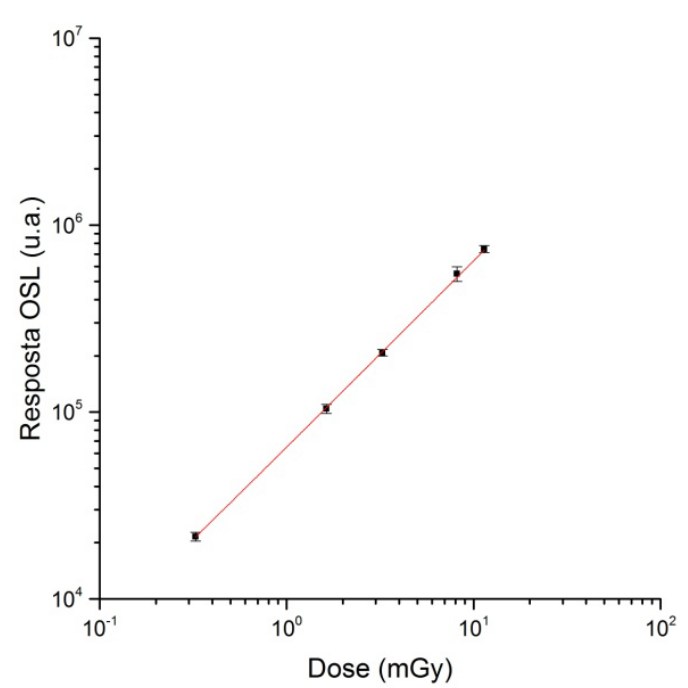

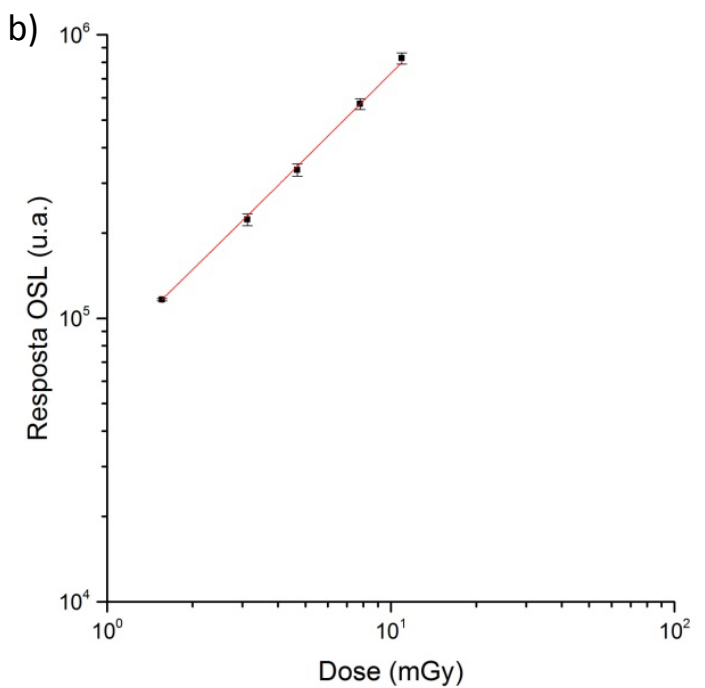

FIGURA 4.10 - Curvas dose-resposta OSL do BeO para as qualidades de radiodiagnóstico convencional, feixes atenuados (a) RQA 3 e (b) RQA 5.

a)

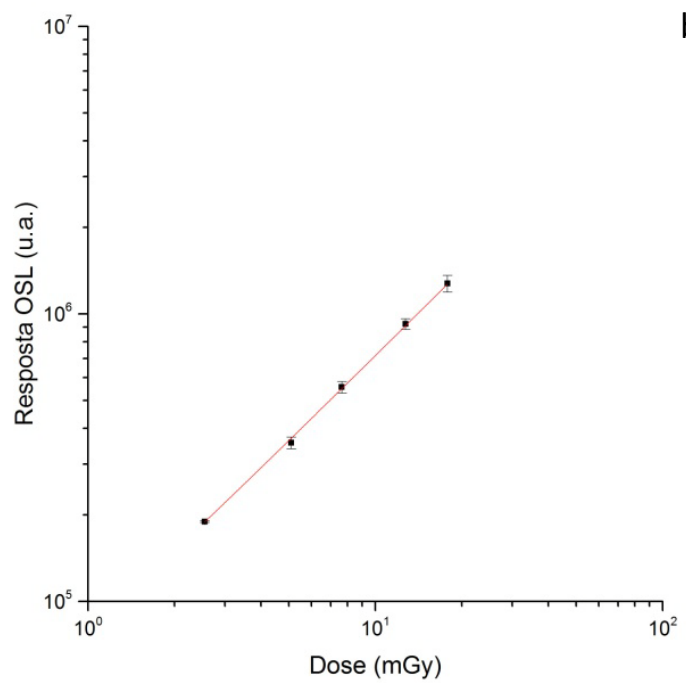

b)

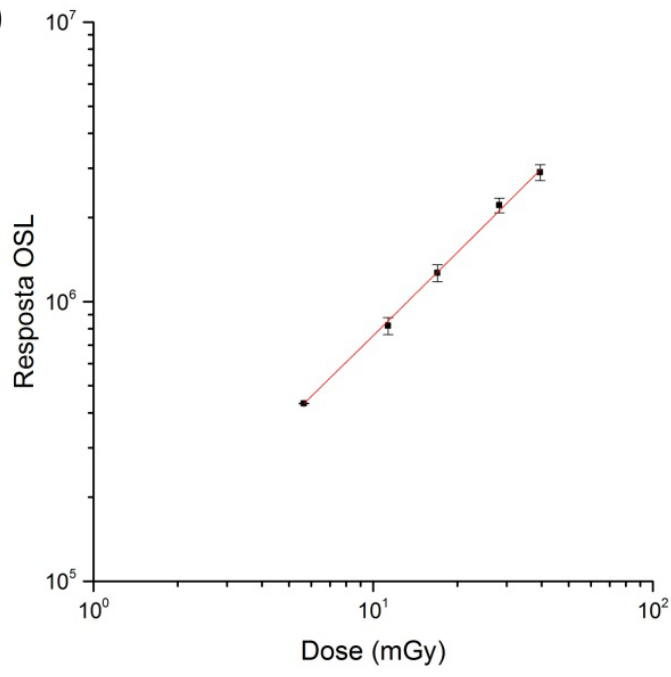

FIGURA 4.11 - Curvas dose-resposta OSL do BeO para as qualidades de radiodiagnóstico convencional, feixes atenuados (a) RQA 8 e (b) RQA 10. 
a)

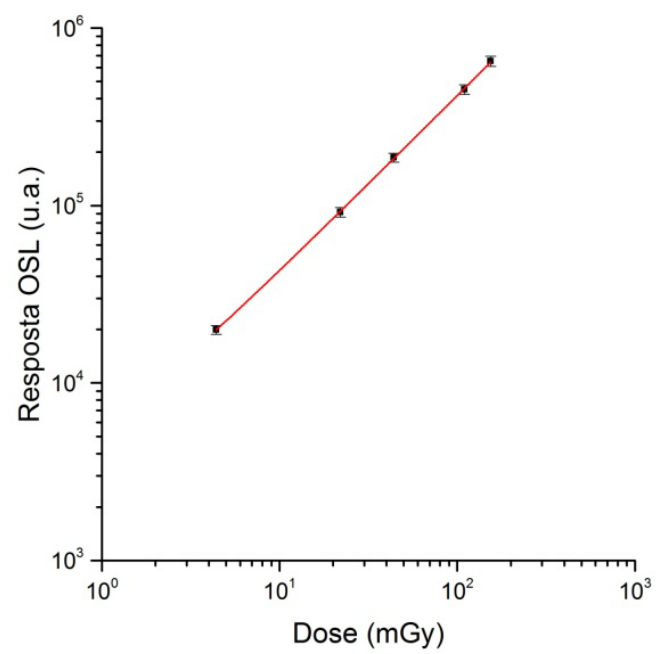

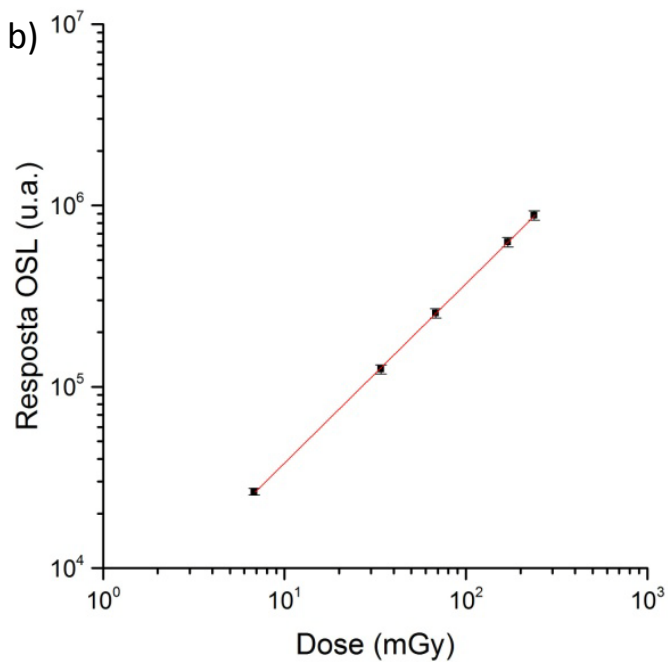

c)

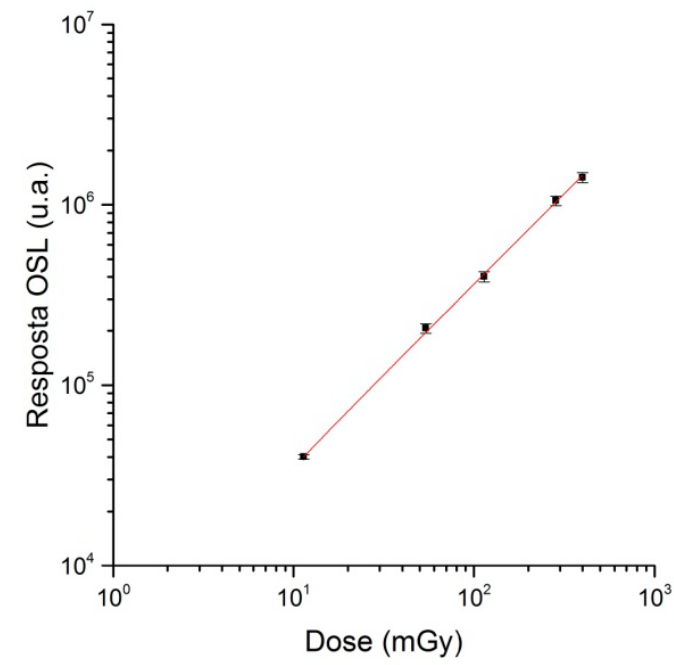

FIGURA 4.12 - Curvas dose-resposta OSL do BeO para as qualidades de tomografia computadorizada (a) RQT 8, (b) RQT 9 e (c) RQT 10. 

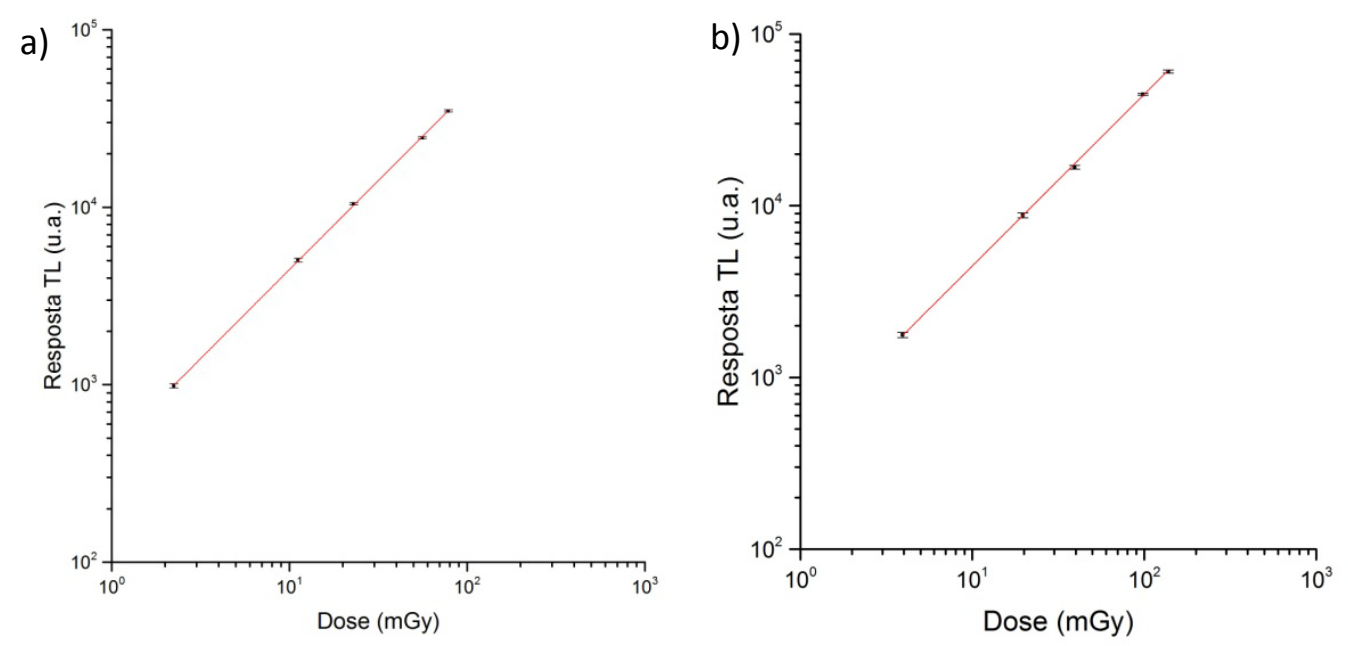

FIGURA 4.13 - Curvas dose-resposta TL do BeO para as qualidades de mamografia, feixes diretos (a) RQR- $2 M$ e(b) RQR - 4M.

a)

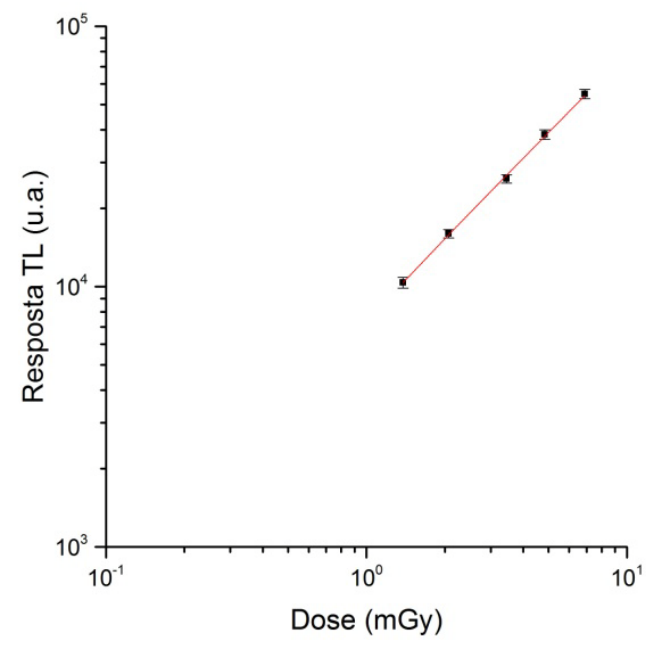

b)

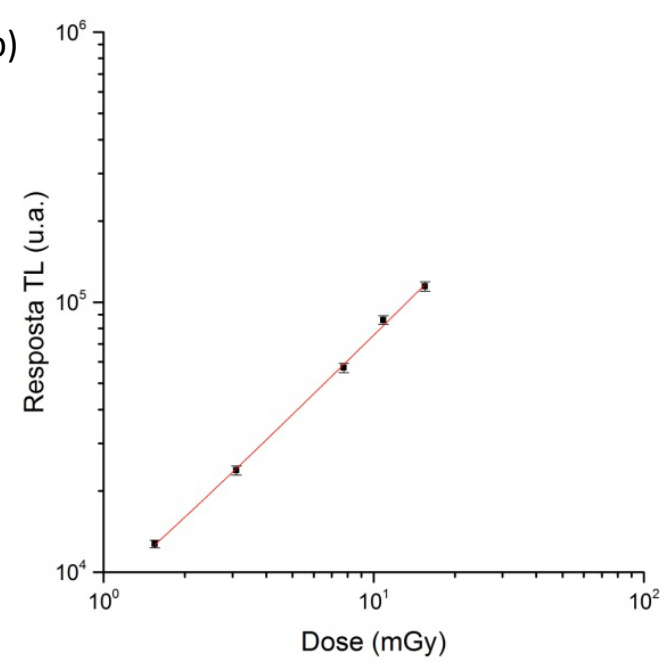

FIGURA 4.14 - Curvas dose-resposta TL do BeO para as qualidades de mamografia, feixes atenuados (a) RQR - $2 \mathrm{M}$ e (b) RQR - 4M. 
a)

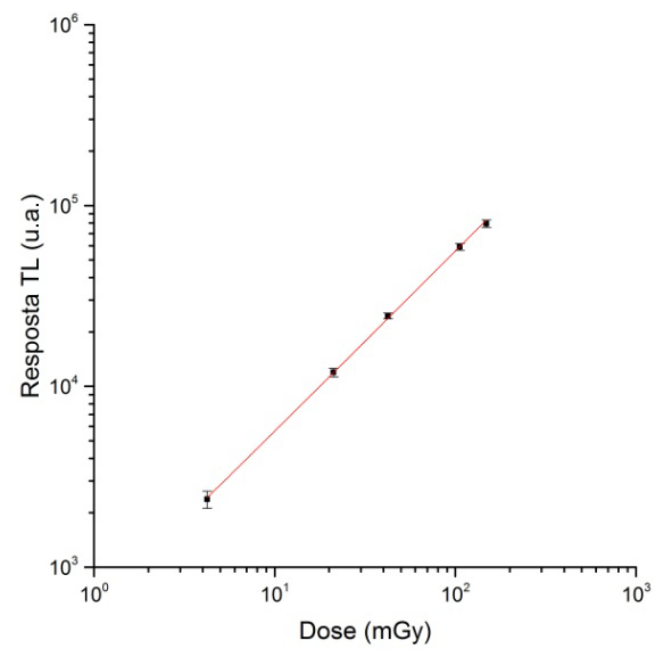

b)

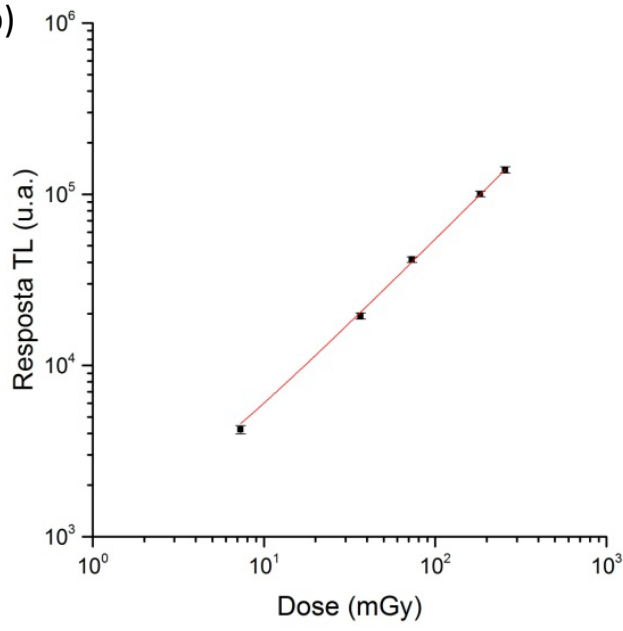

FIGURA 4.15 - Curvas dose-resposta TL do BeO para as qualidades de radiodiagnóstico convencional, feixes diretos (a) RQR 3 e (b) RQR 5.

a)

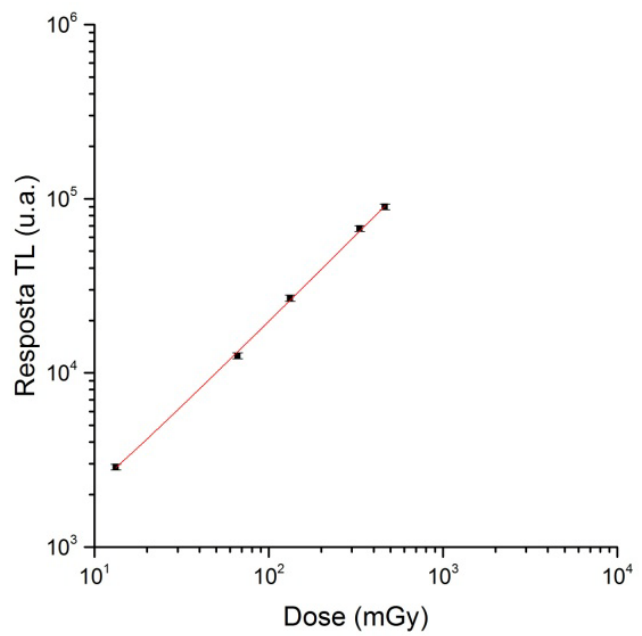

b)

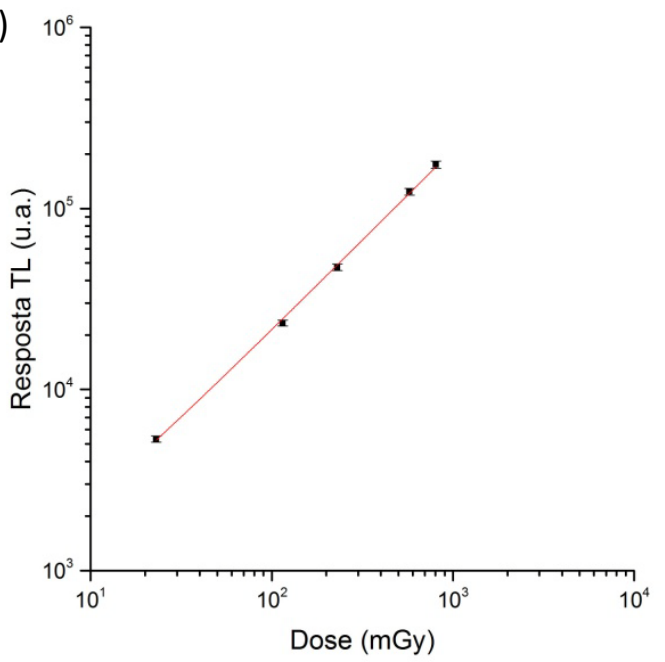

FIGURA 4.16 - Curvas dose-resposta TL do BeO para as qualidades de radiodiagnóstico convencional, feixes diretos (a) RQR 8 e (b) RQR 10. 
a)

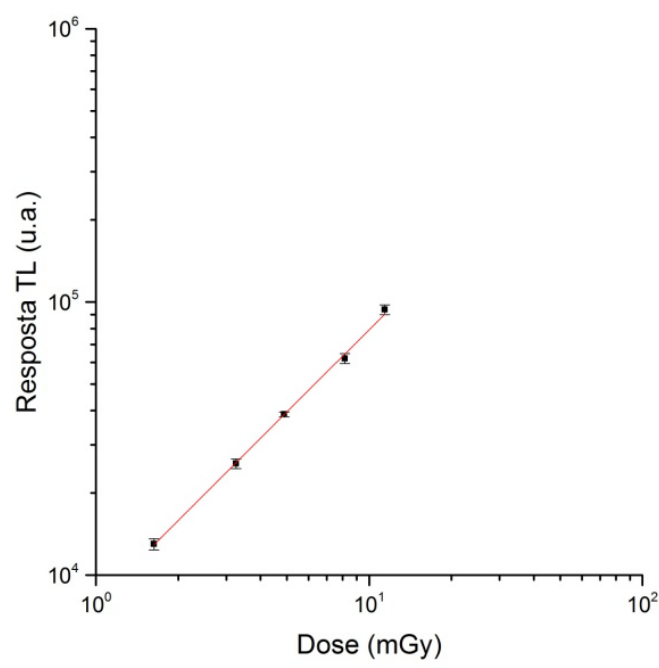

b)

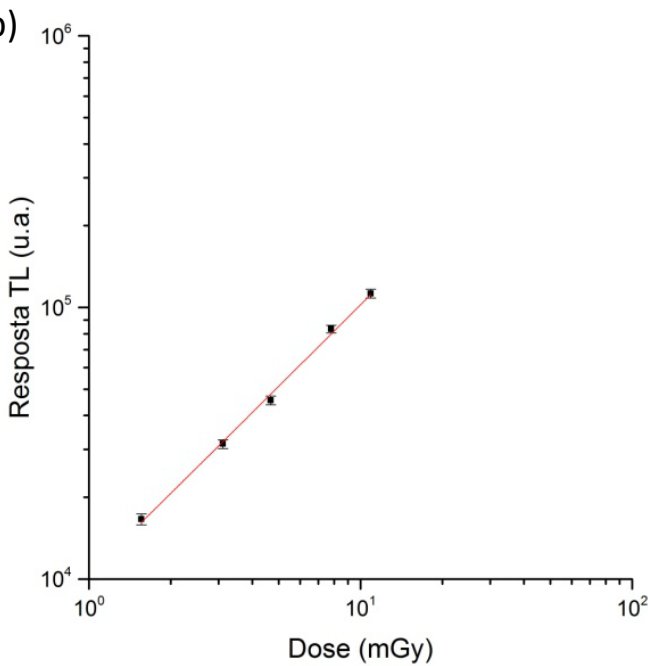

FIGURA 4.17 - Curvas dose-resposta TL do BeO para as qualidades de radiodiagnóstico convencional, feixes atenuados (a) RQA 3 e (b) RQA 5.
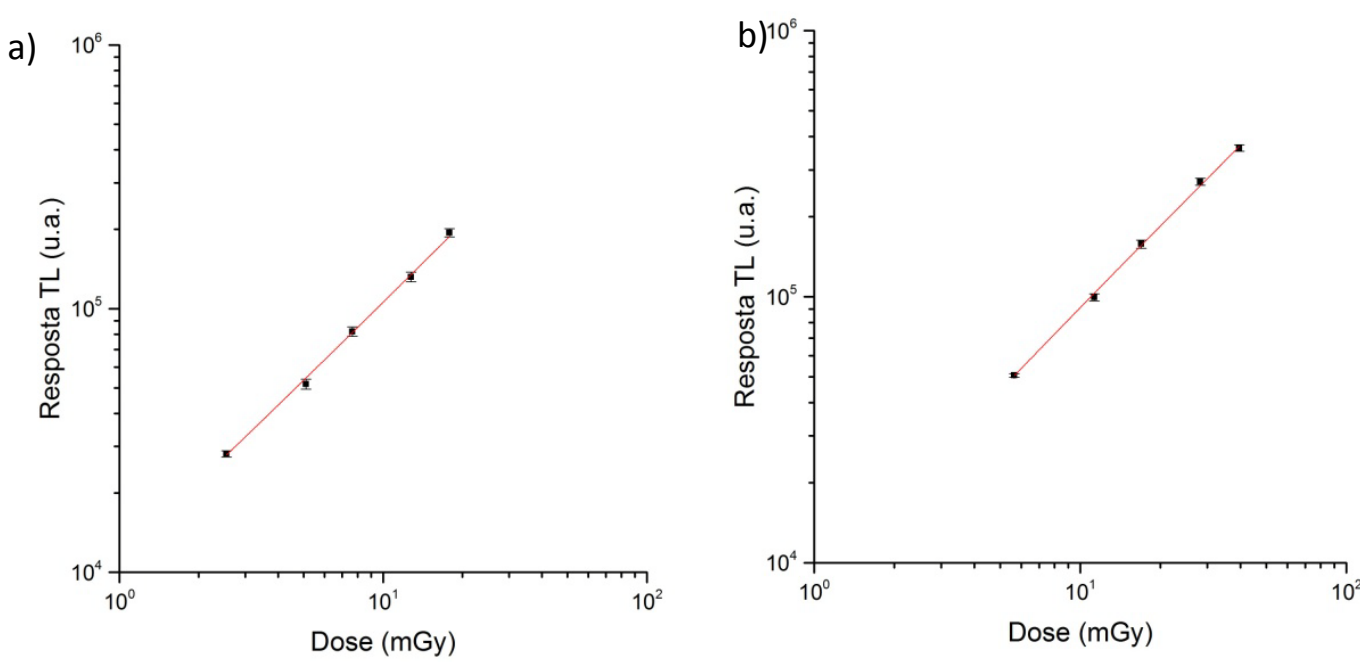

FIGURA 4.18 - Curvas dose-resposta TL do BeO para as qualidades de radiodiagnóstico convencional, feixes atenuados (a) RQA 8 e (b) RQA 10. 
a)

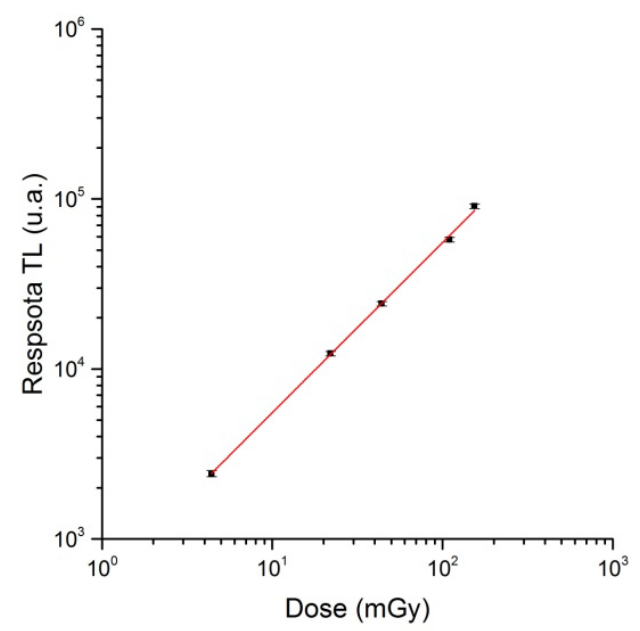

b)

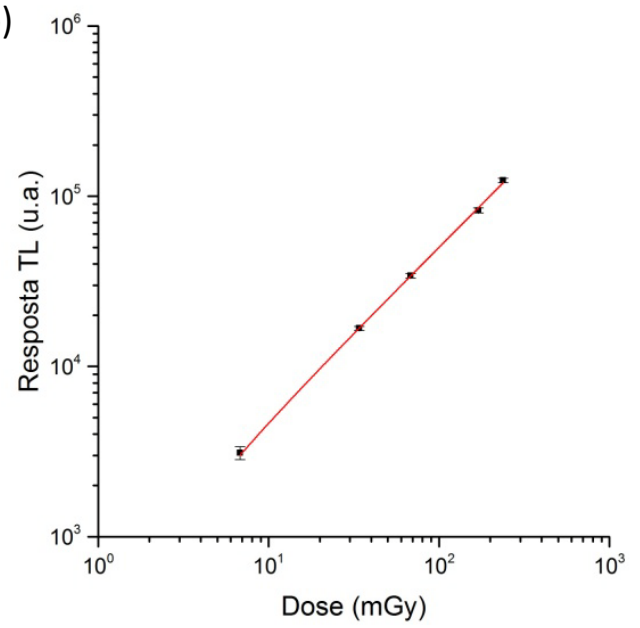

c)

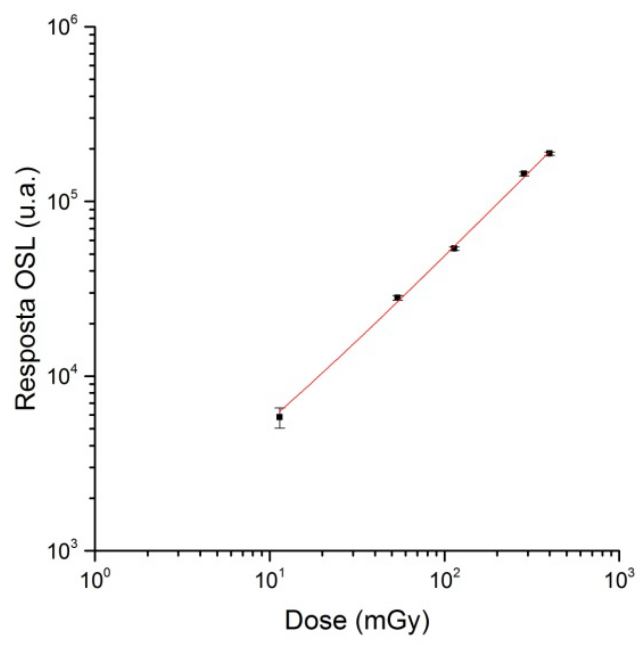

FIGURA 4.19 - Curvas dose-resposta TL do BeO para as qualidades de tomografia computadorizada (a) RQT 8, (b) RQT 9 e (c) RQT 10.

Os coeficientes de calibração obtidos para todas as qualidades da radiação utilizando as Equações (2.13) e (2.14) estão apresentadas nas Tabelas 4.9 e 4.10. 
TABELA 4.9 - Coeficientes de calibração (OSL) do BeO para todas as qualidades testadas.

\begin{tabular}{|c|c|c|c|c|}
\hline \multirow{2}{*}{$\begin{array}{l}\text { Qualidade } \\
\text { de radiação }\end{array}$} & \multirow{2}{*}{$\begin{array}{l}\text { Tipo de } \\
\text { radiação }\end{array}$} & \multicolumn{2}{|c|}{$\begin{array}{l}\text { Coeficiente de calibração } \\
\text { (mGy/u.a.) }\end{array}$} & \multirow{2}{*}{$\begin{array}{c}\text { Diferença } \\
\text { percentual } \\
(\%)\end{array}$} \\
\hline & & Calculado & Ajuste linear & \\
\hline RQR 3 & \multirow{4}{*}{$\begin{array}{c}\mathrm{RC} \\
\text { Feixes } \\
\text { diretos }\end{array}$} & $(2,53 \pm 0,06) \times 10^{-4}$ & $(2,51 \pm 0,03) \times 10^{-4}$ & 0,8 \\
\hline RQR 5 & & $(2,52 \pm 0,05) \times 10^{-4}$ & $(2,552 \pm 0,024) \times 10^{-4}$ & $-1,3$ \\
\hline RQR 8 & & $(7,66 \pm 0,05) \times 10^{-4}$ & $(7,86 \pm 0,10) \times 10^{-4}$ & $-2,5$ \\
\hline RQR 10 & & $(7,87 \pm 0,14) \times 10^{-4}$ & $(8,03 \pm 0,17) \times 10^{-4}$ & $-2,0$ \\
\hline RQA 3 & \multirow{4}{*}{$\begin{array}{c}\mathrm{RC} \\
\text { Feixes } \\
\text { atenuados }\end{array}$} & $(1,55 \pm 0,04) \times 10^{-5}$ & $(1,552 \pm 0,018) \times 10^{-5}$ & $-0,1$ \\
\hline RQA 5 & & $(1,346 \pm 0,015) \times 10^{-5}$ & $(1,38 \pm 0,03) \times 10^{-5}$ & $-2,5$ \\
\hline RQA 8 & & $(1,370 \pm 0,020) \times 10^{-5}$ & $(1,41 \pm 0,03) \times 10^{-5}$ & $-2,8$ \\
\hline RQA 10 & & $(1,311 \pm 0,015) \times 10^{-5}$ & $(1,34 \pm 0,03) \times 10^{-5}$ & $-2,2$ \\
\hline RQT 8 & \multirow{3}{*}{$\mathrm{CT}$} & $(2,33 \pm 0,06) \times 10^{-4}$ & $(2,40 \pm 0,08) \times 10^{-4}$ & $-2,9$ \\
\hline RQT 9 & & $(2,66 \pm 0,07) \times 10^{-4}$ & $(2,710 \pm 0,018) \times 10^{-4}$ & $-1,8$ \\
\hline RQT 10 & & $(2,79 \pm 0,06) \times 10^{-4}$ & $(2,74 \pm 0,06) \times 10^{-4}$ & 1,8 \\
\hline RQR-2M & \multirow{2}{*}{ Mamo - FD } & $(2,08 \pm 0,07) \times 10^{-4}$ & $(2,10 \pm 0,03) \times 10^{-4}$ & $-1,0$ \\
\hline RQR-4M & & $(4,49 \pm 0,06) \times 10^{-4}$ & $(4,47 \pm 0,06) \times 10^{-4}$ & 0,4 \\
\hline RQA-2M & \multirow{2}{*}{ Mamo - FA } & $(1,88 \pm 0,06) \times 10^{-5}$ & $(1,94 \pm 0,07) \times 10^{-5}$ & $-3,1$ \\
\hline RQA-4M & & $(1,86 \pm 0,04) \times 10^{-5}$ & $(1,87 \pm 0,03) \times 10^{-5}$ & $-0,5$ \\
\hline
\end{tabular}

RC: Radiodiagnóstico Convencional

CT: Tomografia Computadorizada

Mamo - FD: Mamografia - Feixes diretos

Mamo - FA: Mamografia - Feixes atenuados 
TABELA 4.10 - Coeficientes de calibração (TL) do BeO para todas as qualidades testadas.

\begin{tabular}{|c|c|c|c|c|}
\hline \multirow{2}{*}{$\begin{array}{l}\text { Qualidade } \\
\text { de radiação }\end{array}$} & \multirow{2}{*}{$\begin{array}{l}\text { Tipo de } \\
\text { radiação }\end{array}$} & \multicolumn{2}{|c|}{$\begin{array}{l}\text { Coeficiente de calibração } \\
\text { (mGy/u.a.) }\end{array}$} & \multirow{2}{*}{$\begin{array}{c}\text { Diferença } \\
\text { percentual } \\
(\%)\end{array}$} \\
\hline & & Calculado & Ajuste linear & \\
\hline RQR 3 & \multirow{4}{*}{$\begin{array}{c}\mathrm{RC} \\
\text { Feixes } \\
\text { diretos }\end{array}$} & $(1,78 \pm 0,04) \times 10^{-3}$ & $(1,79 \pm 0,04) \times 10^{-3}$ & $-0,6$ \\
\hline RQR 5 & & $(1,81 \pm 0,03) \times 10^{-3}$ & $(1,85 \pm 0,04) \times 10^{-3}$ & $-2,2$ \\
\hline RQR 8 & & $(5,03 \pm 0,03) \times 10^{-3}$ & $(5,13 \pm 0,12) \times 10^{-3}$ & $-1,9$ \\
\hline RQR 10 & & $(4,70 \pm 0,09) \times 10^{-3}$ & $(4,82 \pm 0,11) \times 10^{-3}$ & $-2,5$ \\
\hline RQA 3 & \multirow{4}{*}{$\begin{array}{c}\mathrm{RC} \\
\text { Feixes } \\
\text { atenuados }\end{array}$} & $(1,262 \pm 0,019) \times 10^{-4}$ & $(1,26 \pm 0,03) \times 10^{-4}$ & 0,2 \\
\hline RQA 5 & & $(9,69 \pm 0,17) \times 10^{-5}$ & $(9,8 \pm 0,4) \times 10^{-5}$ & $-1,1$ \\
\hline RQA 8 & & $(9,36 \pm 0,16) \times 10^{-5}$ & $(9,6 \pm 0,3) \times 10^{-5}$ & $-2,5$ \\
\hline RQA 10 & & $(1,073 \pm 0,012) \times 10^{-4}$ & $(1,070 \pm 0,024) \times 10^{-4}$ & 0,3 \\
\hline RQT 8 & \multirow{3}{*}{ CT } & $(1,80 \pm 0,03) \times 10^{-3}$ & $(1,82 \pm 0,05) \times 10^{-3}$ & $-1,1$ \\
\hline RQT 9 & & $(2,00 \pm 0,03) \times 10^{-3}$ & $(1,98 \pm 0,04) \times 10^{-3}$ & 1,0 \\
\hline RQT 10 & & $(2,05 \pm 0,03) \times 10^{-3}$ & $(2,09 \pm 0,06) \times 10^{-3}$ & $-1,9$ \\
\hline RQR-2M & \multirow{2}{*}{ Mamo - FD } & $(2,233 \pm 0,018) \times 10^{-3}$ & $(2,242 \pm 0,020) \times 10^{-3}$ & $-0,4$ \\
\hline RQR-4M & & $(2,241 \pm 0,020) \times 10^{-3}$ & $(2,24 \pm 0,03) \times 10^{-3}$ & 0,0 \\
\hline RQA-2M & \multirow{2}{*}{ Mamo - FA } & $(1,28 \pm 0,04) \times 10^{-4}$ & $(1,26 \pm 0,03) \times 10^{-4}$ & 1,6 \\
\hline RQA-4M & & $(1,31 \pm 0,03) \times 10^{-4}$ & $(1,34 \pm 0,03) \times 10^{-4}$ & $-2,2$ \\
\hline
\end{tabular}

RC: Radiodiagnóstico Convencional

CT: Tomografia Computadorizada

Mamo - FD: Mamografia - Feixes diretos

Mamo - FA: Mamografia - Feixes atenuados

Como se pode observar, os valores dos coeficientes de calibração obtidos com a Equação (2.13) são compatíveis e têm uma variação máxima de 3,1\% em relação aos obtidos pelo ajuste linear.

\subsection{Limite Inferior de Detecção - LID}

O limite inferior de detecção é a menor dose que o sistema dosimétrico é capaz de detectar. Ele foi determinado tanto para a técnica de TL quanto para a técnica de OSL utilizando a Equação (2.18) após a determinação da média ponderada pelas 
incertezas da média de 5 leituras da contagem de fundo de cada amostra constituinte do lote. Os resultados estão indicados na Tabela 4.11.

TABELA 4.11 - Valores dos Limites Inferiores de Detecção (LID), pelas técnicas de TL e OSL.

\begin{tabular}{|c|c|c|c|}
\hline \multicolumn{4}{|c|}{ LID (mGy) } \\
\hline $\begin{array}{c}\text { Qualidade de } \\
\text { radiação }\end{array}$ & $\begin{array}{l}\text { Tipo de } \\
\text { radiação }\end{array}$ & TL & OSL \\
\hline RQR 3 & \multirow{4}{*}{$\begin{array}{c}\text { RC } \\
\text { Feixes } \\
\text { diretos }\end{array}$} & $1,59 \pm 0,04$ & $1,03 \pm 0,03$ \\
\hline RQR 5 & & $1,08 \pm 0,03$ & $0,761 \pm 0,004$ \\
\hline RQR 8 & & $2,68 \pm 0,05$ & $3,68 \pm 0,07$ \\
\hline RQR 10 & & $3,79 \pm 0,05$ & $8,62 \pm 0,03$ \\
\hline RQA 3 & \multirow{4}{*}{$\begin{array}{c}\mathrm{RC} \\
\text { Feixes } \\
\text { atenuados }\end{array}$} & $0,292 \pm 0,003$ & $0,437 \pm 0,005$ \\
\hline RQA 5 & & $0,113 \pm 0,003$ & $0,502 \pm 0,004$ \\
\hline RQA 8 & & $0,097 \pm 0,005$ & $0,428 \pm 0,003$ \\
\hline RQA 10 & & $0,114 \pm 0,004$ & $0,604 \pm 0,005$ \\
\hline RQT 8 & \multirow{3}{*}{$\mathrm{CT}$} & $1,61 \pm 0,03$ & $1,31 \pm 0,03$ \\
\hline RQT 9 & & $1,814 \pm 0,013$ & $2,42 \pm 0,10$ \\
\hline RQT 10 & & $1,710 \pm 0,021$ & $3,88 \pm 0,11$ \\
\hline RQR-2M & \multirow{2}{*}{ Mamo - FD } & $0,981 \pm 0,007$ & $1,57 \pm 0,03$ \\
\hline RQR-4M & & $1,19 \pm 0,03$ & $0,841 \pm 0,003$ \\
\hline RQA-2M & \multirow{2}{*}{ Mamo - FA } & $0,1421 \pm 0,0011$ & $0,414 \pm 0,04$ \\
\hline RQA-4M & & $0,0941 \pm 0,0021$ & $0,673 \pm 0,04$ \\
\hline
\end{tabular}

RC: Radiodiagnóstico Convencional

CT: Tomografia Computadorizada

Mamo - FD: Mamografia - Feixes diretos

Mamo - FA: Mamografia - Feixes atenuados

Foi necessário explicitar os valores obtidos para cada qualidade, pois dependem do colimador utilizado na determinação do coeficiente de calibração e, também, devido à flutuação da contagem de fundo da Leitora TL/OSL durante o intervalo de tempo utilizado para as experiências. A flutuação pode ser vista na Figura 4.20. 


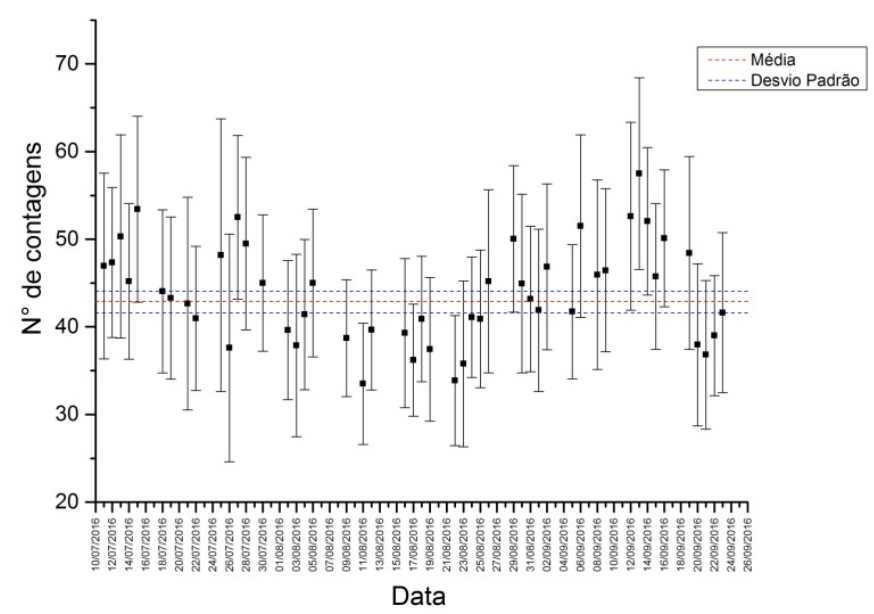

FIGURA 4.20 - Flutuação da contagem de fundo da Leitora TL/OSL da marca RIS $\emptyset^{\mathrm{TM}}$, modelo TL/OSL-DA-20.

Como é possível observar na Figura 4.20, para que se tenha uma leitura de sinal devida a doses baixas, a leitora deve possuir o mínimo de ruído eletrônico, caso contrário não será possível obter uma medição satisfatória.

\subsection{Sensibilidade intrínseca do BeO}

A sensibilidade intrínseca das amostras de $\mathrm{BeO}$ foi determinada por meio da Equação (2.12) para as respostas TL e OSL. Nas Tabelas 4.12 e 4.13 estão apresentados os valores da sensibilidade intrínseca em relação a cada qualidade para as respostas TL e OSL, respectivamente. 
TABELA 4.12- Sensibilidade intrínsica das amostras de $\mathrm{BeO}$ em relação às qualidades de radiação testadas pela técnica de TL.

\begin{tabular}{ccc}
\hline $\begin{array}{c}\text { Qualidade } \\
\text { de radiação }\end{array}$ & $\begin{array}{c}\text { Tipo de } \\
\text { radiação }\end{array}$ & $\begin{array}{c}\text { Sensibilidade } \\
\left(\frac{\text { Cont }}{m G y \times g}\right)\end{array}$ \\
\hline RQR 3 & RC & $\begin{array}{c}(2,07 \pm 0,05) \times 10^{4} \\
(1,99 \pm 0,04) \times 10^{4}\end{array}$ \\
RQR 5 & Feixes diretos & $(7,21 \pm 0,17) \times 10^{3}$ \\
RQR 8 & & $(7,67 \pm 0,17) \times 10^{3}$ \\
RQR 10 & RC & $(29,4 \pm 0,7) \times 10^{4}$ \\
\hline RQA 3 & $(3,77 \pm 0,15) \times 10^{5}$ \\
RQA 5 & Feixes atenuados & $(3,85 \pm 0,12) \times 10^{5}$ \\
RQA 8 & $(34,5 \pm 0,8) \times 10^{4}$ \\
RQA 10 & CT & $(20,3 \pm 0,6) \times 10^{3}$ \\
\hline RQT 8 & & $(18,6 \pm 0,4) \times 10^{3}$ \\
RQT 9 & & $(16,7 \pm 0,5) \times 10^{3}$ \\
RQT 10 & Mamo - FD & $(16,51 \pm 0,22) \times 10^{3}$ \\
\hline RQR 2M & & $(29,4 \pm 0,7) \times 10^{4}$ \\
RQR 4M & & $(27,6 \pm 0,6) \times 10^{4}$ \\
RQA 2M & Mamo - FA & \\
RQA 4M & & \\
\hline RC: Radiodiagnóstico Convencional & \\
CT: Tomografia Computadorizada & \\
Mamo - FD: Mamografia - Feixes diretos \\
Mamo - FA: Mamografia - Feixes atenuados
\end{tabular}


TABELA 4.13 - Sensibilidade intrínseca das amostras de BeO em relação às qualidades de radiação testadas pela técnica de OSL.

\begin{tabular}{ccc}
\hline $\begin{array}{c}\text { Qualidade } \\
\text { de radiação }\end{array}$ & $\begin{array}{c}\text { Tipo de } \\
\text { radiação }\end{array}$ & $\begin{array}{c}\text { Sensibilidade } \\
\left(\frac{\text { Cont }}{m G y \times g}\right)\end{array}$ \\
\hline RQR 3 & RC & $\begin{array}{c}(1,58 \pm 0,13) \times 10^{6} \\
(1,55 \pm 0,13) \times 10^{6} \\
\text { RQR 5 }\end{array}$ \\
RQR 8 & Feixes diretos & $(14,3 \pm 0,5) \times 10^{5}$ \\
RQR 10 & & $(14,0 \pm 0,5) \times 10^{5}$ \\
\hline RQA 3 & RC & $(23,8 \pm 0,3) \times 10^{5}$ \\
RQA 5 & & $(26,8 \pm 0,6) \times 10^{5}$ \\
RQA 8 & Feixes atenuados & $(26,2 \pm 0,6) \times 10^{5}$ \\
RQA 10 & & $(27,6 \pm 0,6) \times 10^{5}$ \\
\hline RQT 8 & & $(1,70 \pm 0,15) \times 10^{6}$ \\
RQT 9 & CT & $(1,46 \pm 0,12) \times 10^{6}$ \\
RQT 10 & & $(1,44 \pm 0,12) \times 10^{6}$ \\
\hline RQR 2M & Mamo - FD & $(1,88 \pm 0,16) \times 10^{6}$ \\
RQR 4M & & $(8,8 \pm 0,7) \times 10^{5}$ \\
RQA 2M & & $(19,1 \pm 0,7) \times 10^{5}$ \\
RQA 4M & Mamo - FA & $(19,8 \pm 0,3) \times 10^{5}$ \\
\hline RC: Radiodiagnóstico Convencional & \\
CT: Tomografia Computadorizada & \\
Mamo - FD: Mamografia - Feixes diretos \\
Mamo - FA: Mamografia - Feixes atenuados
\end{tabular}

Observando as Tabelas 4.12 e 4.13 é possível ver a variação da sensibilidade em relação a cada qualidade de radiação em ambas as técnicas. Isto mostra que há dependência energética da resposta do material no intervalo de energia estudado.

Ao comparar as sensibilidades intrínsecas obtidas para as respostas TL e OSL tem-se a confirmação da alta sensibilidade à luz que o BeO possui, pois a sensibilidade intrínseca obtida com a resposta OSL é maior que a da TL.

\subsection{Dependência Energética}

Neste estudo foi convencionado que a energia efetiva da qualidade de radiação RQA 10 é a energia de referência, pois é a que possui maior energia efetiva dentre as qualidades de radiação estudadas. 
Os coeficientes mássicos de absorção de energia para o Be, O e do Ar foram calculados por interpolação linear a partir dos valores retirados do site do NIST(2016). Na Tabela 4.14 estão os valores dos coeficientes mássicos de absorção para o Be, O e do Ar nas energias efetivas das qualidades estudadas.

TABELA 4.14 - Coeficientes mássicos de absorção de energia para o Ar, O, Be e BeO determinados a partir de NIST (2016).

\begin{tabular}{|c|c|c|c|c|c|}
\hline \multirow{2}{*}{$\begin{array}{l}\text { Qualidade } \\
\text { de radiação }\end{array}$} & \multirow{2}{*}{$\begin{array}{c}\text { Energia } \\
(\mathrm{keV})\end{array}$} & \multicolumn{4}{|c|}{$\left(\frac{\mu_{e n}}{\rho}\right)\left(\mathrm{cm}^{2} / \mathrm{g}\right)$} \\
\hline & & $\mathrm{Ar}$ & $\mathrm{Be}$ & 0 & $\mathrm{BeO}$ \\
\hline RQR - 2M & 18,62 & $0,7584 \pm 0,0004$ & $0,0662 \pm 0,0004$ & $0,8738 \pm 0,0004$ & $0,5827 \pm 0,0004$ \\
\hline$R Q R-4 M$ & 21,64 & $0,4757 \pm 0,0004$ & $0,0431 \pm 0,0004$ & $0,5449 \pm 0,0004$ & $0,3641 \pm 0,0003$ \\
\hline RQA - $2 M$ & 15,70 & $1,2227 \pm 0,0004$ & $0,1050 \pm 0,0004$ & $1,4151 \pm 0,0004$ & $0,9430 \pm 0,0007$ \\
\hline RQA - 4M & 16,25 & $1,1352 \pm 0,0004$ & $0,0977 \pm 0,0004$ & $1,3132 \pm 0,0004$ & $0,8751 \pm 0,0007$ \\
\hline RQR 3 & 29,70 & $0,1653 \pm 0,0005$ & $0,0199 \pm 0,0005$ & $0,1863 \pm 0,0005$ & $0,12628 \pm 0,00010$ \\
\hline RQR 5 & 34,00 & $0,1196 \pm 0,0004$ & $0,0171 \pm 0,0004$ & $0,1339 \pm 0,0004$ & $0,0918 \pm 0,0008$ \\
\hline RQR 8 & 38,10 & $0,0846 \pm 0,0004$ & $0,0153 \pm 0,0004$ & $0,0939 \pm 0,0004$ & $0,0655 \pm 0,0006$ \\
\hline RQR 10 & 46,50 & $0,0506 \pm 0,0004$ & $0,0141 \pm 0,0004$ & $0,0551 \pm 0,0004$ & $0,0403 \pm 0,0006$ \\
\hline RQA 3 & 37,70 & $0,0880 \pm 0,0005$ & $0,0154 \pm 0,0005$ & $0,0978 \pm 0,0005$ & $0,0689 \pm 0,0006$ \\
\hline RQA 5 & 47,60 & $0,0475 \pm 0,0004$ & $0,0141 \pm 0,0004$ & $0,0516 \pm 0,0004$ & $0,0381 \pm 0,0005$ \\
\hline RQA 8 & 65,10 & $0,0288 \pm 0,0004$ & $0,0152 \pm 0,0004$ & $0,0302 \pm 0,0004$ & $0,0248 \pm 0,0004$ \\
\hline RQA 10 & 83,10 & $0,0239 \pm 0,0004$ & $0,0169 \pm 0,0004$ & $0,0245 \pm 0,0004$ & $0,0218 \pm 0,0004$ \\
\hline RQT 8 & 48,00 & $0,0465 \pm 0,0004$ & $0,0141 \pm 0,0004$ & $0,0504 \pm 0,0004$ & $0,0373 \pm 0,0005$ \\
\hline RQT 9 & 55,60 & $0,0351 \pm 0,0004$ & $0,0144 \pm 0,0004$ & $0,0374 \pm 0,0004$ & $0,0291 \pm 0,0005$ \\
\hline RQT 10 & 65,10 & $0,0288 \pm 0,0004$ & $0,0152 \pm 0,0004$ & $0,0302 \pm 0,0004$ & $0,0248 \pm 0,0004$ \\
\hline
\end{tabular}

Para o BeO, a dependência energética das respostas TL e OSL, determinada pelas Equações (2.15), (2.16) e (2.17) com as energias efetivas de cada qualidade de radiação testada, está indicada na Tabela 4.15 e na Figura 4.21. 
TABELA 4.15 - Dependência energética do BeO em relação ao ar, $S(E)$, e dependência energética relativa, $\mathrm{RER}$, à energia de $83,10 \mathrm{keV}$ em relação ao ar.

\begin{tabular}{ccccc}
\hline $\begin{array}{c}\text { Tipo de } \\
\text { radiação }\end{array}$ & $\begin{array}{c}\text { Qualidade de } \\
\text { radiação }\end{array}$ & $\begin{array}{c}\text { Energia } \\
(\mathrm{keV})\end{array}$ & S(E) & RER \\
\hline \multirow{2}{*}{ Mamo - FD } & RQR - 2M & 18,62 & $0,7684 \pm 0,0007$ & $0,846 \pm 0,017$ \\
& RQR - 4M & 21,64 & $0,7653 \pm 0,0009$ & $0,843 \pm 0,017$ \\
Mamo - FA & RQA - 2M & 15,70 & $0,7713 \pm 0,0006$ & $0,849 \pm 0,018$ \\
& RQA - 4M & 16,25 & $0,7709 \pm 0,0006$ & $0,849 \pm 0,018$ \\
\hline \multirow{2}{*}{ RC } & RQR 3 & 29,70 & $0,7641 \pm 0,0023$ & $0,842 \pm 0,018$ \\
Feixes diretos & RQR 5 & 34,00 & $0,7678 \pm 0,0024$ & $0,846 \pm 0,018$ \\
& RQR 8 & 38,10 & $0,775 \pm 0,004$ & $0,854 \pm 0,018$ \\
RC & RQR 10 & 46,50 & $0,797 \pm 0,007$ & $0,878 \pm 0,019$ \\
\hline Feixes & RQA 3 & 37,70 & $0,774 \pm 0,004$ & $0,852 \pm 0,018$ \\
atenuados & RQA 5 & 47,60 & $0,801 \pm 0,007$ & $0,882 \pm 0,019$ \\
& RQA 8 & 65,10 & $0,860 \pm 0,012$ & $0,947 \pm 0,023$ \\
& RQA 10 & 83,10 & $0,908 \pm 0,016$ & $1,00 \pm 0,03$ \\
\hline \multirow{2}{*}{ CT } & RQT 8 & 48,00 & $0,803 \pm 0,007$ & $0,884 \pm 0,020$ \\
& RQT 9 & 55,60 & $0,830 \pm 0,009$ & $0,914 \pm 0,021$ \\
& RQT 10 & 65,10 & $0,860 \pm 0,012$ & $0,947 \pm 0,023$ \\
\hline
\end{tabular}

RC: Radiodiagnóstico Convencional

CT: Tomografia Computadorizada

Mamo - FD: Mamografia - Feixes diretos

Mamo - FA: Mamografia - Feixes atenuados 


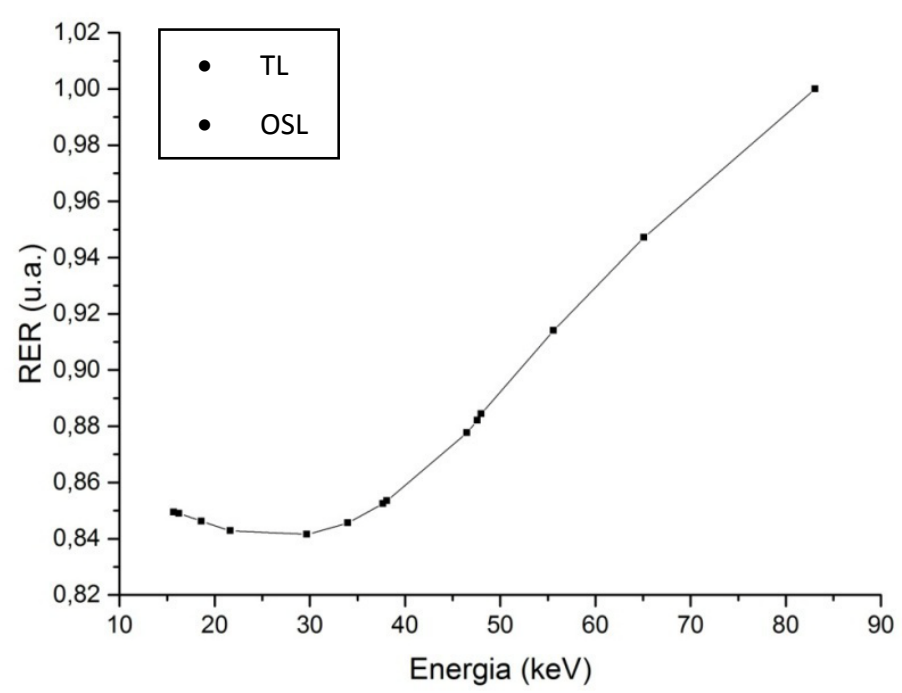

FIGURA 4.21 - Dependência energética relativa das respostas TL e OSL do BeO. A incerteza máxima dos pontos experimentais é de 3\%, não visível na figura.

A Figura 4.21 apresenta a variação das respostas TL e OSL em função da energia efetiva dos feixes das qualidades de radiação estudadas. Nota-se uma variação máxima de $17,7 \%$ na resposta em relação às energias testadas. Este resultado está de acordo com outros trabalhos (TOCHILIN et al, 1969; BASSI et al, 1976; SANTOS et al, 2015).

Como mencionado no item 4.9, realmente existe uma dependência energética do BeO no intervalo de energia estudado. Por este motivo foi realizado um cálculo utilizando os coeficientes de calibração.

Este cálculo utiliza a seguinte equação:

$$
R E R=\frac{C_{c(r e f)}}{C_{C(i)}}
$$

onde $C_{c \text { (ref) }}$ é o coeficiente de calibração de um feixe tomado como referência e $C_{C(i)}$ o coeficiente de calibração das demais qualidades de radiação.

Na Tabela 4.16 estão os resultados dos cálculos com a Equação (4.3). 
TABELA 4.16 - Dependência energética relativa (RER) do BeO.

\begin{tabular}{cccc}
\hline Tipo de & Qualidade de & \multicolumn{2}{c}{ RER } \\
\cline { 3 - 4 } radiação & radiação & TL & OSL \\
& RQR 3 & $(0,0598 \pm 0,0015)$ & $(0,0534 \pm 0,0014)$ \\
RC & RQR 5 & $(0,0578 \pm 0,0011)$ & $(0,05925 \pm 0,0012)$ \\
Feixes diretos & RQR 8 & $(0,0209 \pm 0,0003)$ & $(0,01705 \pm 0,00022)$ \\
& RQR 10 & $(0,0222 \pm 0,0003)$ & $(0,0167 \pm 0,0003)$ \\
\hline \multirow{2}{*}{ RC } & RQA 3 & $(0,849 \pm 0,016)$ & $(0,863 \pm 0,024)$ \\
& RQA 5 & $(1,092 \pm 0,012)$ & $(0,971 \pm 0,015)$ \\
& RQA 8 & $(1,115 \pm 0,022)$ & $(0,950 \pm 0,0017)$ \\
& RQA 10 & $(1,000 \pm 0,016)$ & $(1,000 \pm 0,016)$ \\
\hline CT & RQT 8 & $(0,0588 \pm 0,012)$ & $(0,0558 \pm 0,0015)$ \\
& RQT 9 & $(0,0540 \pm 0,0010)$ & $(0,0494 \pm 0,0006)$ \\
& RQT 10 & $(0,0512 \pm 0,0009)$ & $(0,0489 \pm 0,0012)$ \\
\hline Mamo - FA & RQR-2M & $(0,0477 \pm 0,0007)$ & $(0,0938 \pm 0,0007)$ \\
& RQA-4M & $(0,799 \pm 0,020)$ & $(0,717 \pm 0,017)$ \\
& RQR-4M & $(0,0478 \pm 0,0007)$ & $(0,0300 \pm 0,0005)$ \\
& Ramo - FD & $(0,85 \pm 0,03)$ & $(0,691 \pm 0,019)$ \\
& RQA & &
\end{tabular}

RC: Radiodiagnóstico Convencional

CT: Tomografia Computadorizada

Mamo - FD: Mamografia - Feixes diretos

Mamo - FA: Mamografia - Feixes atenuados

Observando as Tabelas 4.15 e 4.16 observa-se que a resposta em energia determinada com a Equação (2.16) não condiz com a determinada experimentalmente com o auxílio da Equação (4.3), principalmente quando se observa os pontos referentes às qualidades de radiação RQT 10 e RQA 8, cuja energia efetiva é a mesma para ambas as qualidades e esperava-se o mesmo resultado para as duas, tanto com a leitura TL quanto para leitura OSL.

Esta discrepância pode ser explicada devido às impurezas com alto número atômico encontradas nas amostras de $\mathrm{BeO}$ e, também, pelo fato de se considerar a 
energia efetiva de um feixe polienergético, como é o caso das qualidades de radiação estudadas, em vez de se considerar o espectro, não seja correto para o estudo da dependência energética. As impurezas encontradas nas amostras de $\mathrm{BeO}$ foram citadas por Groppo e elas são: Fe $(Z=26)$, Co $(Z=29)$, Si $(Z=14), \mathrm{K}(Z=19)$ e $\mathrm{Al}(Z=13)$ (GROPPO, 2013).

Ao se analisar a Figura 4.21, verifica-se que a dependência energética da resposta é a mesma para ambas as técnicas TL e OSL, o que é esperado pela teoria (TOCHILIN et al, 1969; BASSI et al, 1976; CHEN, MCKEEVER, 1997; FURETTA, WENG, 1998; FURETTA, 2003; CHEN, PAGONIS, 2011; SANTOS et al, 2015).

\subsection{Determinação da Energia de Ativação e do Fator de Frequência}

Os cálculos da energia de ativação foram realizados utilizando os métodos de formato de pico de Chen, Lushchik, Grosswiener, Halperin e Braner, o método da área sob a curva e o método de Urbach (BACCl et al, 1989; CHEN, McKEEVER, 1997; FURETTA, 2003); para o fator de frequência, foi utilizado o método de Chen (BACCl et al, 1989; CHEN, McKEEVER, 1997; FURETTA, 2003).

Na Tabela 4.17 estão os valores obtidos da curva de emissão TL, das temperaturas onde ocorre a intensidade máxima da emissão TL e a metade da intensidade máxima da emissão TL e na Tabela 4.18 estão os valores dos parâmetros do método de formato de pico calculados com a Equação (3.3).

TABELA 4.17 - Temperaturas da intensidade máxima $\left(T_{M}\right)$ e da metade da intensidade máxima $\left(T_{1}\right.$ e $\left.T_{2}\right)$ dos picos $T L$ do $B e O$.

\begin{tabular}{cccc}
\hline Pico & $\mathrm{T}_{\mathrm{M}}$ & $\mathrm{T}_{1}$ & $\mathrm{~T}_{2}$ \\
$\mathrm{TL}$ & $(\mathrm{K})$ & $(\mathrm{K})$ & $(\mathrm{K})$ \\
\hline Primeiro & $474,7 \pm 1,2$ & $449,5 \pm 1,2$ & $500,0 \pm 1,2$ \\
Segundo & $620,5 \pm 1,2$ & $586,3 \pm 1,2$ & $645,8 \pm 1,2$ \\
\hline
\end{tabular}


TABELA 4.18 - Parâmetros utilizados nos métodos de formato de pico.

\begin{tabular}{ccccc}
\hline Pico & $\boldsymbol{\omega}(\mathrm{K})$ & $\boldsymbol{\delta}(\mathrm{K})$ & $\boldsymbol{\tau}(\mathrm{K})$ & $\boldsymbol{\mu}$ \\
$\mathrm{TL}$ & $\left(\mathrm{T}_{2}-\mathrm{T}_{1}\right)$ & $\left(\mathrm{T}_{2}-\mathrm{T}_{\mathrm{M}}\right)$ & $\left(\mathrm{T}_{2}-\mathrm{T}_{1}\right)$ & $(\delta / \omega)$ \\
\hline Primeiro & $50,40 \pm 0,13$ & $25,20 \pm 0,13$ & $25,20 \pm 0,13$ & $0,500 \pm 0,003$ \\
Segundo & $59,40 \pm 0,13$ & $25,20 \pm 0,13$ & $34,20 \pm 0,13$ & $0,424 \pm 0,003$ \\
\hline
\end{tabular}

Utilizando o método da área sob a curva TL, para o ajuste das curvas dos picos do $\mathrm{BeO}$ foi considerado que a ordem cinética do primeiro pico está entre 1,0 e 2,0 e do segundo pico entre 0,7 e 2,0. Os resultados dos ajustes estão na Figura 4.22.

(a)

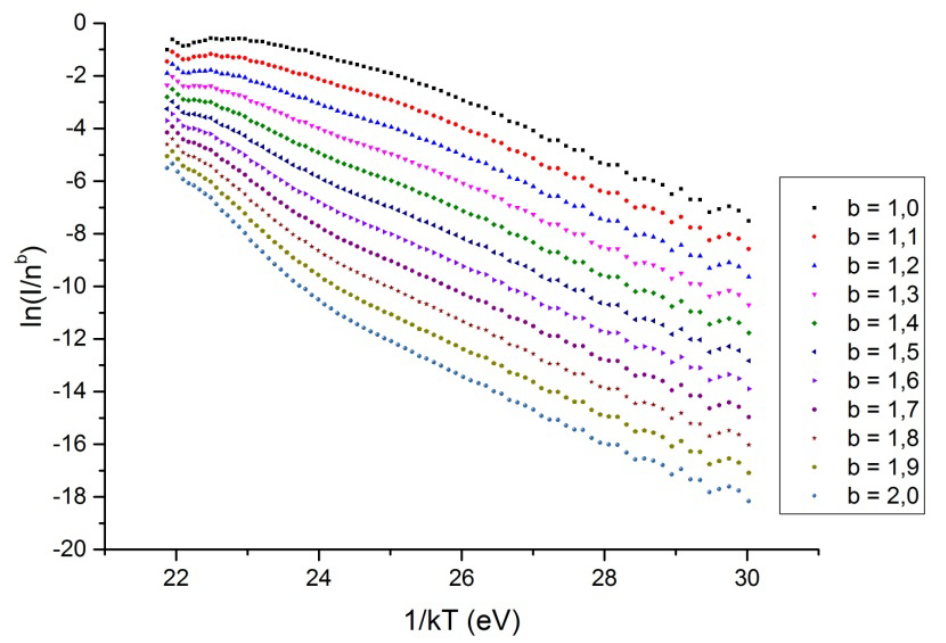

(b)

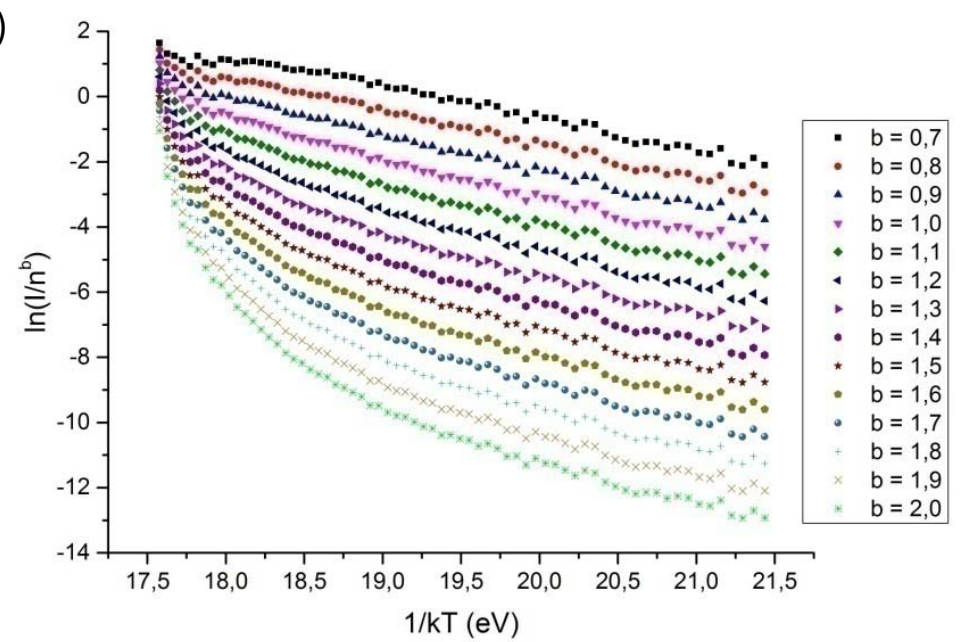

FIGURA 4.22 - Determinação das ordens cinéticas do (a) primeiro pico TL e do (b) segundo pico TL do BeO com o método da área sob a curva TL. 
Para se determinar qual o melhor ajuste linear e, consequentemente a ordem cinética, foi considerado o fator de correlação mais próximo de 1 obtido com o software Origin, indicado na Figura 4.23.

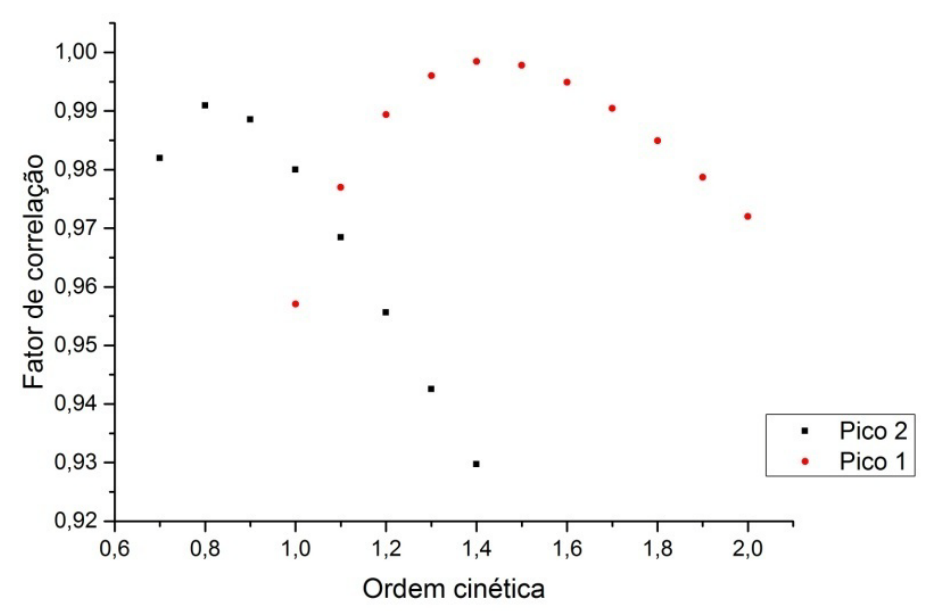

FIGURA 4.23 - Fator de correlação versus ordem cinética dos picos TL 1 e 2 do BeO.

O valor da ordem cinética para o primeiro pico é de $(1,40 \pm 0,20)$ e para o segundo pico é de $(0,80 \pm 0,20)$.

Os valores da energia de ativação e do fator de frequência determinados com os métodos empregados neste trabalho estão indicados nas Tabelas 4.19 e 4.20 e nas Tabelas 4.21 e 4.22 estão os valores obtidos por Bacci et al (1989). 
TABELA 4.19 - Energia de ativação e fator de frequência para o primeiro pico do BeO.

\begin{tabular}{cccc}
\hline & \multicolumn{3}{c}{ Primeiro pico TL } \\
\cline { 2 - 4 } Métodos & Energia de ativação & Fator de frequência & Ordem cinética \\
& $0,9495 \pm 0,0004$ & $\left(\mathrm{~s}^{-1}\right)$ & 1 \\
\hline Urbach & $1,226 \pm 0,006$ & $(3,07 \pm 0,21) \times 10^{12}$ & 2 \\
Grosswiener & $1,315 \pm 0,007$ & $(2,89 \pm 0,04) \times 10^{13}$ & 2 \\
Lushchik & $1,234 \pm 0,007$ & $(3,72 \pm 0,06) \times 10^{12}$ & 2 \\
Halperin e Braner & $1,149 \pm 0,005$ & $(4,53 \pm 0,04) \times 10^{11}$ & $1,40 \pm 0,20$ \\
Área & $1,204 \pm 0,012$ & $(1,74 \pm 0,03) \times 10^{12}$ & $1,60 \pm 0,10$ \\
Chen $(\omega)$ & $1,19 \pm 0,02$ & $(1,294 \pm 0,021) \times 10^{12}$ & $1,60 \pm 0,10$ \\
$(\tau)$ & $1,202 \pm 0,017$ & $(1,682 \pm 0,021) \times 10^{12}$ & $1,60 \pm 0,10$ \\
$(\delta)$ & $1,2715 \pm 0,0010$ & $(9,715 \pm 0,015) \times 10^{12}$ & 2 \\
$(\omega)$ & & &
\end{tabular}

TABELA 4.20 - Energia de ativação e fator de frequência para o segundo pico TL do BeO.

\begin{tabular}{cccc}
\hline & \multicolumn{3}{c}{ Segundo pico TL } \\
Métodos & $(\mathrm{eV})$ & $\left(\mathrm{s}^{-1}\right)$ & 1 \\
\cline { 2 - 4 } & Energia de ativação & Fator de frequência & Ordem cinética \\
\hline Urbach & $1,2411 \pm 0,0004$ & $10^{9}$ & 1 \\
Grosswiener & $1,293 \pm 0,006$ & $(6,14 \pm 0,09) \times 10^{9}$ & 1 \\
Lushchik & $1,285 \pm 0,012$ & $(5,31 \pm 0,08) \times 10^{9}$ & 1 \\
Halperin e Braner & $1,306 \pm 0,007$ & $(7,93 \pm 0,10) \times 10^{9}$ & $0,80 \pm 0,20$ \\
Área & $1,240 \pm 0,012$ & $(2,13 \pm 0,03) \times 10^{9}$ & $1,00 \pm 0,10$ \\
Chen $(\omega)$ & $1,325 \pm 0,014$ & $(1,152 \pm 0,021) \times 10^{10}$ & $1,00 \pm 0,10$ \\
$(\tau)$ & $1,317 \pm 0,014$ & $(8,048 \pm 0,010) \times 10^{9}$ & $1,00 \pm 0,10$ \\
$(\delta)$ & $1,326 \pm 0,004$ & $(1,174 \pm 0,022) \times 10^{10}$ & 1,00 \\
$(\omega)$ & $1,2793 \pm 0,0011$ & $(4,73 \pm 0,07) \times 10^{9}$ & 1 \\
\hline
\end{tabular}


TABELA 4.21 - Energia de ativação e fator de frequência para o primeiro pico TL do BeO, informação extraída de Bacci et al (1989).

\begin{tabular}{cccc}
\hline & \multicolumn{3}{c}{ Primeiro pico TL } \\
Métodos & $(\mathrm{eV})$ & $\left(\mathrm{s}^{-1}\right)$ & Ordem cinética \\
\cline { 2 - 4 } & $0,99 \pm 0,01$ & $10^{9}$ & 2 \\
\hline Urbach & $1,47 \pm 0,02$ & $(1,0 \pm 0,2) \times 10^{15}$ & 2 \\
Grosswiener & $1,55 \pm 0,02$ & $(7,1 \pm 0,3) \times 10^{15}$ & 2 \\
Lushchik & $1,49 \pm 0,03$ & $(1,6 \pm 0,2) \times 10^{15}$ & $1,61 \pm 0,04$ \\
Halperin e Braner & $1,14 \pm 0,01$ & $(2,4 \pm 0,5) \times 10^{14}$ & $1,7 \pm 0,2$ \\
Área & $1,45 \pm 0,05$ & $(6,4 \pm 0,2) \times 10^{14}$ & $1,7 \pm 0,2$ \\
Chen $(\omega)$ & $1,45 \pm 0,05$ & $(6,4 \pm 0,1) \times 10^{14}$ & $1,7 \pm 0,2$ \\
$(\tau)$ & $1,43 \pm 0,05$ & $(3,9 \pm 0,3) \times 10^{14}$ & 2 \\
$(\delta)$ & $1,52 \pm 0,01$ & $(3,4 \pm 0,2) \times 10^{14}$ & \\
$\left(\omega^{\prime}\right)$ & & & \\
\hline
\end{tabular}

TABELA 4.22 - Energia de ativação e fator de frequência para o segundo pico do BeO, informação extraída de Bacci et al (1989).

\begin{tabular}{cccc}
\hline & \multicolumn{3}{c}{ Segundo pico TL } \\
Métodos & $(\mathrm{eV})$ & $\left(\mathrm{s}^{-1}\right)$ & Ordem cinética \\
\cline { 2 - 4 } & $1,28 \pm 0,01$ & $10^{9}$ & \\
\hline Urbach & $1,24 \pm 0,05$ & $(3,1 \pm 0,4) \times 10^{9}$ & 1 \\
Grosswiener & $1,36 \pm 0,06$ & $(3,0 \pm 0,2) \times 10^{9}$ & 1 \\
Lushchik & $1,25 \pm 0,06$ & $(3,7 \pm 0,4) \times 10^{9}$ & 1 \\
Halperin e Braner & $1,27 \pm 0,03$ & $(5,4 \pm 0,2) \times 10^{9}$ & $1,0 \pm 0,2$ \\
Área & $1,19 \pm 0,08$ & $(1,2 \pm 0,2) \times 10^{9}$ & $1,0 \pm 0,1$ \\
Chen $(\omega)$ & $1,19 \pm 0,07$ & $(1,2 \pm 0,5) \times 10^{9}$ & $1,0 \pm 0,1$ \\
$(\tau)$ & $1,16 \pm 0,09$ & $(0,7 \pm 0,1) \times 10^{9}$ & $1,0 \pm 0,1$ \\
$(\delta)$ & $1,29 \pm 0,05$ & $(7,9 \pm 0,2) \times 10^{9}$ & 1 \\
$\left(\omega^{\prime}\right)$ & & &
\end{tabular}


Analisando as Tabelas 4.19 e 4.20, é possível ver a concordância dos valores obtidos com os diferentes métodos. Os valores obtidos com os métodos de formato de pico e o de área estão mais de acordo entre si que o método de Urbach para o primeiro pico. Isto ocorre, porque Urbach considerou o valor do fator de frequência igual a $10^{9} \mathrm{~s}^{-1}$ ao desenvolver seu método de cálculo para a energia de ativação (BACCl et al, 1989; CHEN, MCKEEVER, 1997; FURETTA, 2003).

De acordo com Chen, os valores de energia de ativação envolvenđœ $\omega$ resultam em uma avaliação inadequada, onde as equações que utilizaño mais corretas (BACCl et al, 1989).

Ao comparar os valores das Tabelas $4.19,4.20,4.21$ e 4.22 conclui-se que as energias de ativação e os fatores de frequência não estão de acordo. Isto ocorre, porque as amostras de $\mathrm{BeO}$ utilizadas neste estudo têm impurezas que não existem nas amostras estudadas por Bacciet al, que influenciam os tipos de armadilhas possivelmente no material. Na Tabela 4.23 estão as impurezas encontradas nas amostras de BeO estudadas neste trabalho e as de Bacci et al (1989), para comparação.

TABELA 4.23 - Impurezas nas amostras de BeO.

\begin{tabular}{cc}
\hline & Impurezas \\
\hline Neste estudo (GROPPO, 2013) & $\mathrm{Si}, \mathrm{K}, \mathrm{Fe}, \mathrm{Al}$ e Co \\
Bacci et al (BACCl et al, 1989) & $\mathrm{Mg}$ e Si \\
\hline
\end{tabular}

\subsection{Deconvolução do Sinal TL}

A deconvolução da curva de emissão TL foi obtida utilizando um software desenvolvido neste estudo com base nas Equações (3.17), (3.18), (3.19) e (3.20), e considerando os valores de energia de ativação e fator de frequência obtidos com todos os métodos empregados neste trabalho indicados nas Tabelas 4.19 e 4.20.

Os resultados estão indicados nas Figuras 4.24, 4.25 e 4.26. 


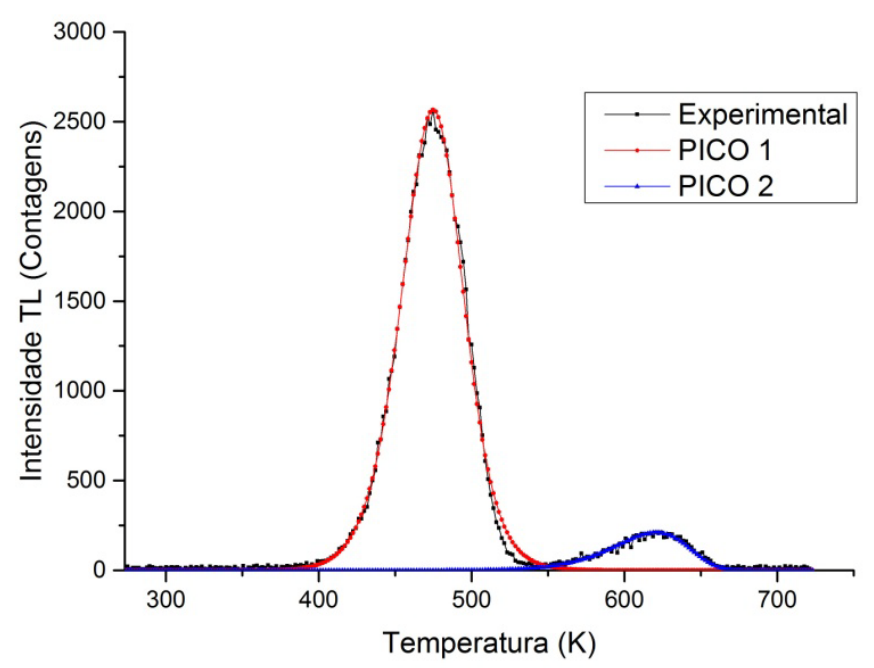

FIGURA 4.24 - Deconvolução da curva de emissão TL do BeO utilizando os valores de fator de frequência e energia de ativação obtido pelo método de Chen com o parâmetro $\delta$.

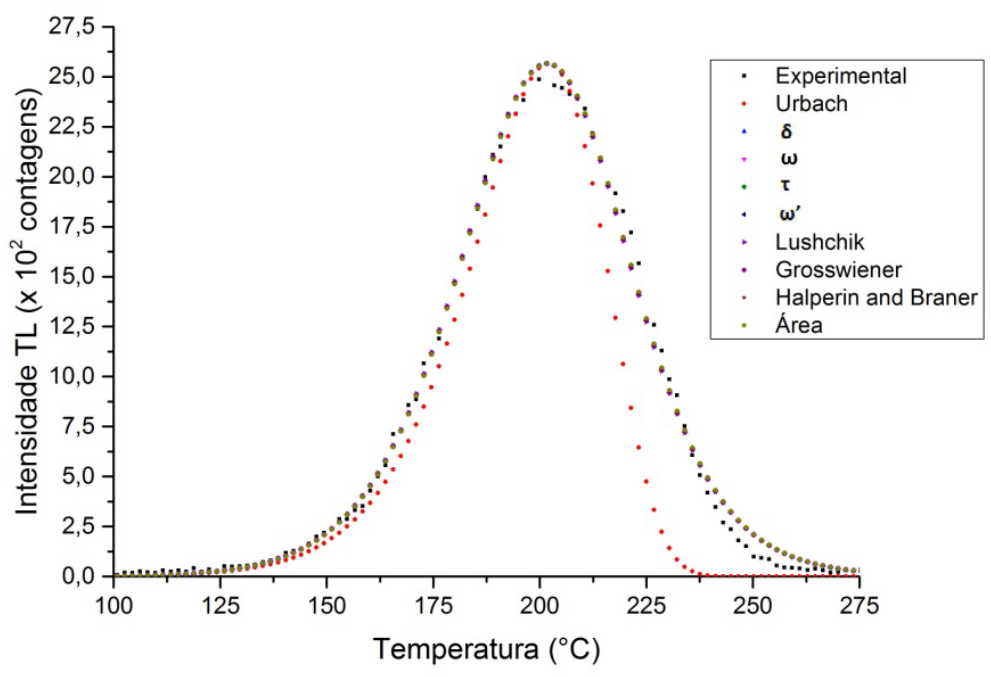

FIGURA 4.25 - Deconvolução do primeiro pico da curva de emissão TL do BeO utilizando os valores de fator de frequência e energia de ativação da Tabela 4.18. 


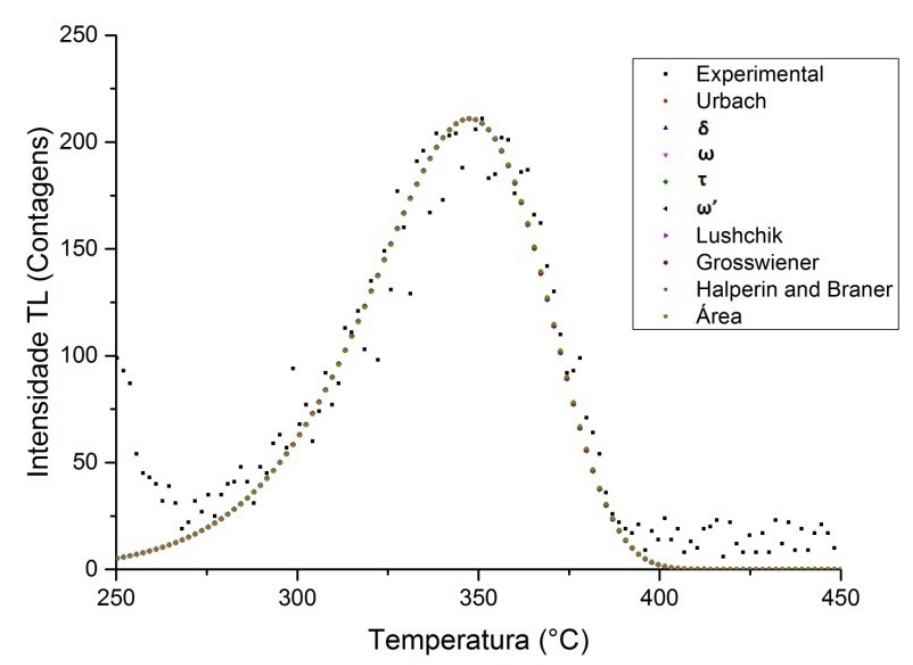

FIGURA 4.26 - Deconvolução do segundo pico da curva de emissão TL do BeO utilizando os valores de fator de frequência e energia de ativação da Tabela 4.19.

Comparando as curvas obtidas com a deconvolução, utilizando os valores de energia de ativação e de fator de frequência das Tabelas 4.19 e 4.20, é possível verificar que não existem grandes diferenças entre elas, somente na curva que utilizou os parâmetros cinéticos obtidos com o método de Urbah. Deste modo, qualquer método de determinação do fator de frequência e da energia de ativação, exceto o método de Urbach, é aceitável.

\subsection{Sinal Residual}

O estudo do sinal residual apresenta o quanto de sinal permanece na amostra após uma leitura TL e/ou OSL. Para verificar esse sinal, as amostras de BeO foram irradiadas com 18,3 mGy, 36,6 mGy, 73,2 mGy e 109,8 mGy de dose na qualidade de radiação $R Q R$ 5; estas doses e esta qualidade foram selecionadas arbitrariamente, realizado uma leitura TL ou OSL e uma leitura TL logo em sequência. Na Tabela 4.24 estão os resultados da segunda leitura e na Figura 4.27 estão representadas as curvas de emissão TL obtidas após as leituras OSL. 
TABELA 4.24 - Sinal Residual após leituras TL e OSL

TL

\begin{tabular}{|c|c|c|c|c|}
\hline $\begin{array}{c}\text { Dose } \\
\text { Absorvida } \\
\text { (mGy) }\end{array}$ & $\begin{array}{c}\text { Contagem de Fundo } \\
\text { (u.a.) }\end{array}$ & $\begin{array}{c}\text { Sinal } \\
\text { Residual } \\
\text { (u.a.) }\end{array}$ & $\begin{array}{l}\text { Contagem de } \\
\text { Fundo } \\
\text { (u.a.) }\end{array}$ & $\begin{array}{c}\text { Sinal } \\
\text { Residual } \\
\text { (u.a.) }\end{array}$ \\
\hline 18,3 & \multirow{3}{*}{$(3,47 \pm 0,11) \times 10^{3}$} & $(3,39 \pm 0,11) \times 10^{3}$ & & $(3,76 \pm 0,12) \times 10^{3}$ \\
\hline 36,6 & & $\begin{array}{c}(3,41 \pm 0,13) \times 10^{3} \\
(3,387 \pm 0,010) \times 10^{3}\end{array}$ & $(3,86 \pm 0,15) \times 10^{3}$ & $\begin{array}{l}(20,3 \pm 0,3) \times 10^{3} \\
(35,9 \pm 0,4) \times 10^{3}\end{array}$ \\
\hline 109,8 & & $(3,50 \pm 0,13) \times 10^{3}$ & & $(51,3 \pm 0,6) \times 10^{3}$ \\
\hline
\end{tabular}

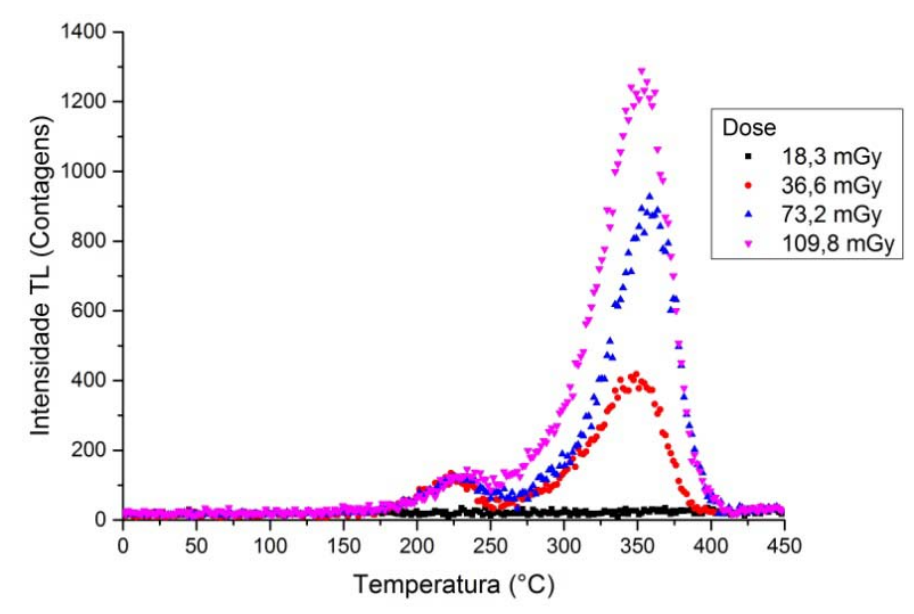

FIGURA 4.27 - Emissão TL após uma leitura OSL para diversas doses absorvidas.

Como pode ser observado na Figura 4.27, a leitura TL para a dose de 18,3 mGy não foi detectada; isto não significa que o processo de leitura OSL esvaziou todas as armadilhas, pois nesta qualidade de radiação utiliza-se um colimador que diminui a quantidade de fótons que chegam à fotomultiplicadora. No entanto, para as demais doses foi observada uma resposta TL indicando que a leitura OSL não esvazia todas as armadilhas, necessitando de um tratamento óptico das amostras antes de sua reutilização.

Outro aspecto interessante observado na Figura 4.27 é que a leitura OSL esvazia praticamente $100 \%$ as armadilhas correspondentes ao primeiro pico, o que não ocorre com o segundo pico TL. Este fato possibilita a calibração dessas amostras para ambas as técnicas, irradiando-as uma única vez. Deste modo, o tempo para calibrar as amostras de $\mathrm{BeO}$ para ambas as técnicas pode ser reduzido, ou ainda pode-se obter uma 
segunda estimativa da dose recebida pela amostra caso fiquem dúvidas na primeira medição.

\subsection{Desvanecimento da Resposta TL e OSL (Fading)}

O desvanecimento da resposta (Fading) é o quanto de resposta é perdido ao longo do tempo à temperatura ambiente. Seu estudo é importante para saber por quanto tempo as armadilhas conseguem manter os elétrons presos. Isto também ajuda nos casos onde o intervalo de tempo entre a exposição até a leitura seja longo.

Neste estudo foi utilizada uma dose absorvida de $115 \mathrm{mGy}$ na qualidade RQR 10, escolhida arbitrariamente. Os intervalos de tempo, entre a irradiação e a leitura, escolhidos para este estudo foram 0, 7, 15 e 30 dias, onde 0 é a medição logo após a irradiação. O lote das amostras foi irradiado somente uma vez para cada intervalo de tempo.

Os resultados para o desvanecimento TL e OSL estão indicados nas Figuras 4.28 e 4.29 respectivamente.

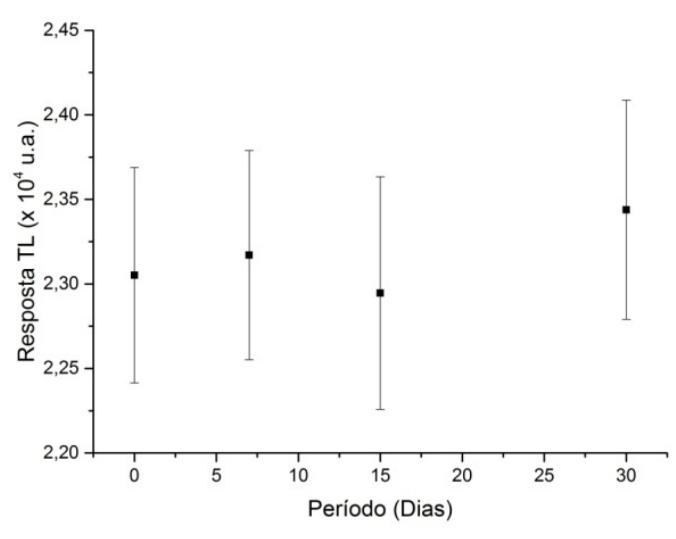

FIGURA 4.28 - Desvanecimento da resposta (Fading) TL. 


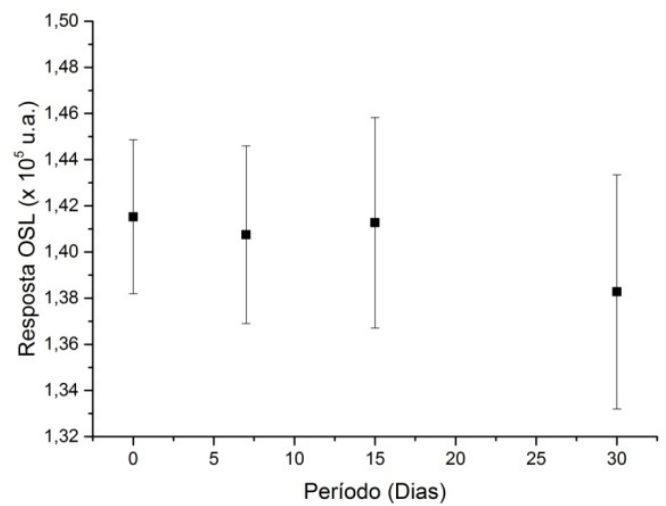

FIGURA 4.29 - Desvanecimento da resposta (Fading) OSL.

Conforme apresentado nas Figuras 4.28 e 4.29 não há desvanecimento das respostas TL e OSL no período estudado e está de acordo com estudos apresentados em outros trabalhos na literatura (VIJ, SINGH, 1997; YUKIHARA, McKEEVER, 2011; SOUZA et al, 2014). A variação máxima obtida para o desvanecimento da resposta TL foi de $2,15 \%$ e para o desvanecimento da resposta OSL foi de $2,35 \%$, portanto dentro da variação máxima permitida pelo teste de reprodutibilidade obtido neste trabalho $(4,9 \%)$. 


\section{CONCLUSÕES}

Os resultados obtidos neste trabalho são de grande interesse para a caracterização de materiais a serem empregados como dosímetros.

O estudo da influência da lâmpada fosforescente do laboratório durante a irradiação das amostras resultou que todas as irradiações devem ocorrer com a lâmpada apagada. No estudo dos colimadores da leitora RISÖ determinou-se quais colimadores são necessários para cada qualidade de radiação estudada. O estudo do tratamento térmico determinou que o tratamento térmico a $500^{\circ} \mathrm{C}$ por 15 minutos deve ser realizado para a reutilização do material.

A tampa de acrílico de $1 \mathrm{~mm}$ do suporte tem influência mínima, não sendo significativa, na resposta do material, podendo ser utilizada, na faixa de energia estudada.

Os testes de reprodutibilidade e homogeneidade propiciaram a determinação do lote de amostras de $\mathrm{BeO}$ que foram utilizadas ao longo deste trabalho. O maior coeficiente de variação obtido no estudo da reprodutibilidade foi de $4,9 \%$, no entanto após o teste de homogeneidade o maior coeficiente de variação foi de 4,7\%, representando, em ambos os casos, uma ótima reprodutibilidade, sendo inferiores a $5 \%$.

$\mathrm{O}$ BeO apresenta resposta adequada em dosimetria das radiações para ambas as técnicas TL e OSL; no entanto, ele é mais sensível à OSL. Seus parâmetros cinéticos correspondem aos valores obtidos em todos os métodos, exceto pelo método de Urbach,o que fica evidente na deconvolução da curva de emissão TL quando comparado à curva de emissão TL obtida experimentalmente.

A dependência energética, no intervalo de energia estudado, é um parâmetro que deve ser levado em consideração e a melhor opção é obter uma curva de doseresposta para cada qualidade de radiodiagnóstico convencional, mamografia e tomografia computadorizada, como foi realizado neste trabalho.

Ao longo deste trabalho foi observada uma flutuação na contagem de fundo da leitora RISÖ TL/OSL, que deve ser levado em consideração. Uma flutuação elevada impede de se obter uma medição de doses baixas. É necessário controle e revisão da leitora RISÖ TL/OSL para diminuir a flutuação da contagem de fundo.

As amostras de $\mathrm{BeO}$ apresentaram nos estudos do desvanecimento da resposta uma variação de 2,15\% para a resposta TL e de 2,35\% para a resposta OSL. Esta 
variação está dentro da variação permitida pelo estudo da reprodutibilidade, portanto, não teve desvanecimento da resposta dentro do intervalo de tempo estudado. Este resultado está de acordo com os resultados obtidos por outros autores.

Existe um sinal residual após as leituras OSL que pode ser utilizado para se obter curvas de dose-resposta TL. Isto possibilita obter duas curvas dose-resposta, uma para OSL e outra para TL, com uma única irradiação, realizando uma leitura TL após uma leitura OSL.

O BeO apresenta potencial de utilização como dosímetro em clínicas e hospitais que realizam exames com as qualidades de radiação testadas neste trabalho, ou seja, em feixes de radiodiagnóstico convencional, mamografia e tomografia computadorizada. 


\section{REFERÊNCIAS BIBLIOGRÁFICAS}

AKSELROD, M. S.; BOTTER-JENSEN, L.; McKEEVER, S. W. S. Optically stimulated luminescence and its use in medical dosimetry. Radiat. Meas., v. 41, p. S78 - S99, 2007.

BACCI, C.; BERNARDI, P.; DAMILANO, A.; FURETTA, C.; RISPOLI, B. Kinetics parameters in BeO thermoluminescent material. J. Phys. D: Appl. Phys., v. 22, p. 1751 - 1757, 1989.

BASSI, P.; BUSUOLI, G.; RIMONDI, O. Calculated energy dependence of some RTL and RPL detectors. Int. J. Appl. Radiat. Isot., v. 27, p. 291-305, 1976.

BOS, A. J. J. Theory of thermoluminescence. Radiat. Meas., v. 41, p. 545-556, 2007.

CHEN, R. Glow curves with general order kinetics. J. Eletrochem. Soc., v. 116, n. 9, p.1254 - 1257, 1969.

CHEN, R.; PAGONIS, V. Thermally and Optically Stimulated Luminescence: A Simulation Approach. Londres: Wiley, 2011.

CHEN, R.; McKEEVER, S. W. S. Theory of Thermoluminescence and Related Phenomena. Singapura: World Scientific, 1997.

DTU NUTECH. Guide to “The Risö TL/OSL Reader". Denmark: DTU Nutech, 2015.

EISBERG, R.; RESNICK, R. Física Quântica. São Paulo: Elsevier. 1994.

EVANS, R. D. The Atomic Nucleus. New York: McGraw-Hill. 1955.

FURETTA, C.; WENG, P. Operational Thermoluminescence Dosimetry. Singapura: World Scientific Publishing, 1998.

FURETTA, C. Handbook of Thermoluminescence. Londres: World Scientific Publishing, 2003.

FURETTA, C. Questions and Answers on Thermoluminescence (TL) and Optically Stimulated Luminescence (OSL). Londres: World Scientific Publishing, 2008;

GROPPO, D. P. Caracterização dosimétrica de amostras de BeO em feixes de radiação alfa, beta e X por técnicas luminescentes. IPEN: São Paulo, Dissertação (Mestrado) Universidade de São Paulo, 2013.

GROPPO, D. P.; CALDAS, L. V. E. Luminescent response from BeO exposed to alpha, beta and $X$ radiations. Radiat. Meas., v. 71, p. 81-85, 2014.

HEWITT, P. G. Física Conceitual. São Paulo: Bookman. 2011. 
INMETRO. Avaliação de dados de medição - Guia para a expressão de incerteza de medição - GUM 2008. Duque de Caxias: INMETRO/CICMA/SEPIN, 2012.

KNOLL, G. F. Radiation Detection and Measurement. Oklahoma: John Wiley \& Sons, 2010.

MATERION. Beryllium oxide ceramics. Disponível em https://materion.com/products/beryllium-products/beryllium-oxide-ceramics, acessado em 21/02/2017.

MCKEEVER, S. W. S. Thermoluminescence of solids. Cambridge: Cambridge University Press, 1988.

MCKEEVER, S. W. S.; MOSCOVITH, M. Topics under debate: on the advantages and disadvantages of optically stimulated luminescence dosimetry and thermoluminescence dosimetry. Radiat. Prot. Dosim., v. 104, n. 3, p. 263 - 270, 2003.

McKEEVER, S. W. S. Optically stimulated luminescence: A brief overview. Radiat. Meas., v. 46, p. 1336 - 1341, 2011.

NIST. National Institute of Standards and Technology. Disponível em http://www.nist.gov/pml/data/xraycoef/index.cfm, acessado em 20/01/2017.

OLIVEIRA, P. M. C.; PINHEIRO, L. J. S.; CASTRO, W. J.; GONZAGA, N. B.; SQUAIR, P. L.; NOGUEIRA, M. S.; DA SILVA, T. A. Estudo comparativo de dosímetros termoluminescentes para aplicação dosimétrica de pacientes em radiodiagnóstico. Anais do XV Congresso Brasileiro de Física Médica. Aracajú, 18 - 21 de Agosto, 2010.

OKUNO, E.; YOSHIMURA, E. Física das Radiações. São Paulo: Oficina de Textos; 2010.

PAGONIS, V.; KITIS, G.; FURETTA, C. Numerical and Practical Exercises in Thermoluminescence.USA: Springer Science+Business Media, 2006.

PERUZZO, J. Física e Energia Nuclear. São Paulo: Livraria da Física. 2012.

PROVECTO ANALÍTICA. Manual do forno. Disponível em http://provectoanalitica.com.br/produtos.swf, acessado em 10/03/2017.

SAHIN, S.; TANIR, A. G.; MERIÇ, N.; AYDINKARAHALILOGLU, E. Measurement of radiation dose with $\mathrm{BeO}$ dosimeters using optically stimulated luminescence technique in radiotherapy applications. Appl. Radiat. Isot., v. 103, p. 31-36, 2015.

SANTOS, A. M. C.; MOHAMMADI, M.; ASP, J.; MONRO, T. M.; AFSHAR, S. V. Characterization of a real-time fiber-coupled beryllium oxide (BeO) luminescence dosimeter in X-ray beams. Radiat. Meas., v. 53-54, p. 1-7, 2013. 
SANTOS, A. M.; MOHAMMADI, M.; AFSHAR, S. V. Energy dependency of a waterequivalent fiber-coupled beryllium oxide (BeO) dosimetry system. Radiat. Meas., v. 74, p. 1-9, 2015.

SCHEMBRI, V. E.; HEIJMEN, J. M. Optically stimulated luminescence (OSL) of carbon-doped aluminum oxide $\left(\mathrm{Al}_{2} \mathrm{O}_{3}: \mathrm{C}\right)$ for film dosimetry in radiotherapy. Med. Phys., v. 34, n. 6, p. 2113-2118, 2007.

SOUZA, S. O.; YAMAMOTO, T.; d'ERRICO, F. Estado da arte em dosimetria do estado sólido. Anais do International Joint Conference RADIO, p. 1028 - 1035, 26 - 29 Agosto, 2014.

SOMMER, M.; HENNIGER, A. Investigation of a BeO-based optically stimulated luminescence dosimeter. Radiat. Prot. Dosim., v. 119, p. 394-397, 2006.

SOMMER, M.; JAHN, A., HENNIGER, J. Beryllium oxide as optically stimulated luminescence dosimeter. Radiat. Meas., v. 43, p. 353-356, 2008.

TAYLOR, J. R. Introdução à Análise de Erros: $O$ estudo de Incertezas em Medições Físicas. Porto Alegre: Bookman, 2012.

TOUCHILIN, E.; GOLDSTEIN, N.; MILLER, W. G. Beryllium oxide as a thermoluminescent dosimeter. Health Phys., v. 16, p. 1-7, 1969.

TSOULFANIDIS, N. Measurement and Detection of Radiation. 2nd Edition. Washington: Taylor and Francis. 1995

VIJ, D. R.; SINGH, N. Review on thermoluminescence dosimetric properties of beryllium oxide. J. Mat. Scie., v. 32, p. 2791-2796, 1997.

VUOLO, J. H. Fundamentos da Teoria de Erros. São Paulo: Blucher, 2015.

WATANABE, S.; GUNDU, T. K. R.; PAGE, P. S.; BHATT, B. C.; TL, OSL and ESR studies on beryllium oxide. J. Lumin., v. 130, p. 2146-2152, 2010.

X-5 MONTE CARLO TEAM. MCNP - A general Monte Carlo N-Particle transport code, version 5 - Volume II: User's guide. EUA: Los Alamos, 2003.

YORIYAZ, H. Método de Monte Carlo: princípios e aplicações em Física Médica. Rev. Bras. Fis. Med., v. 3(1), p. 141-149, 2009.

YUKIHARA, E. G.; McKEEVER, S. W. S. Optically stimulated luminescence (OSL) dosimetry in medicine. Phys. Med. Biol., v. 53, p. R351-R379, 2008.

YUKIHARA, E. G. Luminescence properties of BeO optically stimulated luminescence (OSL) detectors. Radiat. Meas., v. 46, p. 580-587, 2011. 
YUKIHARA, E. G.; McKEEVER, S. W. S. Optically Stimulated Luminescence: Fundamentals and Applications. Oklahoma: Wiley. 2011. 


\section{ANEXO 1 - Código do MCNP5 para Simulação do Suporte de Acrílico.}

Código do MCNP5 desenvolvido e utilizado nas realizações das simulações no estudo sobre a interferência do suporte de acrílico na resposta do BeO.

Título: Projeto

c suporte

$101-1.19-12$-3 4 -5 68 imp:p=1 imp:e=1

$301-1.192-8-9$ imp:p=1 imp:e=1

c tampa

$1201-1.191-34-11-56$ imp:p=1 imp:e=1

c pastilha

$202-2.7997-79-10$ imp:p=1 imp:e=1

c vãos entre o suporte e a pastilha

$403-0.001205-879-10$ imp:p=1 imp:e=1

$503-0.001205-810-1$ imp:p=1 imp:e=1

c partes fora do suporte

$603-0.00120511-12$ imp:p=1 imp:e=1

$703-0.001205-2-12$ imp:p=1 imp:e=1

$803-0.00120532-11-56-12$ imp:p=1 imp:e=1

$903-0.001205-42-11-56-12$ imp:p=1 imp:e=1

$1003-0.00120552-11-12$ imp:p=1 imp:e=1

$1103-0.001205-62-11-12$ imp:p=1 imp:e=1

c limite do laboratorio

130012 imp:p=0 imp:e=0

csuperficies

$1 \mathrm{px} 0.159$

2 px -0.159

3 py 0.4275

4 py -0.4275

5 pz 0.4275 
$6 p z-0.4275$

$7 \mathrm{cx} 0.2002$

$8 \mathrm{cx} 0.3$

$9 \mathrm{px} 0.009$

10 px 0.0861

11 px 0.259

12 sx 500600

c materiais

m1 1000. -0.085038 6000. -0.599848 8000. -0.319614

m2 4000. -0.3608 8000. -0.63968

m3 6000. -0.000124 7000. -0.755268 8000. -0.231781 18000. -0.012827

mode $p$

c fonte

sdef pos=99.913900 erg=0,0157 vec $=-100$ dir $=1$ par $=2$

c saidas

*f8:p 20

nps 10000000

print 11040 